\title{
Matricellular proteins : crucial regulators of cardiac remodeling
}

Citation for published version (APA):

Swinnen, M. (2010). Matricellular proteins : crucial regulators of cardiac remodeling. [Doctoral Thesis, Maastricht University]. Maastricht University. https://doi.org/10.26481/dis.20100331ms

Document status and date:

Published: 01/01/2010

DOI:

10.26481/dis.20100331ms

Document Version:

Publisher's PDF, also known as Version of record

\section{Please check the document version of this publication:}

- A submitted manuscript is the version of the article upon submission and before peer-review. There can be important differences between the submitted version and the official published version of record.

People interested in the research are advised to contact the author for the final version of the publication, or visit the DOI to the publisher's website.

- The final author version and the galley proof are versions of the publication after peer review.

- The final published version features the final layout of the paper including the volume, issue and page numbers.

Link to publication

\footnotetext{
General rights rights.

- You may freely distribute the URL identifying the publication in the public portal. please follow below link for the End User Agreement:

www.umlib.nl/taverne-license

Take down policy

If you believe that this document breaches copyright please contact us at:

repository@maastrichtuniversity.nl

providing details and we will investigate your claim.
}

Copyright and moral rights for the publications made accessible in the public portal are retained by the authors and/or other copyright owners and it is a condition of accessing publications that users recognise and abide by the legal requirements associated with these

- Users may download and print one copy of any publication from the public portal for the purpose of private study or research.

- You may not further distribute the material or use it for any profit-making activity or commercial gain

If the publication is distributed under the terms of Article $25 \mathrm{fa}$ of the Dutch Copyright Act, indicated by the "Taverne" license above, 


\section{Matricellular Proteins: Crucial REgulators of CARDiac Remodeling}


(c) Copyright Melissa Swinnen, Maastricht 2010 ISBN 978-90-9025216-2

Cover design: Melissa Swinnen Layout: Melissa Swinnen

Production: Procopia NV 


\title{
Matricellular Proteins: Crucial REgulators OF CARDIAC REMOdELING
}

\author{
PROEFSCHRIFT
}

ter verkrijging van de graad van doctor aan de Universiteit Maastricht, op gezag van de Rector Magnificus, Prof. mr. G.P.M.F. Mols

volgens het besluit van het College van Decanen,

in het openbaar te verdedigen

op woensdag 31 maart 2010 om 16.00 uur

door

\section{Melissa Swinnen}

geboren te Heusden-Zolder op 11 september 1982 


\section{Promotores:}

Prof. dr. Y.M. Pinto

Prof. dr. P. Carmeliet (Katholieke Universiteit Leuven, België)

\section{Copromotor:}

Dr. S. Heymans

\section{Beoordelingscommissie:}

Prof. dr. H.J.G.M. Crijns (voorzitter)

Dr. M. van Bilsen

Prof. dr. M. Hoylaerts (Katholieke Universiteit Leuven, België)

Dr. E. Lutgens

Prof. dr. F. Van de Werf (Katholieke Universitiet Leuven, België) 


\section{Contents}

Chapter 1. General Introduction and aims of the thesis

Chapter 2. The absence of thrombospondin-2 causes age-related dilated cardiomyopathy

Chapter 3. Thrombospondin-2 improves cardiac function during viralInduced cardiomyopathy

Chapter 4. The absence of SPARC results in increased cardiac rupture vivo and dysfunction after acute myocardial infarction

Chapter 5. General Discussion and concluding remarks

Chapter 6. Summary

Samenvatting

Dankwoord

Curriculum Vitae 



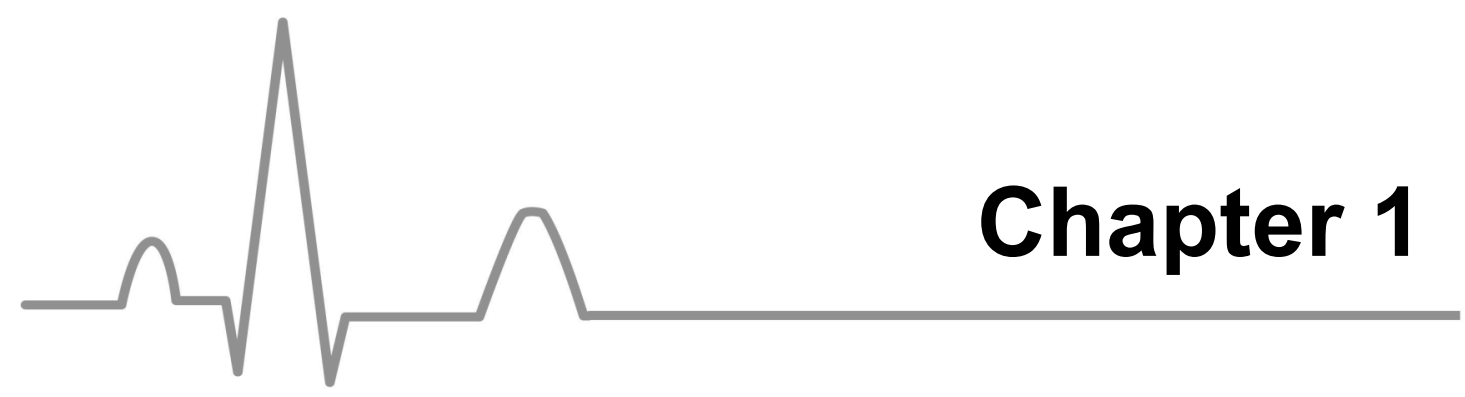

General Introduction 
Chapter 1 


\section{Heart Failure and the need for innovative therapeutic options}

Heart Failure afflicts over 15 million Europeans, results in increased hospitalization and mortality representing a significant and growing healthcare burden. The major causes of heart failure are ischemic heart disease, hypertension and viral infection of the heart.

With the increasing average age of the global population, the incidence of HF is increasing and the number of patients at risk of developing this condition is expected to grow. Despite clinical standards, improved medical technologies, better understanding of the pathogenesis of heart failure is essential to improve diagnosis and treatment strategies ${ }^{1}$.

\section{The extracellular matrix of the heart}

The heart consists of cellular and extracellular compartments of which approximately one third of the cells from the cellular compartment consists of cardiomyocytes yet this accounts for $70 \%$ of the total myocardial volume. Fibroblasts, endothelial cells and vascular smooth muscle cells predominate as non-myocytes constituting the remaining two-third of the cellular compartment.

The extracellular matrix (ECM) provides the structural backbone of the heart and forms a multifunctional complex of proteins and proteoglycans assembled in a highly organized manner that contributes to the structural and functional integrity of the heart ${ }^{2}$.

The ECM surrounding the cardiomyocytes, fibroblasts, capillaries and larger vessels is a vital component of the heart. It is composed of basic structural elements such as collagen and elastin, and more specialized proteins, like fibrillin, fibronectin, proteoglycans and matricellular proteins ${ }^{2}$ forming a highly complicated and dynamic system.

While the ECM is ubiquitous, its composition varies significantly from organ to organ, and is carefully regulated. Fibrillar collagen type I and III are the predominant collagens and matrix components in the myocardium. The interstitial collagen fibers form a wide network that merges throughout the 
myocardium, providing supportive scaffolding for myocytes and blood vessels, thereby preserving myocardial thickness and architecture and protect myocytes from overstretching. As a whole, the ECM provides a 3Denivronment that regulates cell behavior by influencing cell proliferation, survival shape, migration and differentiation, thereby establishing a connection between cell and tissue function. The cardiac fibroblast is the most abundant cell type in the myocardium. Cardiac fibroblasts are the main regulators of the ECM and act via at least three mechanisms: by regulating the synthesis and deposition of matrix molecules, by mediating matrix degradation and turnover by production and the release of matrix metalloproteinases (MMPs) and their endogenous inhibitors (TIMPs) and by maintaining mechanical tension on the collagen network. In the normal heart, ECM synthesis and degradation, also called ECM remodeling, is a continuous and tightly regulated process.

\section{Physiological cardiac aging}

Although highly variable between individuals, the function of the cardiovascular system declines with age. Cardiac aging is a complex process which includes aging and deposition of ECM, aging of the coronary vasculature, aging of cardiac fibroblasts, and aging of the contractile apparatus of the heart.

Constituting the core of cardiac function and the contractile apparatus, cardiomyocytes display a number of physiological and morphological features, which are affected by the aging process, and these changes are thought to give rise to reduced cardiac function and heart disease. It has been demonstrated that approximately one-third of the cardiomyocytes are lost from the human heart between the ages of 17 and 90 years, an age-related phenomenon that is more pronounced in males than females ${ }^{3,4}$. While some of the remaining cardiomyocytes do undergo adaptive hypertrophy as a compensation, the net effect is a decrease in pumping capacity leading to impaired cardiac function. Throughout life, this attrition of cardiomyocytes will be caused by various natural and pathological insults to the myocardium. As the cardiac functional reserve is progressively compromised, a critical point 
will be reached when clinical features of heart failure become evident. The onset of heart failure triggers compensatory mechanisms, some of which in turn may fasten the progression of cardiomyocyte damage. However, the greater the frequency of cardiac injury and death, the greater the depletion of the pool of viable cardiomyocytes will be. With already one-third less viable cardiomyocytes than in young adults, it is not unexpected that aged hearts are more susceptible to complications following myocardial injuries. It is clear that with time, the functional integrity of the heart will gradually diminish in response to any decline in the overall number of cardiomyoytes ${ }^{5}$.

Cardiac myocytes, skeletal muscle fibers, and other long-lived post-mitotic cells show dramatic age-related alterations ${ }^{6}$. Aging affects all types of muscle cells, yet the degree of age-related changes is the highest in cardiomyocytes. The central principle that initiates the physiological aging of cardiomyoyctes is oxidative stress and appears to involve the deterioration of cellular function by the generation of reactive oxygen or nitrogen species and/or radicals that interact and thereby change the properties of biological molecules. Among organelles of senescent cells, the most remarkable changes in cardiomyocytes are observed in mitochondria and lysosomes. Swelling, loss of cristae, and even complete destruction of inner membranes resulting in the formation of homogenous electron-dense material often occur in senescent mitochondria, especially in large ones. Mitochondrial alterations are paralleled by an increase in number and size of lysosomes, many of which are enlarged and loaded with an undegradable material, lipofucin, or age pigment.

\section{Viral myocarditis}

Myocarditis, an inflammatory disease of the heart muscle, is an important cause of heart failure among adolescent and young adults. The relation between infection and chronic heart disease was suggested as early as 1806, when Corvisart described a cardiac inflammatory disorder that could result in progressive abnormalities of cardiac function after all evidence of the infective agent had disappeared. Myocarditis can be initiated by several different infective agents, including viruses, parasites, protozoa and fungi. Viral 
infection is thought to be the most common cause of myocarditis, causing mild to severe injury in the myocardium with ultimate manifestation of end-stage dilated cardiomyopathy and heart failure. Coxsackievirus B3 (CVB3), a small non-enveloped single-stranded RNA enterovirus in the Picornaviridae family, is the major causative agent of myocarditis in humans and has been implicated in $25 \%$ to $40 \%$ cases of acute myocarditis and dilated cardiomyopathy in infants and young adolescents.

Myocarditis is a poorly understood disease because it progresses through different stages with distinct mechanisms and manifestations. A 'triphasic disease process' has been ascribed to the pathogenesis of this cardiac inflammatory disorder, comprising a viral phase, an inflammatory phase and a dilated cardiomyopathic phase ${ }^{7}$ (Figure 1).

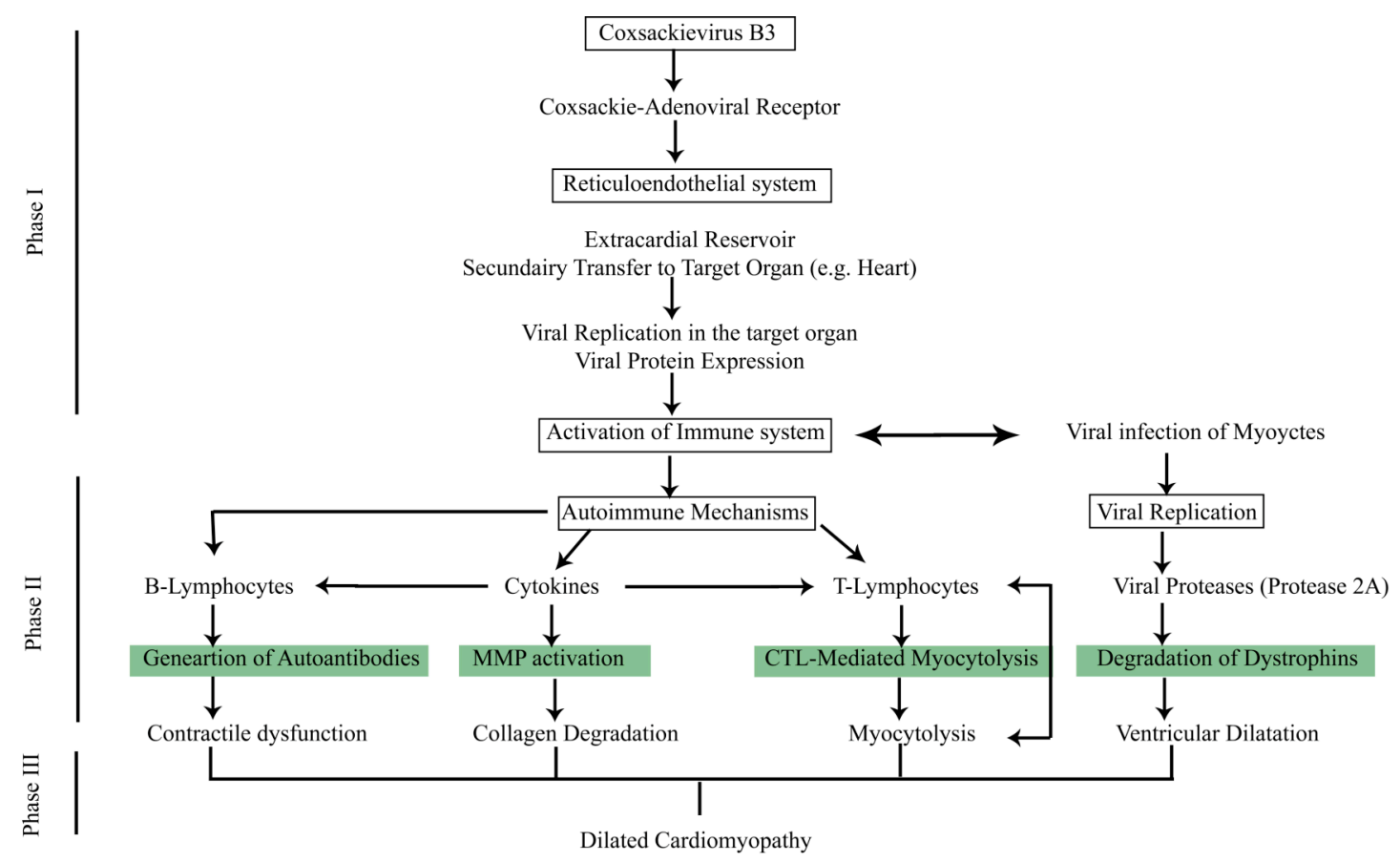

Figure 1. Viral myocarditis: A triphasic disease process. Proposed mechanisms of development of dilated cardiomyopathy following viral infection of the heart

\section{Phase I: the acute phase, viral infection}

Viruses enter the myocardium and the viral genome gets internalized via coxsackie-adenoviral receptor $(\mathrm{CAR})^{8}$, in turn activating immune responses. Subsequently, virus-induced cytotoxicity can be associated with focal necrosis 
of cardiomyocytes in the absence of an inflammatory cell infiltration within a few days after viral infection ${ }^{8,9}$.

Additionally, viral metabolism may also have direct consequences on myocardial architecture ${ }^{7,10}$. A coxsackieviral protease specifically cleaves the dystrophin-sarcoglycans complex, which is responsible for the linkage of the myocyte cytoskeleton to the $\mathrm{ECM}^{11}$. This cleavage leads to dystrophin dysfunction and to loss of sarcolemmal integrity, likely aiding viral entry, providing partial clarification for the significant ventricular dilatation observed immediately following viral infection leading to dilated cardiomyopathy ${ }^{7}$.

\section{Phase II: the subacute phase, autoimmunity}

After viral invasion of the myocardium, the immune response, stimulated by viral proteins, limits viral replication, and in the majority of patients the virus is cleared from the host. However, the immune responses themselves can cause myocardial damage, and the balance between beneficial and detrimental effects of this immune response significantly influences the extent of cardiomyocyte cell loss and the transition of myocarditis to the dilated cardiomyopathic phase (phase III).

The presence of viral peptides can trigger the activation of innate immune responses in the host tissue through a family of toll-like receptors (TLRs). In contrast to the acquired immunity, the TLRs require only very general triggers or pathogen-associated molecular patterns. This activation triggers the translocation of interferon regulator factor transcription factor to the nucleus to produce interferons, and this activation also generates translocation of Nuclear Factor-kappa B (NF-kB) to produce cytokines. The first wave of infiltrating cells in the heart consists mainly of natural killer (NK) cells ${ }^{12}$. Various cytokines, including Interleukin(IL)-1 $\beta$, Tumor Necrosis Factor (TNF)$\alpha$, Interferon(IFN)- $\gamma$ and IL-2, are produced at this stage and persist for a long time $^{13,14}$. During the second wave of cell infiltrates in the myocardium, Tlymphocytes and macrophages become predominant and peak 7 to 14 days after virus inoculation. This coincides with the most acute pathological damage in the myocardium ${ }^{15,16}$. Immune response beyond a limit may 
become detrimental to myocardial function because both T-cell- and cytokinemediated myocyte damage reduce the number of contractile units, which can ultimately lead to long term remodeling. Moreover, the virus may also trigger a Th2 response, thereby recruiting more activated CD8 killer cells. Activation of CD4 cells also leads to B-cell clonal expansion and antibody production and this may be an important modifier of the disease phenotype.

It has been proposed that molecular mimicry, the presence of related epitopes, exists between CVB3 and a variety of myocardial proteins ${ }^{17}$. This can lead to antibodies or CD8 cytotoxic T lymphocytes originally directed against the virus, but which cross-react with host antigens and induce

myocyte damage ${ }^{15,16,18}$. The products of cardiac cell destruction themselves may then further stimulate subsequent cell lysis by CD8+ cytotoxic T cells.

\section{Phase III: the chronic phase, dilated cardiomyopathy}

A switch in the delicate balance between protective and deleterious effects of immune response may follow and determine disease progression and therefore, may be the decisive factor in the development of dilated cardiomyopathy. Indeed chronic inflammation is observed in the myocardium of patients with dilated cardiomyopathy, but also in animal models of chronic viral myocarditis ${ }^{19}$. The cumulative effect may eventually lead to impairment of left ventricular function and long-term remodeling, giving rise to phase 3 of the disease, dilated cardiomyopathy. Once the virus is cleared, as a result of the fulminant inflammatory response, inflammatory cells will disappear and the cardiac matrix may recover, resulting in normalization of cardiac dimensions. However, when chronic autoimmune myocarditis develops, inflammation induces alterations in cellular and extracellular metabolism, resulting in reparative fibrosis and left ventricular (LV) dilatation and dysfunction.

As already described in phase I, protease $2 \mathrm{~A}$ produced by $\mathrm{CVB} 3^{10}$, can directly cleave the dystrophin-sarcoglycans complex resulting in impaired sarcoglycan function in infected myocytes, that in turn can lead to ventricular dilatation $^{11}$. Additionally, cytokines can play a key role in the transition of myocarditits towards development and progression of dilated cardiomyopathy, 
by activating and regulating the expression of MMPs, such as gelatinase; collagenases and elastases ${ }^{20}$ (Figure 1).

At the present time, little effective treatment and diagnosis exists for patients with viral myocarditis, apart from general supportive therapy and anti-failure management.

In the first phase, viral infection can only be proven by direct or serological identification of the virus. Proper treatment at this stage is suppression of virus and limiting viral injury. In this phase, avoidance of potentially harmful immunosuppressive agents, non-specific antiviral actions or direct antiviral therapy in the few cases where an organism had been identified or in the context of a known viral epidemic is recommended.

The autoimmunity phase is diagnosed by endomyocardial biopsy, even though serological markers may be abnormal. At this stage, immune suppression is the most appropriate therapy. However, at the present time only well-studied immunosuppressive drugs can be used and only when the phase is well defined. Steroids, azathiopine, clyclosporine and OKT-3 have been used as immunosuppressive agents in humans with viral myocarditis.

Finally, in the third phase, in the absence of chronic ongoing viral infection or recurrent autoimmune activity, patients should be managed like those with idiopathic, dilated cardiomyopathy and congestive heart feailure. The assumption is that further ventricular remodeling and clinical deterioration may be prevented with ACE-inhibitors, $\beta$-blockers, spironolactone and possibly amiodarone. An implantable defibrillator should be considered for those patients with documented life-threatening arrhythmias.

A better molecular comprehension of both the direct effect of viral infection on cardiomyocytes and the balance of beneficial and detrimental effects of the immune response will ultimately provide essential insights into the mechanisms by which viral infections cause cardiomyopathy in humans and will subsequently help to design new and improved clinical and therapeutic strategies. This will be the subject of chapter 3 . 


\section{Myocardial infarction}

Myocardial infarction (MI) and the consequent loss of contractile myocardium is a frequent cause of heart failure. Almost all myocardial infarcts result from coronary atherosclerosis with superimposition of coronary thrombosis. Sudden induction of ischemia by coronary artery occlusion triggers a series of events that culminates in the death of ischemic cardiomyocytes.

Cardiac repair after MI requires a tightly-regulated process of wound healing and scar formation that consists of three overlapping phases that include inflammation, formation of granulation tissue and scar formation and overall LV remodeling (Figure 2).

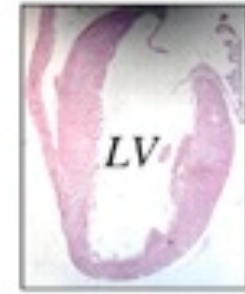

Occlusion of Cononary Artery

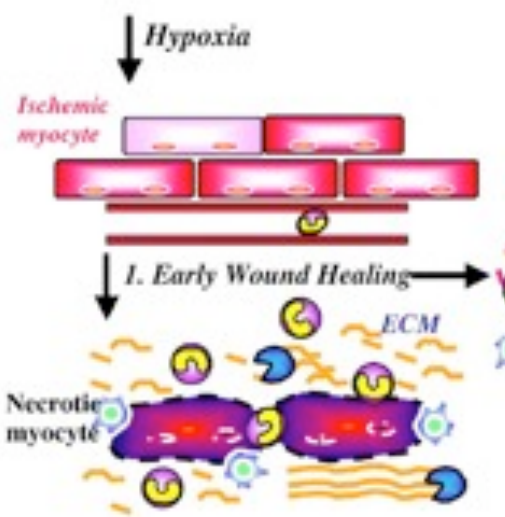

Post-MI Repair and LV Remodeling

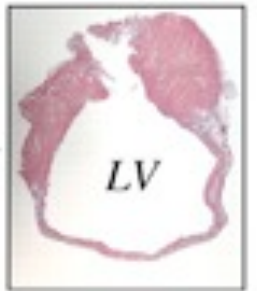

Architectural-Functional Changes

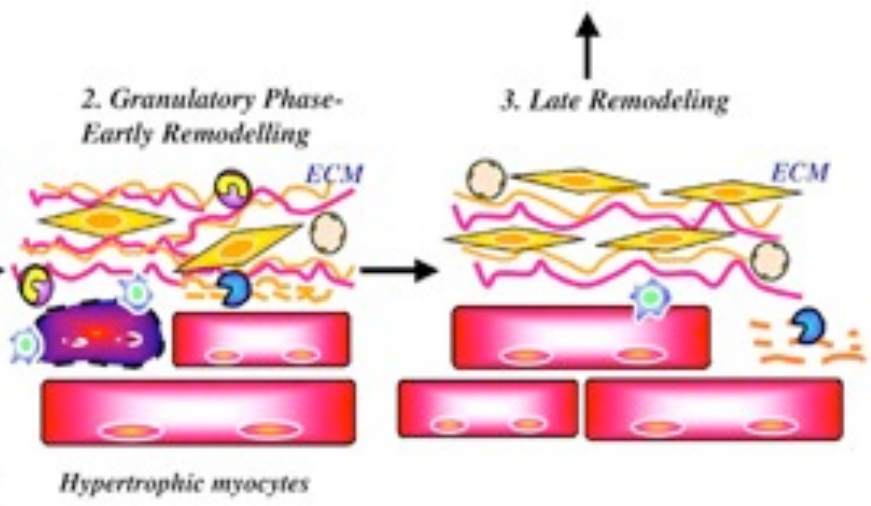

Increased MMP/TIMPs in the different phases post-MI

$\begin{array}{llll}\text { MMP } & 1,2,3,9 \text { and } 13 & 2,3,8,9 \text { and } 13 & 2,8,13 \text { and MT-1-MMP } \\ \text { TIMP } & 1 \text { and } 2\end{array}$

(5)

LV, Left Ventricle; MI, Myocardial Infarction; ECM, extracellular matrix; MMPs, Matrix MetalloProteinases; TIMPs, Tissue Inhibitors of MMPs.

Figure 2. Post myocardial healing process and Left ventricle (LV) remodeling. 


\section{Phase 1: inflammatory phase of wound healing: 0-7 days post-MI}

When a previously atherosclerotic coronary artery becomes totally occluded due to thrombus formation, the LV tissue becomes hypoxic and a MI occurs (Figure 2). Interruption of the blood supply leads to rapid cardiomyocyte death in the affected part of the cardiac wall. Cardiomyocyte necrosis evokes an inflammatory response in the infarct area by the activation of the complement system and free radical generation (ROS), triggering a cytokine cascade initiated by TNF- $\alpha$ and Interleukin-1 $\beta$. Successive activation of NF$\kappa \mathrm{B}$ is a critical element in the regulation of cytokine, chemokine and adhesion expression in the ischemic myocardium, mediating leukocyte recruitment in the myocardium. During this initial stage of healing, activated proteolytic enzymes degrade the existing ECM and disrupt the fibrillar collagen network, allowing inflammatory cells, such as neutrophils and monocytes, to migrate into the infarct tissue to remove necrotic myocytes ${ }^{21,22}$. Subsequently, these inflammatory cells release MMPs, cytokines, growth factors and angiogenic factors ${ }^{2}$.

\section{Phase 2: granulation and early remodeling phase: 7-21 days post-MI}

Granulation tissue formation constitutes a critical step in infarct repair. Macrophages phagocytose the necrotic myocytes, and concomitantly, myofibroblasts and endothelial cells proliferate and migrate into the infarcted zone. The necrotic cardiac tissue is then replaced by granulation tissue, a provisional tissue with a matrix consisting of collagens, proteoglycans and matricellular proteins such as osteopontin, thrombospondin-1 and $-2^{23}$, fibronectin ${ }^{24,25}$. As repair proceeds, myofibroblasts deposit a network of collagen, and the provisional matrix is reabsorbed. Extensive apoptosis of granulation tissue cells finally results in a thin, hypocellular scar ${ }^{26,27}$. Another key feature of granulation tissue is the abundance of small blood vessels. The blood vessels can either be newly formed or derived from pre-existing collateral blood vessels that remained perfused during the ischemic event. $A$ 
hypertrophic response of the non-infarcted cardiomyocytes further influences the myocardial performance.

\section{Phase 3: Late remodeling phase: >21 days post-MI}

Myocardial infarction leads to structural alterations involving not only the infarcted area but also the non-infarcted myocardium. Left ventricular regional remodeling is a continuous process that lasts for months to years after the acute injury ${ }^{28-33}$, which will eventually lead to the development of heart failure. During wound healing not only deposition of ECM proteins can be observed, but also degradation of pre-existing extracellular matrix proteins takes place. This is considered to be a key event of wound healing, because it enables cells to migrate from their original position into the wound healing area. Degradation of the ECM in the infarct area may result in the loss of structural support, which can lead to LV wall thinning, and even rupture of the infarct area. This accentuates the importance of the maintenance of a proper balance between extracellular matrix deposition and degradation in the infarct area $^{2}$.

Although recent advances in cardiovascular therapeutics have resulted in the development of novel strategies that salvage myocardium and improve early mortality in patients with myocardial infarction, approaches directly targeting the healing process are lacking. Neurohumoral pharmacologic interventions, such as the administration of angiotensin converting enzyme (ACE) inhibitors, beta blockers and aldosterone antagonist are the only established therapeutic modalities that reduce adverse remodeling in patients with myocardial infarction ${ }^{34,35}$. Understanding of the specific events involved in infarct healing is crucial to design novel therapeutic strategies aiming at optimizing cardiac repair and attenuating post-infarction remodeling. This will be the subject of chapter 4. 


\section{Matricellular proteins}

Matricellular proteins (MCPs) are secreted into the extracellular environment, or matrix but do not play a primary structural role in this location. These proteins modulate cell function by interacting with cell-surface receptors, proteases, hormones, and other bioeffector molecules, as with structural matrix proteins such as collagens. The term 'matricellular' was introduced to explain the unusual diversity of functions that were to be recognized in proteins such as thrombospondin (TSP)-1, TSP-2, Secreted Protein Acid Rich in Cystein (SPARC), Osteopontin (OPN) and tenascin- $\mathrm{C}^{36-39}$. The intent of segregating this subclass of secreted proteins was to emphasize that the extracellular environment was a major factor in regulating their synthesis.

\section{Thrombospondin-2}

Thrombospondin-2 (TSP-2) belongs to a 5-member family of secreted, modular glycoproteins whose function do not appear to contribute directly to the integrity of a physical entity but influence cell function by modulating cellmatrix interactions. The 5 thrombospondins can be subdivided into 2 subgroups, depending on their molecular structural organization. TSP-1 and TSP-2 comprise the first subgroup, each forming trimers. In contrast, TSP-3, TSP-4 and TSP-5 form pentamers. TSP-2 is involved in numerous biological processes and can interact with specific cell-surface receptors, cytokines, growth factors, and proteases, and the availability of each of these diverse molecules may help define their function in a given environment.

\section{Structure and biological function of Thrombospondin-2}

TSP-2 is a homotrimeric protein consisting of three identical TSP-2 chains. In view of the sequence similarity between TSP-1 and TSP-2, it is tempting to assume that many of these interactions will also apply to TSP-2, but in fact relatively little is known about the binding properties of TSP-2. 
TSP-2 binds to heparin-sepharose columns and can be presumed to bind to heparan sulfate proteoglycans ${ }^{40},{ }^{41}$. TSP-1 and TSP-2 share a large overall similarity in their protein structure and therefore interact with the same ligands. TSP-2 contains three different repeated sequence motifs (TSRs), known as type 1, type 2, and type 3 repeats (Figure 3 ). These TSRs allow TSP-2 to interact with MMPs, thereby regulating the activity of these proteinases $^{42,43}$. TSP-2-null skin fibroblasts have a defect in attachment to different matricellular proteins in vitro as a consequence of increased levels of active MMP-2 ${ }^{43}$. In addition, the increased activity of MMP-2 causes enhanced proteolysis of cell-surface tissue transglutaminase (tTG), an enzyme important for collagen cross-linking ${ }^{44}$. Later, it was demonstrated that TSP-2 is actively involved in the clearance of MMP-2 by directly targeting MMP-2 to form a complex that is endocytosed by the low density lipoproteinrelated scavenger receptor (LRP1) ${ }^{45}$ (Figure 3). In a model of dermal wound healing, mice that lack TSP-2 showed aberrant ECM remodeling associated with increased levels of MMP-2, MMP-9, TIMP-1 and TIMP- ${ }^{46}$. In concordance, TSP-2-null mice had increased MMP-2 activity after infusion of angiotensin II, contributing to an increased incidence of left ventricular rupture and dilatation ${ }^{47}$.

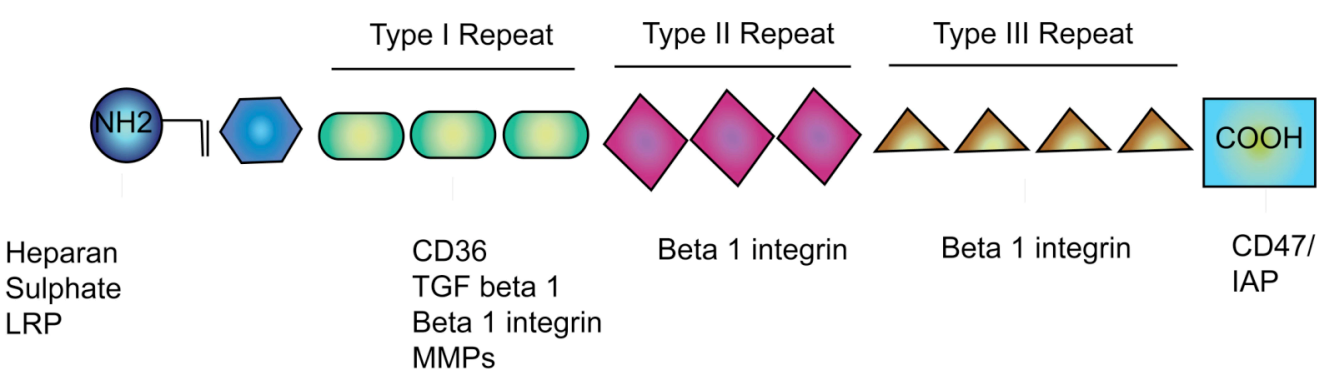

Figure 3. Location of ligand-binding sites for cell-surface receptors and protein-protein interactions within the domain structure of TSP-2. The identification of binding sites for heparan sulphate, Low density lipoprotein-related receptor protein;LRP, CD36, MMPs, TGF beta 1, beta 1 integrin and CD47 (Integrin Associated Protein; IAP). Figure based on Bornstein $\mathrm{P}$ et $\mathrm{al}^{48}$

TSP-2 also binds to latent TGF beta $1^{49}$. The interaction of TSP-2 with latent TGF-beta1 is of particular interest because it has been shown that TSP-1 both binds and activates latent TGF-Beta 1, whereas TSP-2 binds but does not 
activate the precursor ${ }^{49}$. Additionally, the hexapeptide GGWSHW, which is common to TSP-1 and TSP-2, inhibited the activation of latent TGF-beta 1 by TSP-1. The physiological relevance of TSP-1 as an activator of latent TGFbeta 1 was shown by analyses of TSP-1 KO mice, in which histological evidence of TGF-beta 1 deficiency was obtained. Furthermore Crawford et al were able to restore normal histology by treatment of TSP-1 null pubs with an activating peptide from TSP-1. These findings raise the possibility that TSP-2 modulates the activation of latent TGF-beta 1 by binding to the protein and preventing its activation by TSP- $1^{48}$. TSP-2 inhibits activation of latent TGFbeta 1 by TSP-1, presumably via competitive binding to TGF-beta 1 when both TSPs are present ${ }^{49}$.

Several studies have recognized TSP-2 as binding partners of integrins and CD47/Integrin Associated Protein (IAP). Via its type III repeat TSP-2 can bind integrin $\alpha v \beta 3^{40,50}$. The $\mathrm{N}$-terminal domain, type I and II repeats contain several recognition sites for $\beta 1$ integrin $^{51}{ }^{52}$. TSP-2 can induce Akt survival signaling via CD47/IAP interaction ${ }^{53}$

\section{Thrombospondin-2 in the heart}

The ECM plays an important role in hypertrophic remodeling by providing architectural support to the cardiac tissue, and mediating cell-ECM communication.

Expression of TSP-1, TSP-2, and TSP-3 is increased during heart failure in a model of hypertensive hypertrophic remodeling ${ }^{47}$. The homozygous renin transgenic TGR(mRen2)27 rat suffers from severe hypertension that leads to cardiac hypertrophy at 10 weeks of age, with approximately $50 \%$ developing quick decompensation at 12-14 weeks of age. Biopsies taken at 10 weeks of age allowed retrospective comparison of gene expression between the decompensated and compensated group. TSP-1, TSP-2, and TSP-3 transcript levels were all significantly enhanced at 10 weeks of age in the rats prone to develop rapid decompensation. Moreover, TSP-2 transcript levels were also increased in patients with cardiac hypertrophy, secondary to aortic stenosis, and TSP-2 expression was particularly elevated in patients with a 
depressed ejection fraction $(<55 \%)^{47}$. TSP-2 is recognized as potent inhibitors of angiogenesis ${ }^{54}$. TSP-2 exerts its anti-angiogenic effects through several mechanisms: inhibition of endothelial cell-cycle progression, prevention of endothelial cell mobilization, and/or induction of endothelial cell apoptosis $^{55-56}$. Additionally, TSP-2 influences angiogenesis through modulation of MMP-activity ${ }^{57}$. Pathological hypertrophy is associated with a reduced capillary density, as found in several human cardiac diseases ${ }^{58,59}$. The influence of TSP-2 on physiological angiogenesis was demonstrated in a three-dimensional angiogenesis assay in which TSP-2 limited angiogenesis by decreasing gelatinolytic activity, and by accelerated recovery of blood flow in TSP-2-null mice after hind limb ischemia ${ }^{57,60,61 . ~ A l s o, ~ i n c r e a s e d ~}$ endothelial cell organization and migration was observed when these cells were cultured on TSP-2-null ECM. Thus, TSP-2 can inhibit physiological angiogenesis by limiting the gelatinolytic activity of endothelial cells and by its influence on ECM structure.

TSP-2 plays a role in response to injury. TSP-2 null mice mount an altered response to injurious challenges, such as wounding and implantation of biomaterials. In addition to an increase in neovascularisation, abnormalities were observed in the spatio-temporal deposition of ECM proteins. The net result of these alterations was accelerated healing and reduced scarring of wounds, and increases vascularity of foreign body capsules in TSP-2 -null mice ${ }^{62,63}$. The dynamic regulation of TSP-2 deposition during normal wound healing, coupled with the inability of TSP-2 null mice to organize newly formed tissue properly, suggest that TSP-2 plays an important role in the wound healing response. This role may be complex since the anti-angiogenic properties of TSP-2, together with its ability to modulate the activity of MMP-2 and possibly TGF-beta 1, could have diverse effects on repair mechanisms.

\section{Secreted Protein Acicic and Rich in Cystein, 'SPARC'}

SPARC, originally discovered as osteonectin, is a $32 \mathrm{kDa}$ glycoprotein and prototypicial member of the MCP family. SPARC was first described as a major constituent of bovine and human bone and as a protein secreted by proliferating cells in vitro ${ }^{64}$. Since its characterization, SPARC has been 
shown to be a calcium-binding glycoprotein that is expressed by many different cell types. It functions as a counteradhesive protein, as a modulator of growth factor activity, and as a cell-cycle inhibitor.

\section{Structure and biological functions of SPARC}

SPARC is the product of a single gene, which is very well conserved in a variety of species. It consists of three distinct modules: the $\mathrm{NH}$-terminal acidic domain, a cystein-rich follistatin-like domain (FSD) and a $\mathrm{C}$ terminal extracellular domain. Importantly, in vitro studies revealed that SPARC can be proteolytically cleaved into peptides that can exert functions distinct from those of the native SPARC ${ }^{65}$ (Figure 4).
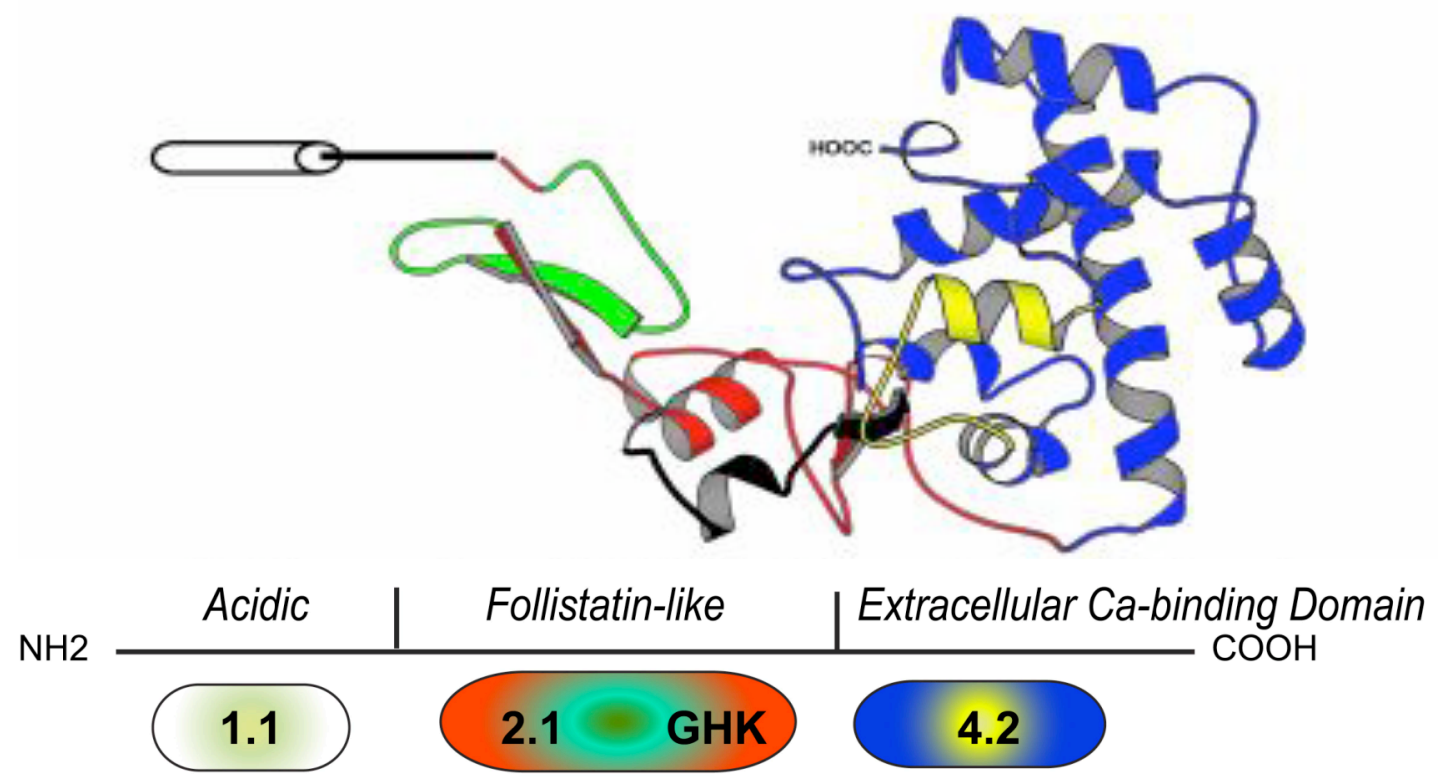

\begin{tabular}{|c|c|c|}
\hline $\begin{array}{l}\text { low-affinity Ca2+-binding } \\
\text { domain }\end{array}$ & Ilnhibits proliferation & High affinity $\mathrm{Ca} 2+-$ binding \\
\hline $\begin{array}{l}\text { Transglulatminase/cross- } \\
\text { linking site }\end{array}$ & $\begin{array}{l}\text { Abrogates focal adhe- } \\
\text { sions }\end{array}$ & $\begin{array}{l}\text { Inhibits cell spreading } \\
\text { Inhibits proliferation }\end{array}$ \\
\hline Inhibits cell spreading & $\begin{array}{l}\text { Release of }(\mathrm{K}) \mathrm{GHK} \\
\text { stimulates proliferation } \\
\text { and angiogenesis }\end{array}$ & $\begin{array}{l}\text { Abrogates focal adhe- } \\
\text { sions. Binds to cells and } \\
\text { matrix }\end{array}$ \\
\hline
\end{tabular}

Figure 4. Modular structure of SPARC. The ribbon diagram derived from crystallographic data indicates three structural modules. The Acidic domain shows peptide 1.1. The follistatinlike domain, shows peptide 2.1 and the (K)GHK angiogenic peptide. The Extracellular $\mathrm{Ca} 2+$ binding-domain shows peptide 4.2. Figure based on the findings of Brekken et $\mathrm{al}^{66}$ andSage et $\mathrm{al}^{6 \mathrm{6}}$. 
Module I is the NH2-terminal acidic domain that binds calcium ions with low affinity and mediates interactions with hydroxyapatite (Figure 4$)^{67}$. It contains the major immunological epitope of SPARC and was shown to be involved in inhibition of cell spreading. It also contains a cross-linking site to one of the major enzymes involved in ECM-cross linking, transgultaminase ${ }^{67,68}$.

Module II is a cystein-rich FSD (Figure 4$)^{67}$. It contains a sequence designated as peptide 2.1 that inhibits the endothelial cell cycle ${ }^{69}$, causes deadhesion $^{70}$, inhibits endothelial cell proliferation and angiogenesis ${ }^{71}$ and displays both positive and negative effects on proliferation of fibroblasts ${ }^{69,} 71$. Its peptide 2.3 and the GHK sequence increase the expression of MMPs, enhance proliferation of endothelial cells and fibroblasts and enhance angiogenesis ${ }^{72}$. In addition, it has been suggested that the $\mathrm{NH}_{2}$-terminal region of the FSD binds heparin or proteoglycans, which might be important for the recruitment of SPARC to its cell surface receptor(s).

Module III constitutes a C-terminal extracellular calcium-binding domain (Figure 4$)^{67}$. It contains a sequence known as peptide 4.2 , which has been shown to bind to endothelial cells and to inhibit their proliferation and migration $^{73,74}$, as well as affecting the expression of ECM proteins ${ }^{75}$, causes cell rounding and abrogates cell adhesion ${ }^{70}$. The fibril-forming collagen types I, III and V and the basement membrane collagen type IV bind to the Cterminal module of SPARC in a $\mathrm{Ca}^{2+}$-dependent manner ${ }^{76}$. Interestingly, cleavage of a single peptide bond located in module III by a number of MMPs, including MMP-2,-3,-7 and-13, increases the affinity of SPARC for collagen ${ }^{76}$, 77 . The functional significance of the interaction of SPARC with collagens in tissues is still unclear. Collagens may serve as a storage site for SPARC in the ECM or might modulate the activity of SPARC.

SPARC has been shown to abrogate cellular responses for important growth factors: Platelet derived growth factor (PDGF) ${ }^{78}$, Vascular Endothelial growth factor (VEGF) $)^{71}$ and Fibroblast growth factor-2 (FGF-2) ${ }^{73,74}$, although the mechanisms vary and are incompletely defined ${ }^{66}$. In addition to its high affinity binding to PDGF-B and VEGF, SPARC was shown to compete for the binding of PDGF to fibroblasts, and to interact specifically with smooth muscle cells via its carboxy terminal domain. Consequences of binding of SPARC to VEGF 165 include prevention of VEGF-VEGF receptor 1 interaction, inhibition 
of VEGF receptor phosphorylation and diminution of MAPK (ERKs 1 and 2) phospohorylation. A somewhat different mechanism accounts for the inhibition of FGF-2 -mediated effects on cell division and differentiation. In the absence of a direct interaction with FGF-2, SPARC prevented the phosphorylation of FGF receptor 1 and enhanced differentiation of MM14 myoblast into myocytes. Thus, the expression of SPARC could reduce the level of certain growth factors that might otherwise stimulate excessive cellular proliferation. Alternatively, SPARC could minimize growth factor cognate receptor activity at the cell surface by its interaction with appropriate co-receptors to prevent receptor dimerization or with other effectors of growth factor signal transduction ${ }^{66}$.

SPARC also inhibits epithelial cell proliferation in part through its stimulation of the TGF- $\beta$ signaling pathway. TGF- $\beta$ is the most pleiotropic and multifunctional peptide known. TGF- $\beta$ s are involved in a variety of biological processes, including cell growth and differentiation, cell proliferation, apoptosis, fibrous tissue deposition and ECM remodeling and regulation of the immune response ${ }^{79,80}$. TGF- $\beta$ s play an important role during tissue injury and the maintenance of tissue homeostasis. Recent reports described the effect of SPARC on TGF- $\beta$ synthesis in mesangial cells. Culture of SPARCnull mesangial cells revealed a reduction of collagen-I mRNA and protein that was attributed to the significantly diminished synthesis of TGF- $\beta$ by these cells. Although SPARC does not appear to activate latent TGF- $\beta 1$ directly, SPARC-null mesangial cells show depressed levels of phosphorylation of the THF- $\beta 1$-dependent signal transduction protein, Smad2.

Next, SPARC also binds to a variety of ECM components including TSP-1, vitronectin, fibrillar collagens, entactin, collagen type IV, and could as such have the potency to regulate the organization of the ECM and the basement membranes. In addition, SPARC is a substrate for tissue Transglutaminase (tTG), an enzyme that makes covalent cross-links between MCPs, mediating matrix assembly and cell-ECM interactions ${ }^{64}$. The absence of SPARC affects the processing of pro-collagen-I and collagen fibrillogenesis as 
revealed by smaller and more uniform dermal collagen fibers with reduced tenisile strength.

SPARC has been shown to increase the production and activity of MMPs ${ }^{76}$, proteases that are strongly involved in degrading the ECM. In turn MMP-2 is known to proteolytically cleave SPARC, thereby augmenting the affinity of SPARC for collagen ${ }^{81}$. A possible function of increased SPARC expression in response to injury or tissue remodeling may be to facilitate the production of an ECM that is permissive for cell migration, proliferation and angiogenesis ${ }^{72}$. Another important property of SPARC is its de-adhesive activity. Addition of SPARC in cultured endothelial cells causes association of the focal adhesion complex to the matrix, resulting in modified cell shape with rounding of endothelial cells ${ }^{70}$. However, the exact mechanism of de-adhesion induced by SPARC is not fully understood.

\section{SPARC in the heart}

Little is known about a possible role for SPARC in the heart. However, several studies already highlighted a crucial function for matricellular proteins in the stressed heart. In contrast to the normal adult heart ${ }^{82}$, SPARC is abundantly expressed in the heart during embryonic development, and also re-appears after myocardial infarction $(\mathrm{MI})^{83,84}$ or adrenergic stimulation ${ }^{85}$. Expression of SPARC mRNA strongly increased after $\mathrm{MI}$ in rat $^{86}$ and mice ${ }^{87}$, reaching a peak 14 days after $\mathrm{Ml}$. The temporal and spatial expression pattern paralleled the up-regulation of type I collagen mRNA after $\mathrm{MI}$, suggesting a role for SPARC in collagen deposition and ECM-remodeling during scar formation ${ }^{86}$. In addition, SPARC mRNA was also up-regulated during cardiac remodeling, 3 and 7 days after $\beta$-adrenergic stimulation ${ }^{85}$.

SPARC may modulate the downstream activity of several growth factors, including TGF- $\beta$, FGFs, PDGFs and VEGF, which are strongly involved in migration, proliferation and differentation of several cells, necessary for proper wound healing after cardiac injury ${ }^{66,71,88}$ but also inflammation, collagen deposition and ECM remodeling. SPARC may also modulate MMP production and activity ${ }^{81,89}$. SPARC may control angiogenesis ${ }^{71}$ and might 
thereby influence wound healing and cardiac function after cardiac injury. SPARC may induce de-adhesion ${ }^{70}$ of wound healing cells or cardiomyocytes from the ECM, a process involved in stimulation invasion of wound healing cells, but which could also facilitate myocyte slippage and cardiac dilatation. 


\section{Aims and outline of the thesis}

Heart Failure afflicts over 15 million Europeans and results in increased hospitalization and mortality representing a significant and growing health care burden. The major causes of heart failure are ischemic heart disease, hypertension and viral infection in the heart. Despite clinical standards, improved medical technologies or better understanding of the pathogenesis of heart failure is essential to improve diagnosis and treatment strategies ${ }^{1}$.

Therefore, my PhD-research focused on the role of Matricellular proteins in different models for cardiovascular disease: physiological aging, viral myoarditis and myocardial infarction. We strived for novel findings providing innovative insights into the mechanisms underlying the development of cardiovascular disease and the progression to heart failure directing to a significant clinical relevance.

\section{Trombospondin-2 acts as a guardian against age-related and virus- associated dilated cardiomyopathy.}

The identification of Thrombospondin-2 (TSP-2) as an important regulator of cardiac injury and cardiac function may have important clinical implications. Therefore, it was our aim to study the role of Thrombospondin-2 in cardiac injury, dilatation and function with advancing age (Chapter 2) and during viral myocarditis (Chapter 3).

In chapter 2, we aimed to evaluate whether TSP-2 attenuates cardiac aging and protects against cardiac injury and dysfunction during aging. Both in vivo and in vitro we aimed to unravel the underlying mechanism of alleviated cardiac aging by TSP-2. Chapter 3 assesses the cardiac consequences of viral myocarditis in a murine model of Coxsackievirus B3 (CVB3)-induced myocarditis. More specifically, we aimed to evaluate the involvement of TSP2 in the cardiac inflammatory response during CVB3-induced myoycarditis and the consequences on cardiac function. Therefore we intended to 
evaluate the therapeutically implications of TSP-2 gene therapy and the effects on cardiac function.

\section{SPARC as a 'novel therapeutic agent in ischemic heart disease'.}

The myocardial infarction wound healing is a complex and tightly orchestrated process, involving an inflammatory phase, formation of granulation tissue, scar formation and overall left ventricular (LV) remodeling. Two common complications of myocardial infarction, associated with the wound healing process are cardiac rupture and heart failure. SPARC is involved in cardiac wound healing and collagen remodeling after cardiac injury. Therefore, we aimed to study the implication of SPARC in heart failure during ischemicinduced cardiac failure and its therapeutic application.

Chapter 4 describes the role of SPARC during infarct healing in a mouse model of myocardial infarction. Additionally, we demonstrate that adenoviralmediated gene transfer of SPARC improves cardiac function after $\mathrm{MI}$ indicating the importance of SPARC in the heart.

Chapter 5 comprises the main findings on matricellular proteins in the pathogenesis of cardiovascular disease, discussed in an integrative approach. 


\section{References}

1. Tendera M. The epidemiology of heart failure. $J$ Renin Angiotensin Aldosterone Syst. 2004; 5 Suppl 1:S2-6.

2. Vanhoutte $D$, Schellings $M$, Pinto $Y$, Heymans $S$. Relevance of matrix metalloproteinases and their inhibitors after myocardial infarction: a temporal and spatial window. Cardiovasc Res. 2006; 69:604-613.

3. Olivetti G, Giordano G, Corradi D, Melissari M, Lagrasta C, Gambert SR, Anversa P. Gender differences and aging: effects on the human heart. J Am Coll Cardiol. 1995; 26:1068-1079.

4. Mallat Z, Fornes P, Costagliola R, Esposito B, Belmin J, Lecomte D, Tedgui A. Age and gender effects on cardiomyocyte apoptosis in the normal human heart. The journals of gerontology. 2001; 56:M719-723.

5. Terman A, Brunk UT. The aging myocardium: roles of mitochondrial damage and lysosomal degradation. Heart, lung \& circulation. 2005; 14:107-114.

6. Sussman MA, Anversa P. Myocardial aging and senescence: where have the stem cells gone? Annual review of physiology. 2004; 66:29-48.

7. Liu PP, Mason JW. Advances in the understanding of myocarditis. Circulation. 2001; 104:1076-1082.

8. Pauschinger M, Chandrasekharan K, Schultheiss HP. Myocardial remodeling in viral heart disease: possible interactions between inflammatory mediators and MMP-TIMP system. Heart failure reviews. 2004; 9:21-31.

9. Pauschinger M, Chandrasekharan K, Noutsias M, Kuhl U, Schwimmbeck LP, Schultheiss HP. Viral heart disease: molecular diagnosis, clinical prognosis, and treatment strategies. Med Microbiol Immunol (Berl). 2004; 193:65-69.

10. Badorff C, Lee GH, Lamphear BJ, Martone ME, Campbell KP, Rhoads RE, Knowlton KU. Enteroviral protease 2A cleaves dystrophin: evidence of cytoskeletal disruption in an acquired cardiomyopathy. Nat Med. 1999; 5:320326.

11. Badorff C, Knowlton KU. Dystrophin disruption in enterovirus-induced myocarditis and dilated cardiomyopathy: from bench to bedside. Med Microbiol Immunol (Berl). 2004; 193:121-126.

12. Godeny EK, Gauntt CJ. Murine natural killer cells limit coxsackievirus B3 replication. J Immunol. 1987; 139:913-918.

13. Kurrer MO, Kopf M, Penninger JM, Eriksson U. Cytokines that regulate autoimmune myocarditis. Swiss Med Wkly. 2002; 132:408-413. 
14. Shioi T, Matsumori A, Sasayama S. Persistent expression of cytokine in the chronic stage of viral myocarditis in mice. Circulation. 1996; 94:2930-2937.

15. Huber SA, Job LP. Cellular immune mechanisms in Coxsackievirus group $B$, type 3 induced myocarditis in Balb/C mice. Adv Exp Med Biol. 1983; 161:491508.

16. Huber SA. Autoimmunity in myocarditis: relevance of animal models. Clinical immunology and immunopathology. 1997; 83:93-102.

17. Cunningham MW, Antone SM, Gulizia JM, McManus BM, Fischetti VA, Gauntt CJ. Cytotoxic and viral neutralizing antibodies crossreact with streptococcal M protein, enteroviruses, and human cardiac myosin. Proc Natl Acad Sci U S A. 1992; 89:1320-1324.

18. Huber SA. Coxsackievirus-induced myocarditis is dependent on distinct immunopathogenic responses in different strains of mice. Laboratory investigation; a journal of technical methods and pathology. 1997; 76:691701.

19. Mason JW. Myocarditis and dilated cardiomyopathy: an inflammatory link. Cardiovasc Res. 2003; 60:5-10.

20. Ono K, Matsumori A, Shioi T, Furukawa Y, Sasayama S. Cytokine gene expression after myocardial infarction in rat hearts: possible implication in left ventricular remodeling. Circulation. 1998; 98:149-156.

21. Frangogiannis NG. Targeting the inflammatory response in healing myocardial infarcts. Curr Med Chem. 2006; 13:1877-1893.

22. Frangogiannis NG. The immune system and cardiac repair. Pharmacol Res. 2008; 58:88-111.

23. Schellings MW, Pinto YM, Heymans S. Matricellular proteins in the heart: possible role during stress and remodeling. Cardiovasc Res. 2004; 64:24-31.

24. Willems IE, Arends JW, Daemen MJ. Tenascin and fibronectin expression in healing human myocardial scars. J Pathol. 1996; 179:321-325.

25. Ulrich MM, Janssen AM, Daemen MJ, Rappaport L, Samuel JL, Contard F, Smits JF, Cleutjens JP. Increased expression of fibronectin isoforms after myocardial infarction in rats. J Mol Cell Cardiol. Vol 29; 1997:2533-2543.

26. Desmouliere A, Redard M, Darby I, Gabbiani G. Apoptosis mediates the decrease in cellularity during the transition between granulation tissue and scar. Am J Pathol. Vol 146; 1995:56-66.

27. Takemura G, Ohno M, Hayakawa Y, Misao J, Kanoh M, Ohno A, Uno Y, Minatoguchi S, Fujiwara T, Fujiwara H. Role of apoptosis in the 
disappearance of infiltrated and proliferated interstitial cells after myocardial infarction. 1998;No. 11:1130-1138. Located at: Circ Res.

28. Pfeffer MA, Braunwald E. Ventricular remodeling after myocardial infarction. Experimental observations and clinical implications 1990.

29. St John Sutton M, Pfeffer MA, Moye L, Plappert T, Rouleau JL, Lamas G, Rouleau J, Parker JO, Arnold MO, Sussex B, Braunwald E. Cardiovascular death and left ventricular remodeling two years after myocardial infarction: baseline predictors and impact of long-term use of captopril: information from the Survival and Ventricular Enlargement (SAVE) trial. Circulation. 1997; 96:3294-3299.

30. Chareonthaitawee P, Christian TF, Hirose K, Gibbons RJ, Rumberger JA. Relation of initial infarct size to extent of left ventricular remodeling in the year after acute myocardial infarction. J Am Coll Cardiol. 1995; 25:567-573.

31. Jugdutt $\mathrm{BI}$, Michorowski BL. Role of infarct expansion in rupture of the ventricular septum after acute myocardial infarction: a two-dimensional echocardiographic study. Clin Cardiol. 1987; 10:641-652.

32. Sutton MG, Sharpe N. Left ventricular remodeling after myocardial infarction: pathophysiology and therapy. Circulation. 2000; 101:2981-2988.

33. Jugdutt BI. Effect of captopril and enalapril on left ventricular geometry, function and collagen during healing after anterior and inferior myocardial infarction in a dog model. J Am Coll Cardiol. 1995; 25:1718-1725.

34. Nieminen MS, Bohm M, Cowie MR, Drexler H, Filippatos GS, Jondeau G, Hasin Y, Lopez-Sendon J, Mebazaa A, Metra M, Rhodes A, Swedberg K, Priori SG, Garcia MA, Blanc JJ, Budaj A, Cowie MR, Dean V, Deckers J, Burgos EF, Lekakis J, Lindahl B, Mazzotta G, Morais J, Oto A, Smiseth OA, Garcia MA, Dickstein K, Albuquerque A, Conthe P, Crespo-Leiro M, Ferrari R, Follath F, Gavazzi A, Janssens U, Komajda M, Morais J, Moreno R, Singer M, Singh S, Tendera M, Thygesen K. Executive summary of the guidelines on the diagnosis and treatment of acute heart failure: the Task Force on Acute Heart Failure of the European Society of Cardiology. Eur Heart J. 2005; 26:384-416.

35. Swedberg K, Held P, Kjekshus J, Rasmussen K, Ryden L, Wedel H. Effects of the early administration of enalapril on mortality in patients with acute myocardial infarction. Results of the Cooperative New Scandinavian Enalapril Survival Study II (CONSENSUS II) [see comments]. N Engl J Med. 1992; 327:678-684. 
36. Bornstein $\mathrm{P}$. Thrombospondins function as regulators of angiogenesis. Journal of cell communication and signaling. 2009.

37. Sage $E H$, Bornstein $P$. Extracellular proteins that modulate cell-matrix interactions. SPARC, tenascin, and thrombospondin. J Biol Chem. 1991; 266:14831-14834.

38. Szalay G, Sauter M, Haberland M, Zuegel U, Steinmeyer A, Kandolf R, Klingel K. Osteopontin: a fibrosis-related marker molecule in cardiac remodeling of enterovirus myocarditis in the susceptible host. Circ Res. 2009; 104:851-859.

39. Agah A, Kyriakides TR, Lawler J, Bornstein P. The lack of thrombospondin-1 (TSP1) dictates the course of wound healing in double-TSP1/TSP2-null mice. Am J Pathol. 2002; 161:831-839.

40. Chen H, Aeschlimann D, Nowlen J, Mosher DF. Expression and initial characterization of recombinant mouse thrombospondin 1 and thrombospondin 3. FEBS Lett. 1996; 387:36-41.

41. Chen $H$, Sottile J, Strickland DK, Mosher DF. Binding and degradation of thrombospondin-1 mediated through heparan sulphate proteoglycans and low-density-lipoprotein receptor-related protein: localization of the functional activity to the trimeric $\mathrm{N}$-terminal heparin-binding region of thrombospondin-1. The Biochemical journal. 1996; 318 ( Pt 3):959-963.

42. Emonard $H$, Bellon $G$, Troeberg L, Berton A, Robinet A, Henriet $P$, Marbaix E, Kirkegaard K, Patthy L, Eeckhout Y, Nagase H, Hornebeck W, Courtoy PJ. Low density lipoprotein receptor-related protein mediates endocytic clearance of pro-MMP-2.TIMP-2 complex through a thrombospondin-independent mechanism. J Biol Chem. 2004; 279:54944-54951.

43. Yang Z, Kyriakides TR, Bornstein P. Matricellular proteins as modulators of cell-matrix interactions: adhesive defect in thrombospondin 2-null fibroblasts is a consequence of increased levels of matrix metalloproteinase-2. Mol Biol Cell. 2000; 11:3353-3364.

44. Agah A, Kyriakides TR, Bornstein P. Proteolysis of cell-surface tissue transglutaminase by matrix metalloproteinase- 2 contributes to the adhesive defect and matrix abnormalities in thrombospondin-2-null fibroblasts and mice. Am J Pathol. 2005; 167:81-88.

45. Yang Z, Strickland DK, Bornstein P. Extracellular matrix metalloproteinase 2 levels are regulated by the low density lipoprotein-related scavenger receptor and thrombospondin 2. J Biol Chem. 2001; 276:8403-8408. 
46. Maclauchlan S, Skokos EA, Agah A, Zeng J, Tian W, Davidson JM, Bornstein $P$, Kyriakides TR. Enhanced angiogenesis and reduced contraction in thrombospondin-2-null wounds is associated with increased levels of matrix metalloproteinases-2 and -9 , and soluble VEGF. J Histochem Cytochem. 2009; 57:301-313.

47. Schroen B, Heymans S, Sharma U, Blankesteijn WM, Pokharel S, Cleutjens JP, Porter JG, Evelo CT, Duisters R, van Leeuwen RE, Janssen BJ, Debets JJ, Smits JF, Daemen MJ, Crijns HJ, Bornstein P, Pinto YM. Thrombospondin-2 is essential for myocardial matrix integrity: increased expression identifies failure-prone cardiac hypertrophy. Circ Res. 2004; 95:515-522.

48. Bornstein $\mathrm{P}$, Armstrong LC, Hankenson KD, Kyriakides TR, Yang Z. Thrombospondin 2, a matricellular protein with diverse functions. Matrix Biol. 2000; 19:557-568.

49. Schultz-Cherry S, Chen H, Mosher DF, Misenheimer TM, Krutzsch HC, Roberts DD, Murphy-Ullrich JE. Regulation of transforming growth factor-beta activation by discrete sequences of thrombospondin 1. J Biol Chem. 1995; 270:7304-7310.

50. Chen H, Sottile J, O'Rourke KM, Dixit VM, Mosher DF. Properties of recombinant mouse thrombospondin 2 expressed in Spodoptera cells. J Biol Chem. 1994; 269:32226-32232.

51. Calzada MJ, Annis DS, Zeng B, Marcinkiewicz C, Banas B, Lawler J, Mosher DF, Roberts DD. Identification of novel beta1 integrin binding sites in the type 1 and type 2 repeats of thrombospondin-1. J Biol Chem. 2004; 279:4173441743.

52. Calzada MJ, Sipes JM, Krutzsch HC, Yurchenco PD, Annis DS, Mosher DF, Roberts DD. Recognition of the N-terminal modules of thrombospondin-1 and thrombospondin-2 by alpha6beta1 integrin. J Biol Chem. 2003; 278:4067940687.

53. Swinnen M, Vanhoutte D, Van Almen GC, Hamdani N, Schellings MW, D'Hooge J, Van der Velden J, Weaver MS, Sage EH, Bornstein P, Verheyen FK, VandenDriessche T, Chuah MK, Westermann D, Paulus WJ, Van de Werf F, Schroen B, Carmeliet P, Pinto YM, Heymans S. Absence of thrombospondin-2 causes age-related dilated cardiomyopathy. Circulation. 2009; 120:1585-1597.

54. Armstrong LC, Bornstein P. Thrombospondins 1 and 2 function as inhibitors of angiogenesis. Matrix Biol. 2003; 22:63-71. 
55. Armstrong LC, Bjorkblom B, Hankenson KD, Siadak AW, Stiles CE, Bornstein P. Thrombospondin 2 inhibits microvascular endothelial cell proliferation by a caspase-independent mechanism. Molecular biology of the cell. 2002; 13:1893-1905.

56. Rodriguez-Manzaneque JC, Lane TF, Ortega MA, Hynes RO, Lawler J, Iruela-Arispe ML. Thrombospondin-1 suppresses spontaneous tumor growth and inhibits activation of matrix metalloproteinase- 9 and mobilization of vascular endothelial growth factor. Proc Natl Acad Sci U S A. 2001; 98:12485-12490.

57. Krady MM, Zeng J, Yu J, MacLauchlan S, Skokos EA, Tian W, Bornstein P, Sessa WC, Kyriakides TR. Thrombospondin-2 modulates extracellular matrix remodeling during physiological angiogenesis. Am J Pathol. 2008; 173:879891.

58. Hudlicka O, Brown M, Egginton S. Angiogenesis in skeletal and cardiac muscle. Physiological reviews. 1992; 72:369-417.

59. Karch R, Neumann F, Ullrich R, Neumuller J, Podesser BK, Neumann M, Schreiner W. The spatial pattern of coronary capillaries in patients with dilated, ischemic, or inflammatory cardiomyopathy. Cardiovasc Pathol. 2005; 14:135-144.

60. Park YW, Kang YM, Butterfield J, Detmar M, Goronzy JJ, Weyand CM. Thrombospondin 2 functions as an endogenous regulator of angiogenesis and inflammation in rheumatoid arthritis. Am J Pathol. 2004; 165:2087-2098.

61. Streit M, Riccardi L, Velasco P, Brown LF, Hawighorst T, Bornstein P, Detmar M. Thrombospondin-2: a potent endogenous inhibitor of tumor growth and angiogenesis. Proc Natl Acad Sci U S A. 1999; 96:14888-14893.

62. Kyriakides TR, Tam JW, Bornstein P. Accelerated wound healing in mice with a disruption of the thrombospondin 2 gene. J Invest Dermatol. 1999; 113:782787.

63. Kyriakides TR, Leach KJ, Hoffman AS, Ratner BD, Bornstein P. Mice that lack the angiogenesis inhibitor, thrombospondin 2, mount an altered foreign body reaction characterized by increased vascularity. Proc Natl Acad Sci U S A. 1999; 96:4449-4454.

64. Lane TF, Sage EH. The biology of SPARC, a protein that modulates cellmatrix interactions. Faseb J. 1994; 8:163-173.

65. Kapadia S, Lee J, Torre-Amione G, Birdsall HH, Ma TS, Mann DL. Tumor necrosis factor-alpha gene and protein expression in adult feline myocardium after endotoxin administration. J Clin Invest. 1995; 96:1042-1052. 
66. Brekken RA, Sage EH. SPARC, a matricellular protein: at the crossroads of cell-matrix communication. Matrix Biol. 2001; 19:816-827.

67. Sage $\mathrm{H}$, Johnson $\mathrm{C}$, Bornstein P. Characterization of a novel serum albuminbinding glycoprotein secreted by endothelial cells in culture. J Biol Chem. 1984; 259:3993-4007.

68. Aeschlimann D, Kaupp O, Paulsson M. Transglutaminase-catalyzed matrix cross-linking in differentiating cartilage: identification of osteonectin as a major glutaminyl substrate. J Cell Biol. 1995; 129:881-892.

69. Funk SE, Sage EH. Differential effects of SPARC and cationic SPARC peptides on DNA synthesis by endothelial cells and fibroblasts. J Cell Physiol. 1993; 154:53-63.

70. Murphy-Ullich JE, Lane TF, Pallero MA, Sage EH. SPARC mediates focal adhesion disassembly in endothelial cells through a follistatin-like region and the $\mathrm{Ca}(2+)$-binding EF-hand. Journal of cellular biochemistry. 1995; 57:341350.

71. Kupprion C, Motamed K, Sage EH. SPARC (BM-40, osteonectin) inhibits the mitogenic effect of vascular endothelial growth factor on microvascular endothelial cells. J Biol Chem. 1998; 273:29635-29640.

72. Lane TF, Iruela-Arispe ML, Johnson RS, Sage EH. SPARC is a source of copper-binding peptides that stimulate angiogenesis. J Cell Biol. 1994; 125:929-943.

73. Hasselaar $P$, Sage EH. SPARC antagonizes the effect of basic fibroblast growth factor on the migration of bovine aortic endothelial cells. Journal of cellular biochemistry. 1992; 49:272-283.

74. Sage EH, Bassuk JA, Yost JC, Folkman MJ, Lane TF. Inhibition of endothelial cell proliferation by SPARC is mediated through a $\mathrm{Ca}(2+)$-binding EF-hand sequence. Journal of cellular biochemistry. 1995; 57:127-140.

75. Lane TF, Iruela-Arispe ML, Sage EH. Regulation of gene expression by SPARC during angiogenesis in vitro. Changes in fibronectin, thrombospondin-1, and plasminogen activator inhibitor-1. J Biol Chem. 1992; 267:16736-16745.

76. Sasaki T, Gohring W, Mann K, Maurer P, Hohenester E, Knauper V, Murphy G, Timpl R. Limited cleavage of extracellular matrix protein BM-40 by matrix metalloproteinases increases its affinity for collagens. J Biol Chem. 1997; 272:9237-9243. 
77. Sasaki T, Hohenester E, Gohring W, Timpl R. Crystal structure and mapping by site-directed mutagenesis of the collagen-binding epitope of an activated form of BM-40/SPARC/osteonectin. Embo J. 1998; 17:1625-1634.

78. Raines EW, Lane TF, Iruela-Arispe ML, Ross R, Sage EH. The extracellular glycoprotein SPARC interacts with platelet-derived growth factor (PDGF)-AB and $-B B$ and inhibits the binding of PDGF to its receptors. Proc Natl Acad Sci U S A. 1992; 89:1281-1285.

79. Schiller M, Javelaud D, Mauviel A. TGF-beta-induced SMAD signaling and gene regulation: consequences for extracellular matrix remodeling and wound healing. Journal of dermatological science. 2004; 35:83-92.

80. Bujak M, Frangogiannis NG. The role of TGF-beta signaling in myocardial infarction and cardiac remodeling. Cardiovasc Res. 2007; 74:184-195.

81. Tremble PM, Lane TF, Sage EH, Werb Z. SPARC, a secreted protein associated with morphogenesis and tissue remodeling, induces expression of metalloproteinases in fibroblasts through a novel extracellular matrixdependent pathway. J Cell Biol. 1993; 121:1433-1444.

82. Sage H, Vernon RB, Decker J, Funk S, Iruela-Arispe ML. Distribution of the calcium-binding protein SPARC in tissues of embryonic and adult mice. $\mathrm{J}$ Histochem Cytochem. 1989; 37:819-829.

83. Holland PW, Harper SJ, McVey JH, Hogan BL. In vivo expression of mRNA for the Ca++-binding protein SPARC (osteonectin) revealed by in situ hybridization. J Cell Biol. 1987; 105:473-482.

84. Stanton LW, Garrard LJ, Damm D, Garrick BL, Lam A, Kapoun AM, Zheng Q, Protter AA, Schreiner GF, White RT. Altered patterns of gene expression in response to myocardial infarction. Circ Res. 2000; 86:939-945.

85. Masson S, Arosio B, Luvara G, Gagliano N, Fiordaliso F, Santambrogio D, Vergani C, Latini R, Annoni G. Remodelling of cardiac extracellular matrix during beta-adrenergic stimulation: upregulation of SPARC in the myocardium of adult rats. J Mol Cell Cardiol. 1998; 30:1505-1514.

86. Komatsubara I, Murakami T, Kusachi S, Nakamura K, Hirohata S, Hayashi J, Takemoto S, Suezawa C, Ninomiya Y, Shiratori Y. Spatially and temporally different expression of osteonectin and osteopontin in the infarct zone of experimentally induced myocardial infarction in rats. Cardiovascular Pathology. 2003; 12:186-194.

87. Dobaczewski M, Bujak M, Zymek P, Ren G, Entman ML, Frangogiannis NG. Extracellular matrix remodeling in canine and mouse myocardial infarcts. Cell Tissue Res. 2006; 324:475-488. 
88. Bradshaw AD, Sage EH. SPARC, a matricellular protein that functions in cellular differentiation and tissue response to injury. J Clin Invest. 2001; 107:1049-1054.

89. Tremble $\mathrm{P}$, Chiquet-Ehrismann $\mathrm{R}$, Werb $\mathrm{Z}$. The extracellular matrix ligands fibronectin and tenascin collaborate in regulating collagenase gene expression in fibroblasts. Molecular biology of the cell. 1994; 5:439-453. 


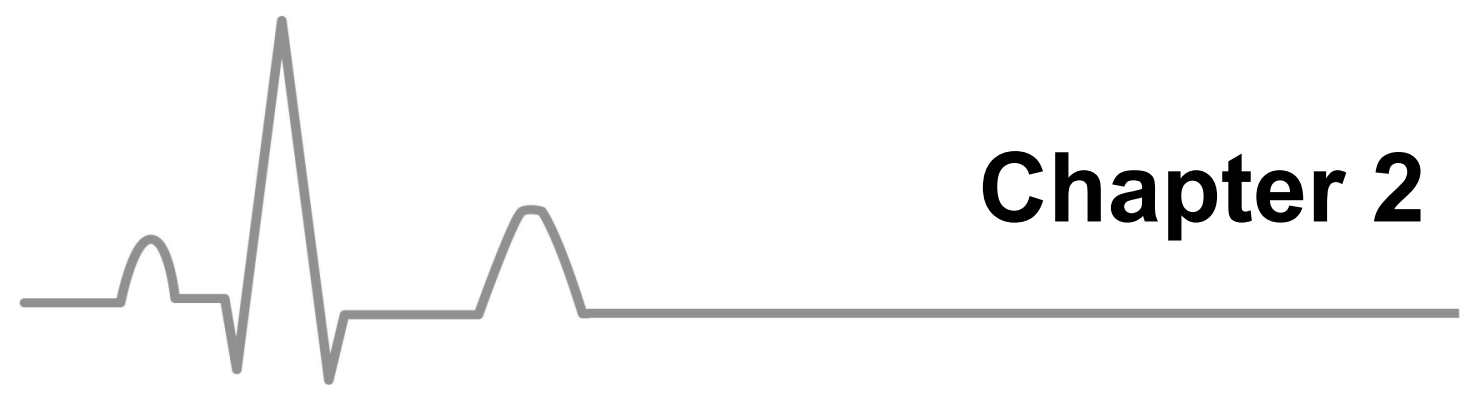

\section{The absence of thrombospondin-2 causes age-related dilated cardiomyopathy}

Melissa Swinnen*, Davy Vanhoutte*, Geert C. Van Almen, Nazha Hamdani, Mark W.M. Schellings, Jan D’hooge, Jolanda Van der Velden, Matthew S. Weaver, E. Helene Sage, Paul Bornstein, Fons K. Verheyen, Thierry VandenDriessche, Marinee K. Chuah, Dirk Westermann, Walter J. Paulus, Frans Van de Werf, Blanche Schroen, Peter Carmeliet, Yigal M. Pinto, Stephane Heymans

\section{Circulation}

2009 Oct 20;120(16):1585-97 


\begin{abstract}
Background-The progressive shift from a young to an aged heart is characterized by alterations in the cardiac matrix. The present study investigated whether the matricellular protein TSP-2 may affect cardiac dimensions and function with physiological aging of the heart.
\end{abstract}

Methods and Results-TSP-2 knockout (KO) and wild type (WT) mice were followed up to an age of 60 weeks. Survival rate, cardiac function and morphology did not differ at a young age in TSP-2 KO compared to WT mice. However, over 55\% of the TSP-2 KO mice died between 24 and 60 weeks of age, whereas less then $10 \%$ of the WT mice succumbed. In the absence of TSP-2, older mice displayed a severe dilated cardiomyopathy with impaired systolic function, increased cardiac dilatation and fibrosis. Ultrastructural analysis revealed progressive myocyte stress and death, accompanied by an inflammatory response and replacement fibrosis in aging TSP-2 KO animals, whereas capillary or coronary morphology or density was not affected.

Importantly, adeno-associated viral vector (AAV9)-mediated transfer of TSP-2 in 7 weeks old TSP-2 KO mice normalized their survival and prevented the dilated cardiomyopathy.

In TSP-2 KO animals, age-related cardiomyopathy was accompanied by increased MMP-2- and decreased tissue-transglutaminase-2 activity, together with impaired collagen cross-linking. At the cardiomyocyte level, TSP-2 deficiency in vivo and its knockdown in vitro decreased the activation of the Akt survival pathway in cardiomyocytes.

Conclusions-TSP-2 expression in the heart protects against age-dependent dilated cardiomyopathy. 


\section{Introduction}

Whether aging of the heart and related functional changes should be regarded as a physiological or pathological process is a puzzling question. In the absence of other diseases such as hypertension, diabetes or detrimental environmental factors such as smoking, the heart is perfectly able to "survive" for a human lifespan. Hence, disease processes such as lamin A/C mutations that result in accelerated aging of the heart and dilated cardiomyopathy, point towards essential protective mechanisms that are mandatory for normal physiological aging of the heart ${ }^{1,2}$.

The extracellular matrix (ECM) is a crucial system that hinders functional and structural deterioration of the heart with aging. Matrix elements not only provide structural support, as collagen does, but are also implicated in maintaining cellular homeostasis and regulating intracellular signaling during normal cardiac physiology. ${ }^{2}$ Thrombospondin-2 (TSP-2) belongs to a family of non-structural matricellular proteins implicated in regulating cell-matrix interactions. Its expression is low in the normal post-natal heart, but reappears at high levels during cardiac pathology 3,4 , and helps to preserve cardiac integrity during hypertension ${ }^{5}$. However, its function in normal physiological aging of the heart remains unknown. We therefore investigated whether TSP-2, by affecting survival pathways in cardiomyocytes, may provide necessary molecular support for the heart with aging, and thus increase lifespan. We provide data showing that hearts lacking TSP-2 progress towards dilated cardiomyopathy with advanced age, but have normal morphology and function at a young age. Importantly, post-natal adenoasociated viral vector (AAV9)-mediated transfer of TSP-2 in young TSP-2 KO completely normalized their survival and prevented the development of cardiac failure. With aging, lack of TSP-2 resulted in decreased activation of the Src/Akt survival pathway, increased MMP-2 activity and decreased collagen cross-linking, leading to progressive cardiomyocyte dropout, and overall cardiac failure and dilatation. 


\section{Materials \& Methods}

See data supplement for additional details, which is added at the end of this chapter 2 (page 66).

\section{Transgenic mice and experimental procedures}

The study was approved by the Institutional Animal Research Committees and all experiments were performed according to official rules formulated in Dutch and Belgian law on care and use of experimental animals. Eight to sixty weeks-old TSP-2 knockout (KO) mice and their WT littermates on a C57BI6/129SvJ/EMS+Ter genetic background were used. ${ }^{6}$. At young age, male and female mice were divided into three age groups for further analysis: (i) Young mice: 8-12 weeks old ( $n=20$ for TSP-2 WT mice and $n=20$ for TSP2 KO mice); (ii) intermediate aged mice: $25-30$ weeks ( $n=20$ for TSP-2 WT mice and $n=20$ for TSP-2 KO mice) and (iii) older mice: 50-60 weeks old ( $n=$ 100 for TSP-2 WT mice and n= 100 for TSP-2 KO mice). Consequently, only mortality rates within the third group were included in the survival curve.

Next, in order to rescue cardiac TSP-2 expression, adeno-associated viral vector (AAV)-9 gene transfer of TSP-2 was performed in TSP-2 KO mice. The construction and production of the AAV9-TSP-2 and AAV9-Green fluorescent protein (GFP) vectors, with both TSP-2 and GFP driven under the cytomegalovirus (CMV) promotor. Additional details in online supplement 1. One hundred $\mu$ l containing $10^{11}$ viral genomic copies (gc) AAV9-TSP-2 or the control AAV9-GFP was injected (i.v.) in the tail vein of adult (7-week-old) male ( $n=10$ for AAV9-TSP-2; $n=25$ for AAV9-GFP) and female $(n=19$ for AAV9TSP-2; n=10 for AAV9-GFP ) TSP-2 KO mice and monitored until 60 weeks of age.

All analyses were performed following standard operating procedures and confirmed by independent observers blinded to genotype or treatment group. 


\section{Cardiac function, histopathological and molecular analysis}

After the study period, all mice were anaesthetized, followed by transthoracic echocardiographic examination. Subsequently, hearts were taken out and prepared for further histological and molecular analysis, including immunohistochemical and electron microscopic analysis; determination of zymographic MMP- and tissue transglutaminase- activity with aging; RNA isolation and real time polymerase chain reaction; immunoblotting; ILK activity and active TGF beta assays; in vitro experimental approaches; force measurements in single permeabilized cardiomyocytes and phosphorylation status of myofilament proteins. Experimental materials and methods are more extensively described in the 'supplemental data'. (See online data supplement).

\section{Statistical analysis}

All data are expressed as mean standard error of mean (SEM). MannWhitney U-test, unpaired t-test or two-way ANOVA were used, when appropriate, to assess statistical significance between groups. Survival curves were obtained by the Kaplan-Meier method, and compared by the logrank test. A two-sides $P<0.05$ was considered statistically significant.

\section{Results}

\section{TSP-2 KO mice develop accelerated aging-induced cardiomyopathy}

To investigate the effect of TSP-2 on aging, a prospective study for mortality was conducted (Figure 1A). Whereas no significant mortality was noted until 20 weeks of age, the survival rate of TSP-2 KO mice progressively declined thereafter as compared to WT mice (Figure 1A). By 60 weeks of age $55 \%$ of the TSP-2 KO mice died (55 out of 100), whereas $90 \%$ of the WT mice (90 out of 100$)$ remained alive $(P<0.01)$. Interestingly, mortality was significantly higher in male (84\% or 42 out of 50 ) compared to female TSP-2 KO mice 
(26\% or 13 out of 50$)(P<0.01$; Figure $1 \mathrm{~A})$. TSP-2 transcript and protein levels were significantly increased (respectively, 3.4 fold and 3.6 fold) in older compared to young TSP-2 WT hearts (Table 1 and Figure 1B). Moreover, immunoblotting revealed that TSP-2 protein levels were more elevated in older female compared to older male WT hearts (Figure 1B). Immunohistochemical analysis confirmed that TSP-2 protein expression was low in young WT hearts (Figure 1C), but abundantly present and primarily located in the ECM surrounding the cardiomyocytes in both older female and male TSP-2 WT hearts (Figure 1C).
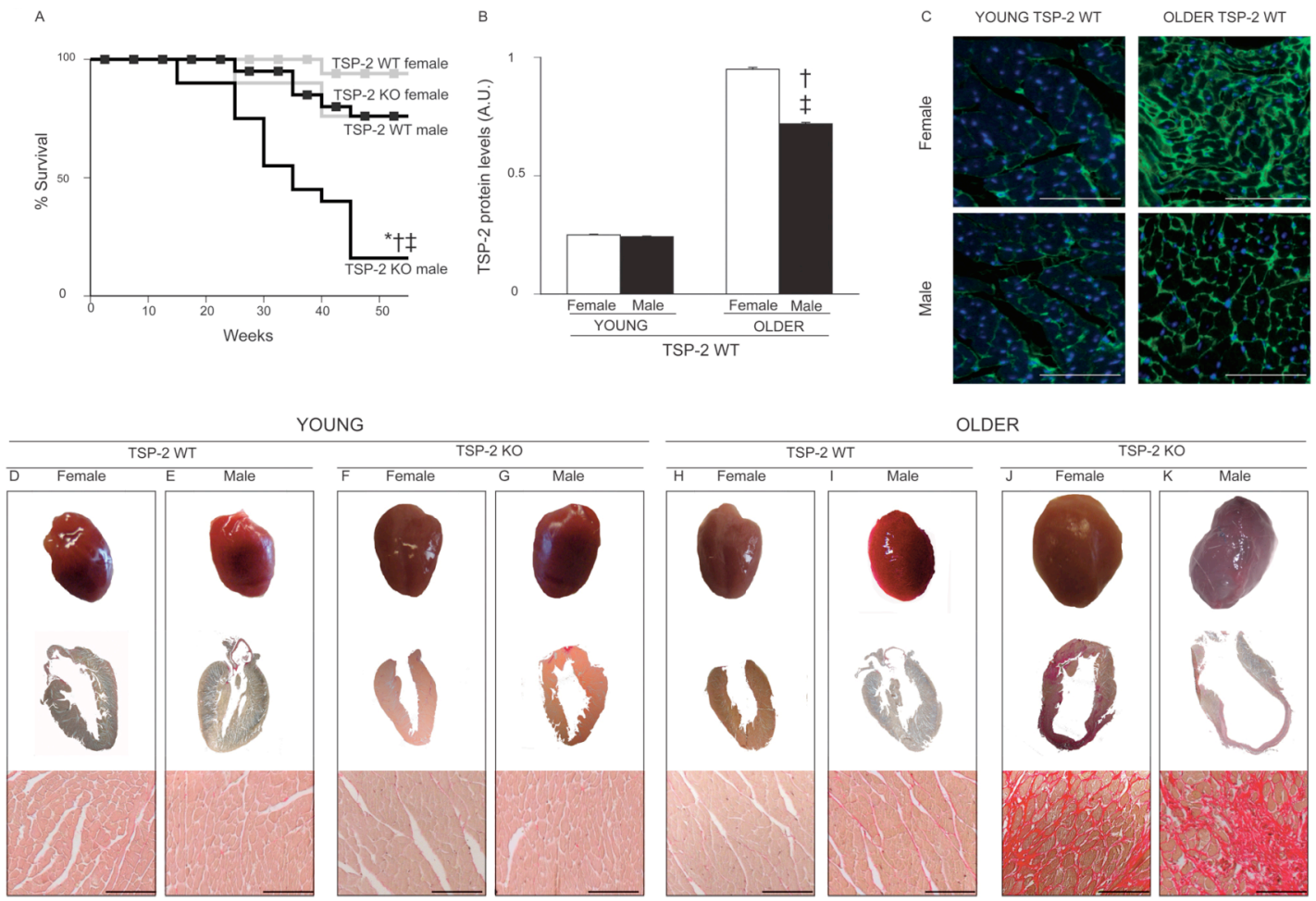

YOUNG

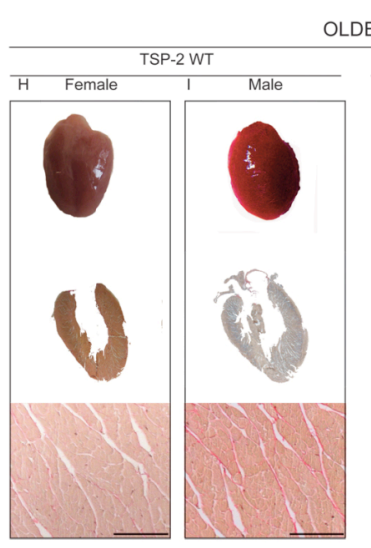

LDER
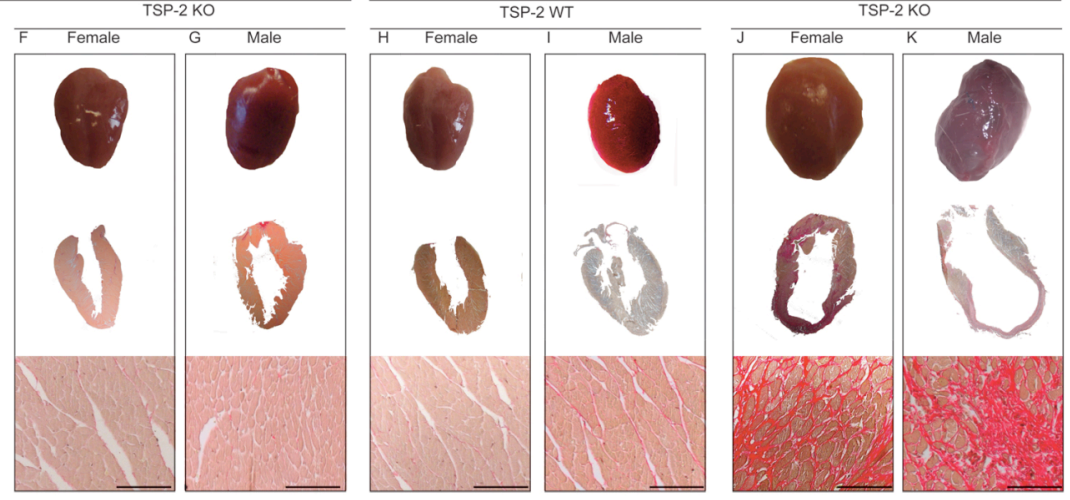

Figure 1. Age-induced dilated cardiomyopathy and increased mortalitiy in the absence of TSP-2. (A) Survival curves of TSP-2 KO and WT mice. (B) Immunoblotting of TSP-2 in WT hearts. (C) Increased TSP-2 immunofluorescent staining in older WT hearts. (D-K) Upper part: Macroscopic hearts and sirius red staining respectively from young and older, male and female TSP-2 WT and KO mice. Additional pictures in supplemental Figure 1. ${ }^{*} P<0.01 \mathrm{TSP}-2$ KO mice vs. TSP-2 WT mice within the same gender and age; $†: P<0.01$ Older TSP-2 mice vs younger TSP-2 mice within the same genotype ; $\ddagger: P<0.01$ TSP-2 female mice vs TSP-2 male mice with the same genotype within the same age-group. Bars: (C-K) $100 \mu \mathrm{m}$.

To investigate whether the absence of TSP-2 resulted in compensatory changes in expression of other TSPs before the onset of heart failure, transcript and/or protein levels of TSP-1, -3 and -4 were determined in the hearts of young and older TSP-2 KO and WT mice (Table 1). Compared to 
WT hearts, a clear trend towards increased TSP-4 transcript levels was observed in TSP-2 KO hearts $(P=0.08$ at young age and $P=0.07$ at older age, Table 1). However, no significant differences in TSP-1, -3 and -4 transcript levels were noted between WT and KO hearts at both young and older age (Table 1). Concordantly, TSP-1 and -3 immunoblotting did not reveal any significant differences between the TSP-2 WT and KO hearts (Table 1).

Table 1. Real time PCR and immunoblotting in young and older TSP-2 WT and KO hearts.

\begin{tabular}{|c|c|c|c|c|}
\hline & \multirow{2}{*}{\multicolumn{2}{|c|}{ YOUNG }} & \multirow{2}{*}{\multicolumn{2}{|c|}{ OLDER }} \\
\hline & & & & \\
\hline & WT & KO & WT & KO \\
\hline & Young & Young & Older & Older \\
\hline & $\mathrm{n}=5$ & $\mathrm{n}=5$ & $n=5$ & $\mathrm{n}=5$ \\
\hline & \multicolumn{4}{|c|}{ Thrombospondins } \\
\hline \multicolumn{5}{|c|}{ Relative mRNA expression (A.U.) } \\
\hline TSP-1 & $1.2 \pm 0.37$ & $1.9 \pm 0.53$ & $1.1 \pm 0.35$ & $1.5 \pm 0.43$ \\
\hline TSP-2 & $1.0 \pm 0.10$ & $<0.1$ & $3.4 \pm 0.55 \dagger$ & $<0.1^{\star}$ \\
\hline TSP-3 & $1.1 \pm 0.23$ & $2.2 \pm 0.35$ & $1.3 \pm 0.49$ & $1.7 \pm 0.27$ \\
\hline TSP-4 & $1.1 \pm 0.28$ & $5.5 \pm 2.1$ & $1.1 \pm 0.35$ & $5.8 \pm 2.7$ \\
\hline \multicolumn{5}{|c|}{ Protein levels (A.U.) } \\
\hline TSP-1 & $0.52 \pm 0.03$ & $0.62 \pm 0.05$ & $0.55 \pm 0.10$ & $0.60 \pm 0.13$ \\
\hline TSP-2 & $0.23 \pm 0.01$ & $<0.1^{*}$ & $0.82 \pm 0.05 \dagger$ & $<0.1^{*}$ \\
\hline \multirow[t]{2}{*}{ TSP-3 } & $0.54 \pm 0.04$ & $0.59 \pm 0.09$ & $0.61 \pm 0.03$ & $0.66 \pm 0.15$ \\
\hline & \multicolumn{4}{|c|}{ Oxidative stress } \\
\hline \multicolumn{5}{|c|}{ Relative mRNA expression (A.U.) } \\
\hline CAT1 & $1.7 \pm 1.0$ & $1.6 \pm 0.9$ & $2.9 \pm 0.2 \dagger$ & $2.1 \pm 0.1^{*}, \dagger$ \\
\hline SOD2 & $1.0 \pm 0.1$ & $0.71 \pm 0.1$ & $6.6 \pm 1.5 \dagger$ & $6.5 \pm 1.2 \dagger$ \\
\hline \multirow[t]{2}{*}{ GXP1 } & $1.0 \pm 0.01$ & $0.99 \pm 0.7$ & $1.0 \pm 0.5^{*}$ & $1.0 \pm 0.4$ \\
\hline & \multicolumn{4}{|c|}{ Inflammation } \\
\hline \multicolumn{5}{|c|}{ Protein levels $(\mathrm{pg} / \mathrm{mL})$} \\
\hline TGF beta & $4.7 \pm 1.0$ & $6.2 \pm 1.1$ & $5.0 \pm 0.9$ & $4.6 \pm 0.8$ \\
\hline \multicolumn{5}{|c|}{ Relative mRNA expression (A.U.) } \\
\hline TGF-beta & $1.0 \pm 0.2$ & $1.0 \pm 0.9$ & $0.15 \pm 0.05 \dagger$ & $0.2 \pm 0.02^{*}, \dagger$ \\
\hline IL-1 beta & $<0.05$ & $<0.05$ & $1.0 \pm 0.5 \dagger$ & $4.6 \pm 0.2^{\star}, \dagger$ \\
\hline IL-6 & $<0.05$ & $<0.05$ & $1.0 \pm 0.2$ & $3.8 \pm 0.4^{*}, \dagger$ \\
\hline IL-12 & $1.0 \pm 0.9$ & $1.0 \pm 0.5$ & $0.96 \pm 0.05 \dagger$ & $8.7 \pm 0.9^{\star}, \dagger$ \\
\hline
\end{tabular}

* $P<0.05$ TSP-2 WT mice vs TSP-2 KO mice within the same age-group and gender. ${ }^{\dagger} P<0.05$ young vs older mice with the same genotype

Further analysis of the aged hearts revealed that the increased mortality was due to a progressive and severe dilated cardiomyopathy, with increasing cardiac fibrosis and dilatation with aging in TSP-2 KO mice (Figure 1D through $1 \mathrm{~K}$, Table 2 and 3 ). In concordance, echocardiographic analysis showed depressed systolic function and increased cardiac dilatation in 
surviving TSP-2 KO compared to older WT mice (Table 2). Cardiac fibrosis, dysfunction and dilatation were more pronounced in the older male as compared to the older female TSP-2 KO hearts (Figure 1D through $1 \mathrm{~K}$, Table 2 and 3). Increased cardiac failure in TSP-2 KO mice was further validated by an increased lung to body weight ratio compared with WT mice at 60 weeks (Table 2). At young age, cardiac function and dimensions did not differ in TSP-2 KO compared to age-matched WT animals (Table 2).

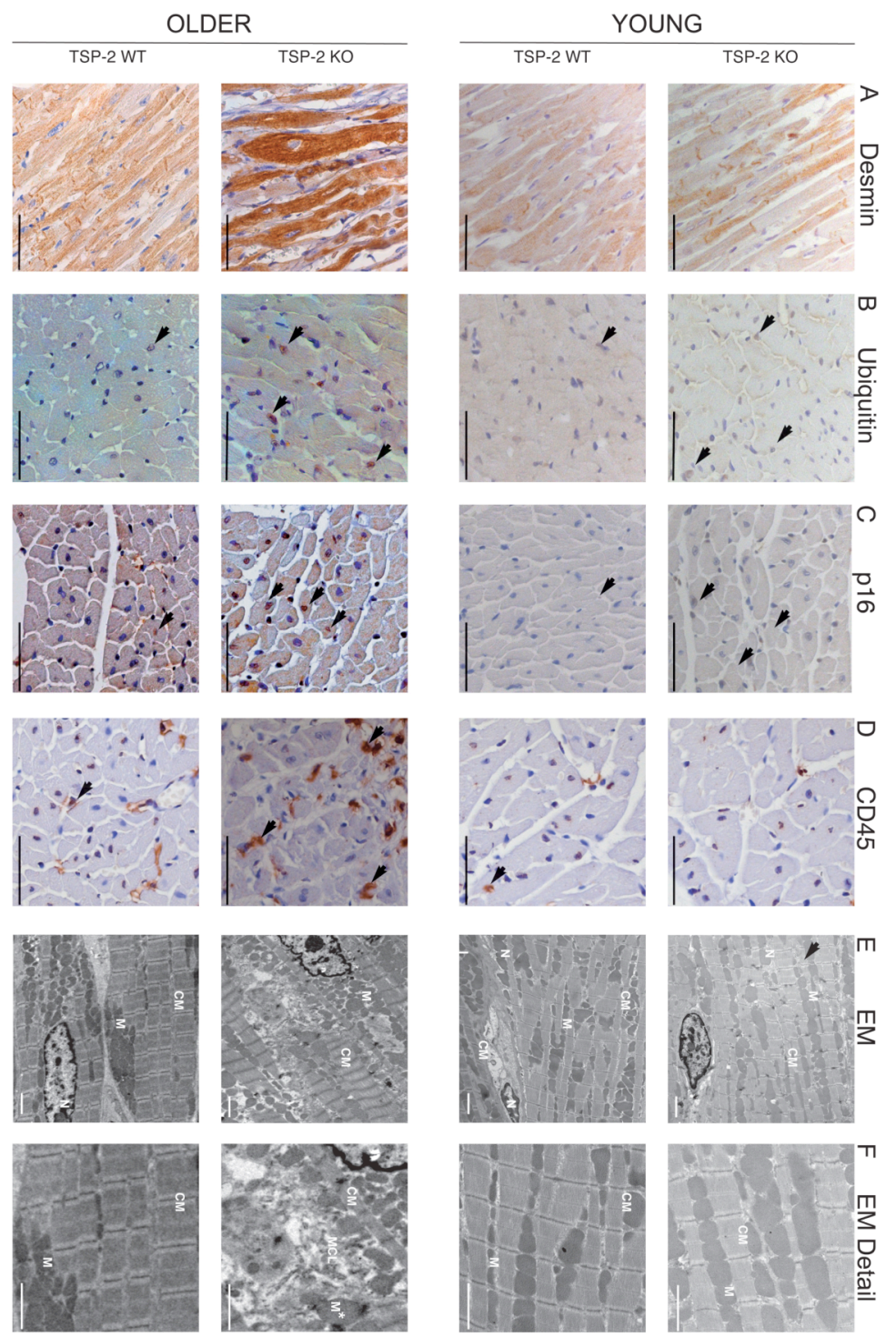

Figure 2. Structural features of accelerated aging of the hearts in TSP-2 KO mice. Histological and ultrastructural analysis of young and older male TSP-2 KO and WT hearts. (A) Desmin and (B) ubiquitin, 2 markers of cell stress; (C) p16, an indicator of aging and (D) infiltrating CD45-positive leukocytes were increased in older TSP-2 KO hearts, but did not differ at younger age. (E-F) Electronmicroscopic analysis revealed increased myocytolitic damage, and mitochondrial dilatation in older TSP-2 KO compared with WT hearts. N: nucleus, M: mitochondria, $M^{*}$ : dilated mitochondria, $C M$ : cardiomyocyte, $M C L$ : myocytolitic damage.

Bars:(A-D): $50 \mu \mathrm{m} ;(E, F) 2 \mu \mathrm{m}$ and $1 \mu \mathrm{m}$ respectively 


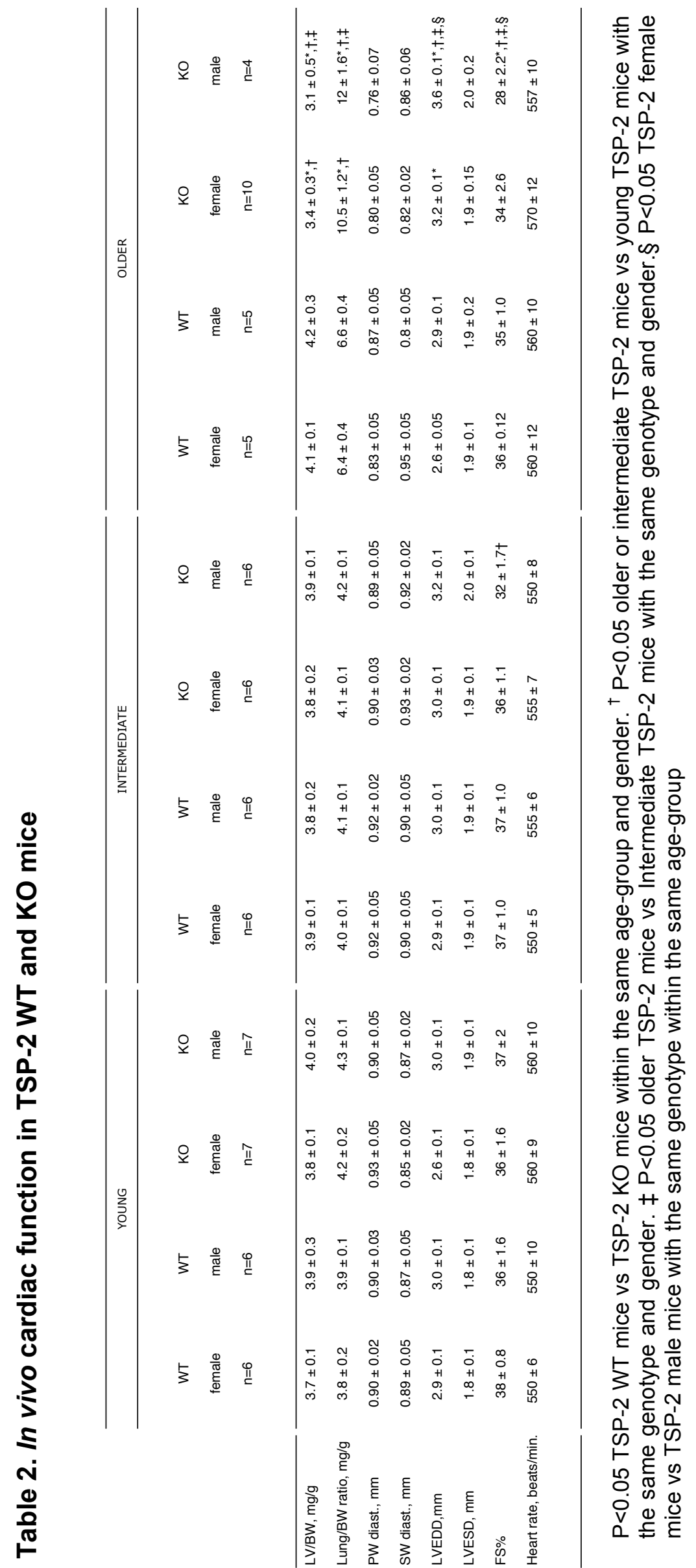




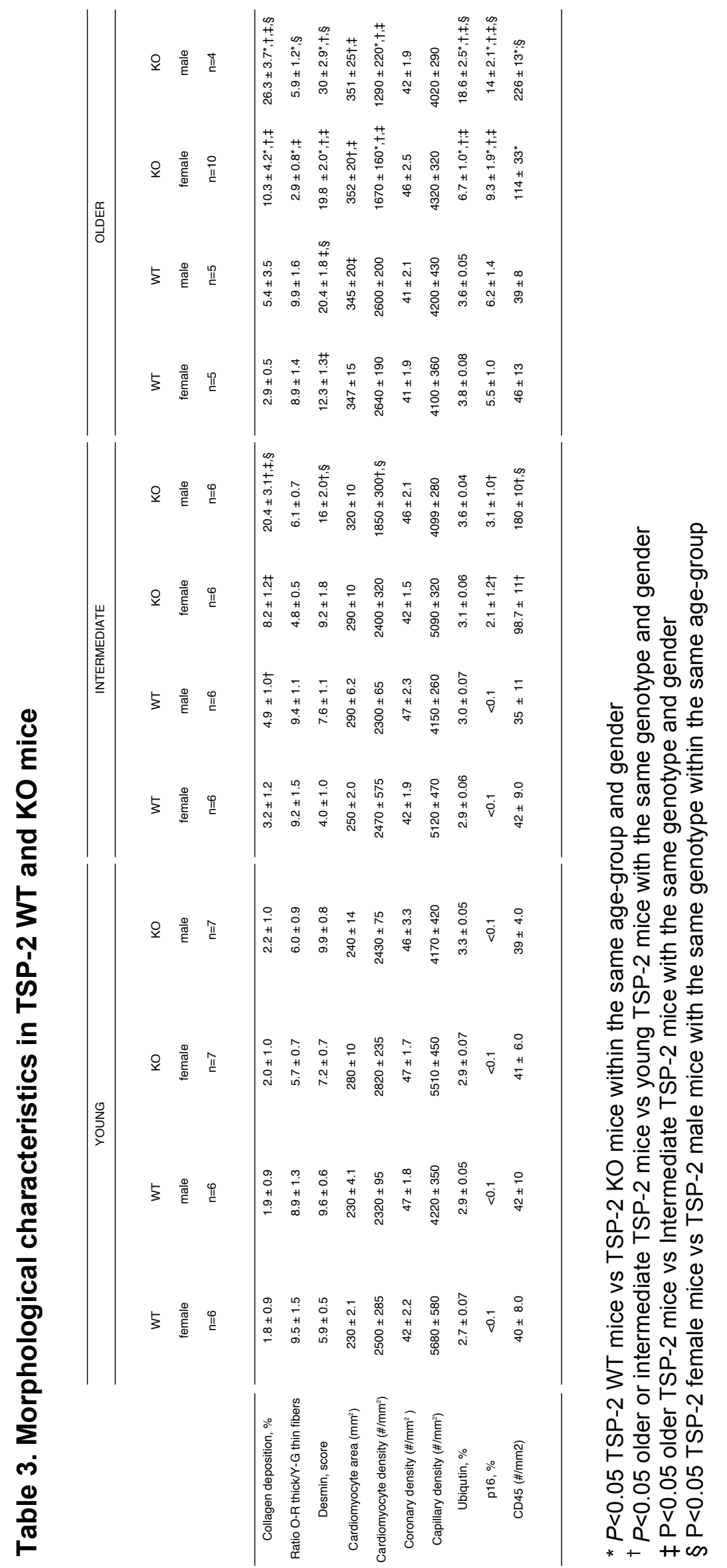




\section{Structural features of accelerated aging of the heart in TSP-2 KO mice}

To study the underlying mechanisms of the age-related cardiomyopathy, the morphological features of cardiomyocytes, the interstitial matrix and the vessels, including markers of apoptosis and cell stress, were examined within the surviving male and female TSP2 WT and KO hearts at young (8-12 weeks), intermediate (25-30 weeks) and older age (50-60 weeks).

Histopathological analysis revealed a progressive decrease in cardiomyocyte density and increase in scar-forming fibrosis with advanced age in the male and female TSP-2 KO hearts, but not in aged WT hearts (Figure 1D through $1 \mathrm{~K}$, Tabel 3, Supplemental Figure 1). No differences were seen at young age. Cardiomyocyte dropout was further indicated by a significantly reduced left ventricular weight to body weight ratio in older TSP-2 KO mice, whereas this ratio did not differ between young WT and TSP-2 KO mice (Figure 1D through $1 \mathrm{~K}$, Table 3). Myocyte stress in older TSP-2 KO hearts was confirmed by desmin staining ${ }^{7}$, revealing a clear desmin disorganization (Figure 2A). Ubiquitin, a marker of cell stress and p16, an indicator of aging ${ }^{8}$, were significantly increased in older TSP-2 KO hearts (Figure 2B and 2C, Table 3).

Electron microscopy substantiated cardiomyocyte stress and a disorganization of the extracellular matrix in older TSP-2 KO compared to WT hearts, whereas myocyte and matrix were normal in younger TSP-2 KO and WT hearts (Figure 2E and 2F). Cardiomyocytes of old TSP-2 KO hearts showed mitochondrial enlargement and lysis of myofilaments (Figure 2E and $2 \mathrm{~F})$.

Decreased cardiac mass was not due to significant changes in myocyte cross-sectional area of older TSP-2 KO hearts compared to age-matched WT hearts (Table 3). Myocyte death and fibrosis was not caused by differences in vascularity (Table 3).

\section{AAV9-TSP-2 treatment of TSP-2 KO mice prevents accelerated aging- induced cardiomyopathy}

To determine whether the age-related cardiomyopathy in TSP-2 KO mice could be rescued by post-natal gene transfer of TSP-2, we treated young 
male and female TSP-2 KO mice with an adeno-associated viral vector harboring mouse TSP-2 (AAV9-TSP-2) compared to a control AAV9-green fluorescent protein vector (AAV9-GFP; Figure 3A through 3F).

A

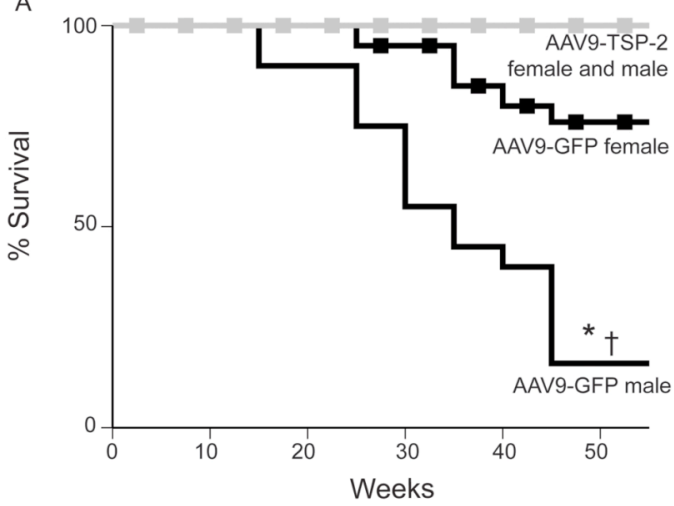

AAV9-GFP

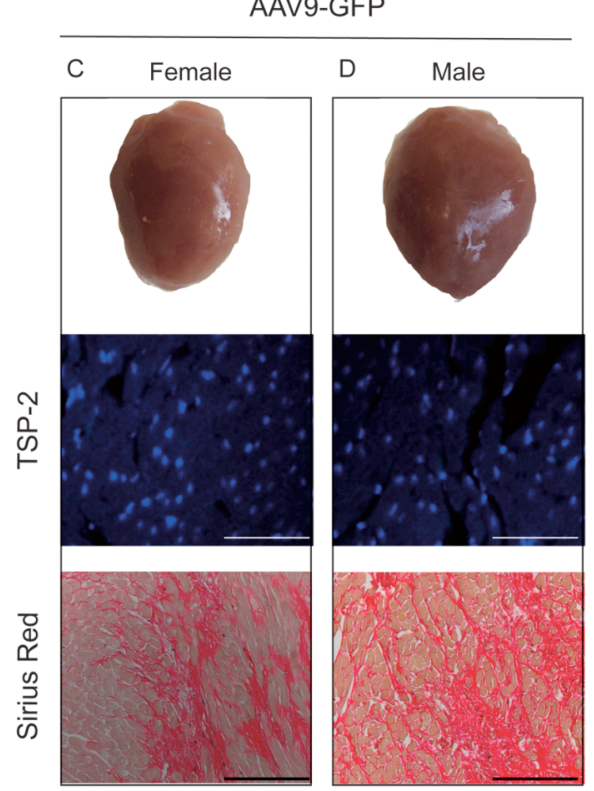

B

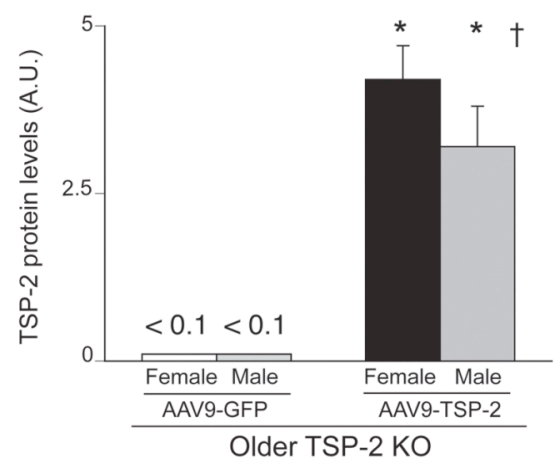

AVV9-TSP-2

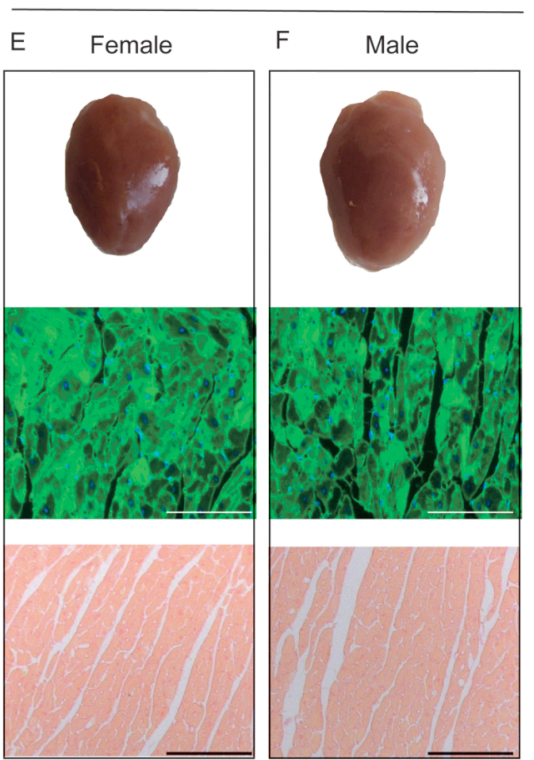

Figure 3. AAV9-TSP-2 treatement of TSP-2 KO mice prevents accelerated aginginduced cardiomyopathy. (A) Survival curve of male and female AAV9-GFP and AAV9TSP-2-treated TSP-2 KO mice. (B-F) At 60 weeks of age, both TSP-2 immunoblotting (B) and immunofluorescent staining ( $\mathrm{C}-\mathrm{F}$, middle, green) confirmed a significant and widespread cardiac TSP-2 protein expression in AAV9-TSP-2 (B, E-F) compared to AAV9-GFP treated TSP-2 KO mice (B, C-D; for B: $n=5$ per group). (C-F, upper part) Blunted cardiac dilatation in AAV9-GFP (C-D) compared with AAV9-TSP-2-treated TSP-2 KO mice (EF). (C-F, lower part) Sirius red staining revealing blunted cardiac fibrosis in AAV9-TSP-2-treated TSP-2 KO mice. *: P<0.05 AAV9-GFP treated vs AAV9-TSP-2-treated TSP-2 KO mice with the same gender; $\dagger$ : $P<0.05$ TSP-2 female mice vs TSP-2 male mice with the same AAV9-treatment. Bars: (CF) $100 \mu \mathrm{m}$

At 60 weeks of age, both immunoblotting and -staining revealed that AAV9mediated transfer of TSP-2 resulted in a significant and widespread cardiac 
TSP-2 protein expression, whereas TSP-2-staining was absent in the control AAV9-GFP treated mice (Figure 3B through 3F).

Importantly, AAV9-TSP-2 blunted the mortality observed in the older control AAV9-GFP-treated TSP-2 KO mice (68\%, 24 out of $35 ; 3$ out of 10 females and 21 out of 25 males; Figure 3A). AAV9-TSP-2 also prevented cardiomyocyte dropout, fibrosis, cardiac dilatation and dysfunction, still present in the aged control-treated TSP-2 KO mice (Figure 3A through 3F, Table 4).

Together, these data confirm that post-natal TSP-2 expression is essential to maintain the myocardial architecture and function with age.

Table 4. Table 4. AAV-9 mediated rescue of TSP-2 KO mice

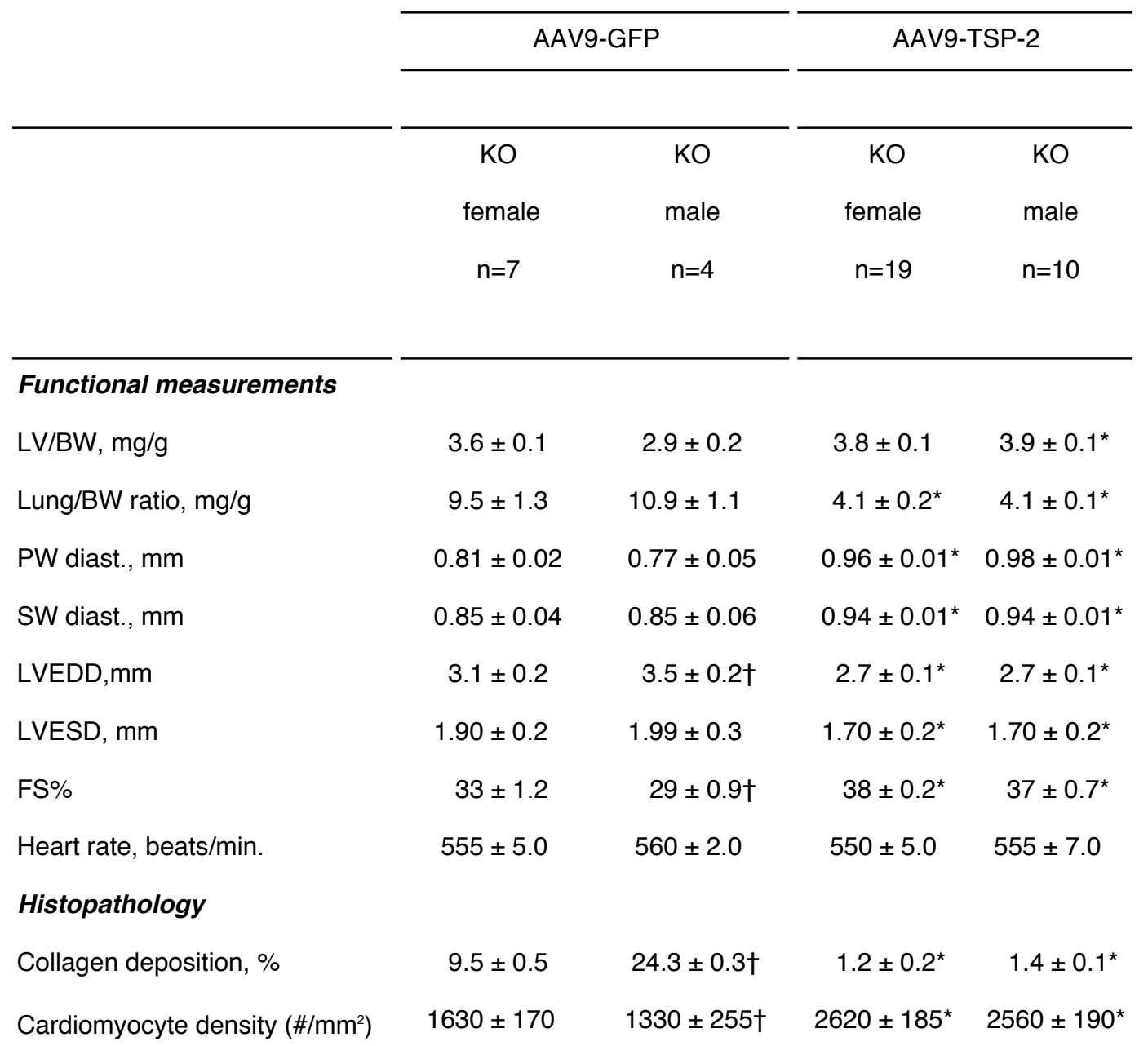

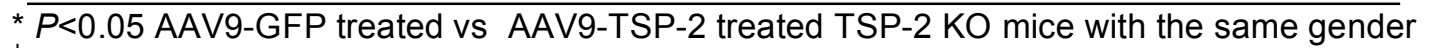
${ }^{\dagger} \mathrm{P}<0.05$ TSP-2 female mice vs TSP-2 male mice with the same AAV9-treatment
} 


\section{Increased inflammation in older TSP-2 KO hearts}

Next, we investigated whether a prolonged low-grade inflammation in response to aging-associated free radical generation could underlie the agerelated cardiomyopathy observed in TSP-2-KO mice. ${ }^{9}$

Cardiac aging and progressive myocyte stress in the absence of TSP-2 were accompanied by increased inflammation. The number of CD45-positive inflammatory cells progressively increased with age, reaching significance in TSP-2 KO compared with WT hearts at older age (Figure 2D, Table 3), but no significant differences were noticed at young age (Figure 2D, Table 3). Inflammation was more pronounced in older male compared to female TSP-2 $\mathrm{KO}$ mice (Figure 2D, Table 3). In concordance, cardiac transcript levels of TGF- $\beta 1$, IL-1 $\beta$, IL- 6 and IL-12 significantly increased with age and in older TSP-2 KO compared to WT hearts (Table 1 ). The activation of TGF- $\beta 1$ did not differ (Table 1). In addition, transcript levels of enzymes influencing the oxidation status of the heart, including super oxide dismutase-2 (SOD2) and glutathione peroxidase-1 (Gxp1) did not significantly differ between TSP-2 WT and $\mathrm{KO}$ hearts (Table 1 ), whereas catalase-1 (CAT1) ${ }^{10}$ was significantly higher in older WT compared to KO hearts (Table 1).

In conclusion, the age-related cardiomyopathy in the absence of TSP-2 is due to progressive cardiomyocyte stress and dropout, accompanied by increased inflammation and scar-forming reparative fibrosis.

Higher MMP-2- and lower tissue-transgulatiminase-2- activity in TSP-2 KO mice.

Previous studies have shown that a lack of TSP-2 results in an increase in MMP-2 activity, which in turn inactivates tissue-transglutaminase-2 (tTG-2). The latter enzyme is involved in collagen cross-linking, and may protect against cardiac dilatation and dysfunction. ${ }^{11,12}$ To investigate whether the increased cardiac dilatation in the absence of TSP-2 may relate to increased MMP-2 and consequently decreased tTG activity, their activity levels were measured in young and older TSP-2 KO and WT hearts. 
Whereas no significant differences were noted in TSP-2 KO hearts, MMP-2 zymographic activity significantly decreased in TSP-2 WT hearts with progressing age (Figure 4A). MMP-2 activity levels were significantly lower in young $\mathrm{KO}$ compared to WT hearts, but significantly higher in older KO compared to older WT hearts. MMP-9 zymographic activity did not significantly differ in TSP-2 KO compared to WT hearts both at young or old age (Figure 4B).
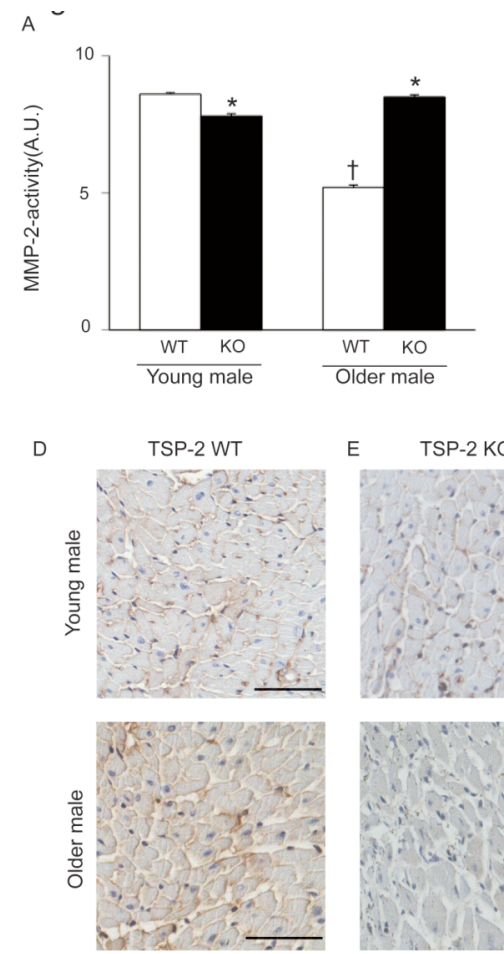
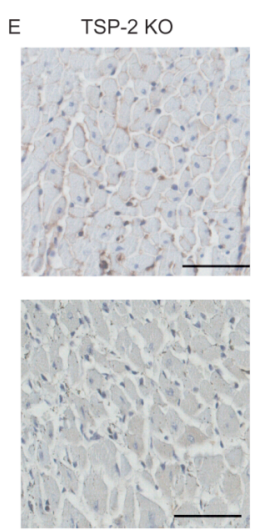
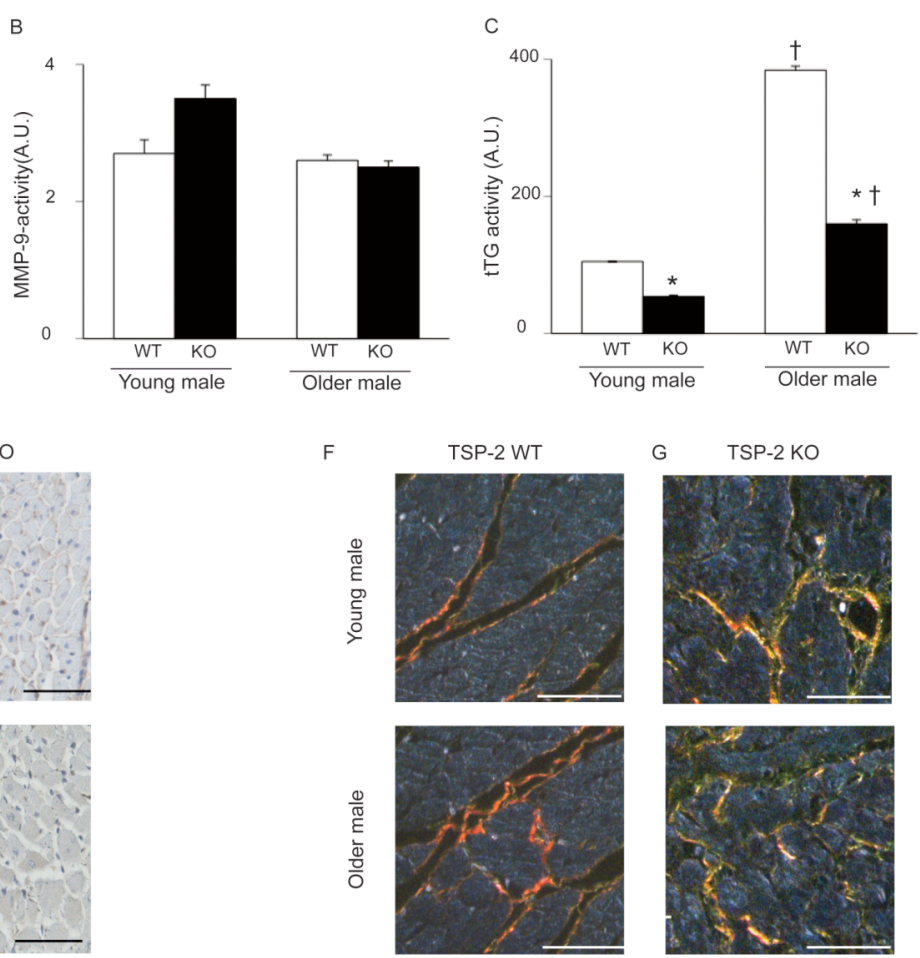

Figure 4. Higher MMP-2- and lower tissue transglutaminase-2 activity in TSP-2-KO mice. (A) Significantly increased MMP-2 zymographic acitvity in older TSP-2 KO hearts. (B) No significant differences in MMP-9 activity in TSP-2 WT compared with KO mice. (C) Significantly decreased levels of tTG-activity in TSP-2 KO aged hearts ( $n=7$ per group). (D-E) Decreased $\varepsilon$-lysyl - $\gamma$-glutaminyl cross-linking staining in older TSP-2 KO hearts (respectively $E$ and $D$, lower panel). (F-G) Sirius red-polarization microscopy revealing more loosely assembled (yellow-green) collagen fibers predominating in older TSP-2 KO hearts. *: $P<0.05$ TSP-2 WT mice vs TSP-2 KO mice but within the same age-group; $\dagger: P<0.05$ : Young TSP-2 mice vs Older TSP-2 mice but with the same genotype.

Decreased MMP-2 activity with progressing age in TSP-2 WT hearts was paralleled by increased tTG-activity (Figure 4C). Concordantly, increased MMP-2 activity in older TSP-2 KO compared to older WT hearts was paralleled by reduced activity of tTG-2, and a decrease in $\varepsilon$-Lysyl Y-glutaminyl cross-links (Figure 4D and 4E). A significant decrease of tTG-2 activity in TSP-2 KO compared to WT hearts was also observed at younger age (Figure 
$4 \mathrm{~A}$ and $4 \mathrm{C})$.

Sirius red-polarization microscopy revealed mainly well-aligned, thick and tightly packed orange-red-collagen fibers in young and older WT hearts, whereas loosely assembled yellow-green collagen fibers predominated the older TSP-2 KO hearts (Figure 4F and 4G, Table 3).

Thus, increased MMP-2, decreased tTG-2 activity and impaired collagen maturation in the absence of TSP-2 contributed to increased cardiac dilatation with aging.

\section{Loss of TSP-2 results in impaired activation of Akt in vivo and in vitro}

The Akt pathway is centrally involved in promoting myocyte survival, and its activation protects against cardiac injury, fibrosis and failure. ${ }^{13,} 14$ TSP-2 contains two conserved domains that are able to activate the Akt pathway, namely the CD47-binding site within its $\mathrm{C}$-terminal domain, and the $\mathrm{N}$-terminal $\beta 1$-integrin recognition site that is proximal to the CD36-binding domain. ${ }^{15}$ Therefore, we investigated whether these interactions might contribute to the cardiomyocyte survival pathway.

First, a significantly reduced activation of Src and Akt was demonstrated in TSP-2 KO compared with WT hearts (Figure 5A and 5B). Immunoblotting for Integrin linked Kinase (ILK) and in vitro kinase activity assays were performed to determine the relative level and activity of ILK in WT and TSP-2 KO hearts. However no differences in ILK activity could be detected in the hearts of TSP2 WT and KO mice. (Supplemental Figure 2). Next, an interaction of TSP-2 with the Src/Akt-pathway was confirmed in cardiac myocytes in vitro. The use of a lentiviral short-hairpin-RNA (shRNA) produced an $80 \%$ knockdown of TSP-2 and resulted in a significantly reduced phosphorylation of Src and Akt (Figure 5C through 5G), whereas a control, unrelated shRNA lentiviral vector did not alter their phosphorylation status.

Finally, monoclonal blocking antibodies either against the CD47- $\left(\alpha-\right.$ TSP $\left.^{\text {CD47 }}\right)$ or the CD36- $\left(\alpha-\mathrm{TSP}^{\mathrm{CD} 36}\right)$ binding sites of TSP were administered to neonatal rat cardiomyocytes (NRCM) in vitro (Figure 6A through 6C). Blocking of the TSP/CD47-interaction resulted in reduced phosphorylation of Src and Akt 
(Figure 6E through 6G) and caused obvious myocyte stress compared to control treatment.

A
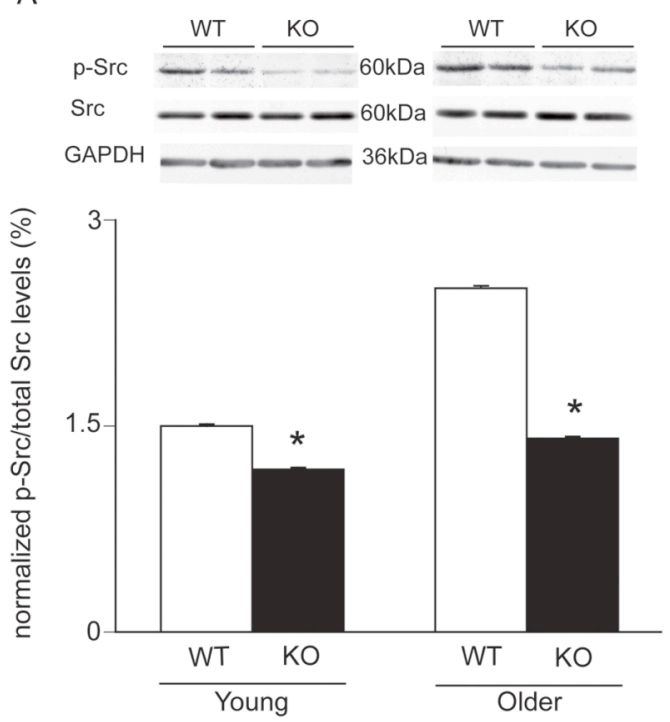

C
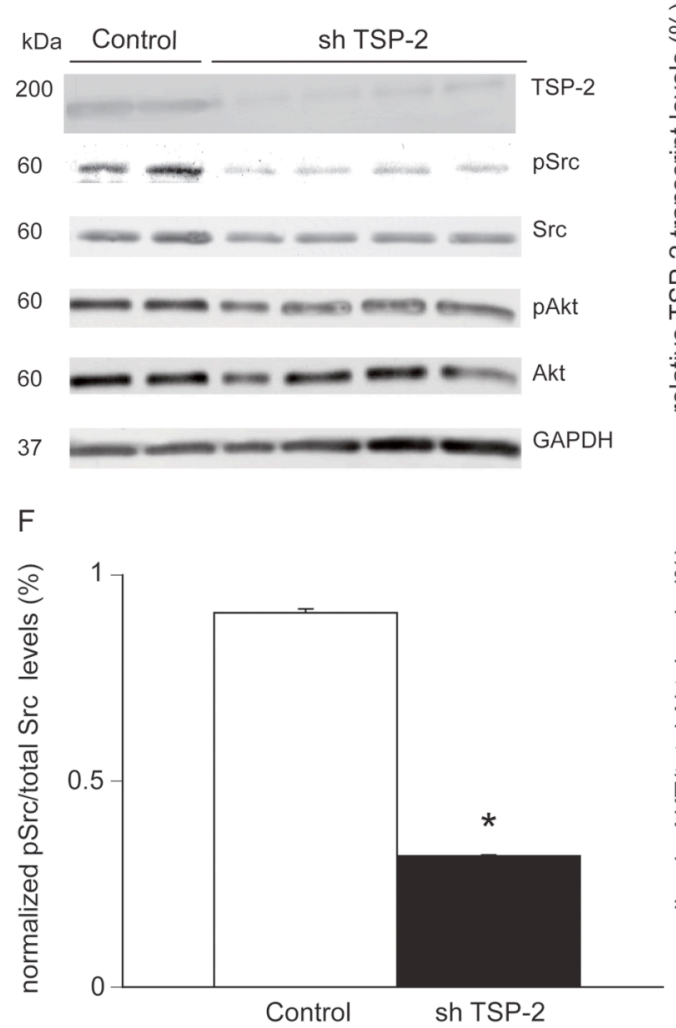

B
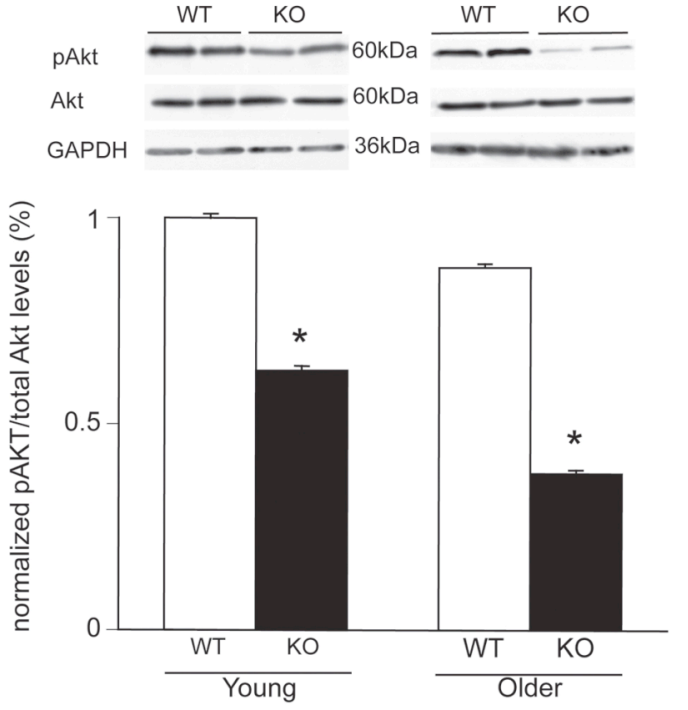

D

$\mathrm{E}$
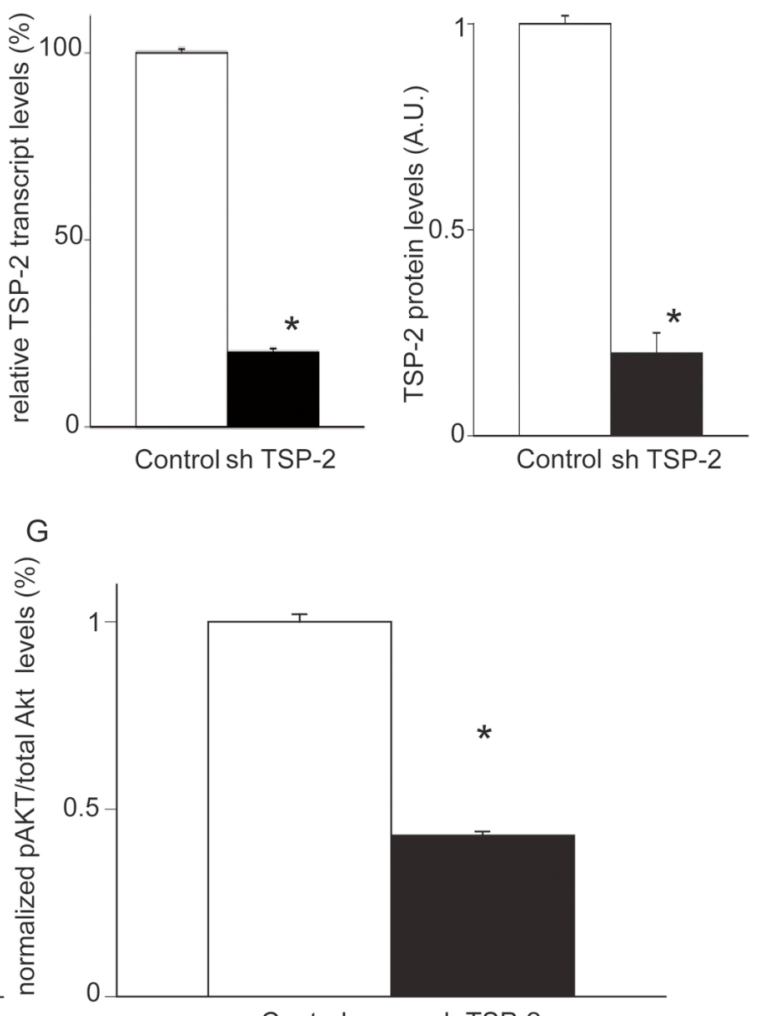

Control

Figure 5. Loss of TSP-2 results in impaired Src/Akt dependent cardiomyocyte survival in vivo and in vitro. (A, B) Src protein levels and ratio of phosphorylated Akt over total Akt were significantly decreased in TSP-2 KO compared with age-matched WT littermates ( $n=7$ per group) (C-G) In vitro experiments showing that knockdown for TSP-2 results in a significant reduction of $\mathrm{Src}$ and Akt phosphorylation in neonatal rat cardiomyocytes. All protein levels were normalized for GAPDH. 
Here, myocyte stress was indicated by changes in the cytoskeletal organization as revealed by altered phalloidin staining, a significantly decreased cardiomyocyte density and increased protein expression of activated caspase-3 (Figure 6A through $\mathrm{D}$ and $6 \mathrm{H}$ ).

Blocking of the CD36-binding site of TSP, however, did not significantly alter Src- or Akt- phosphorylation, nor did it change cardiomyocyte appearance or expression of activated caspase-3 (Figure $6 \mathrm{~A}-\mathrm{H}$ ).
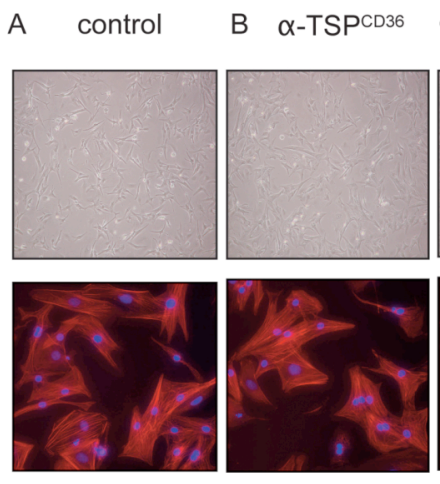

$E$
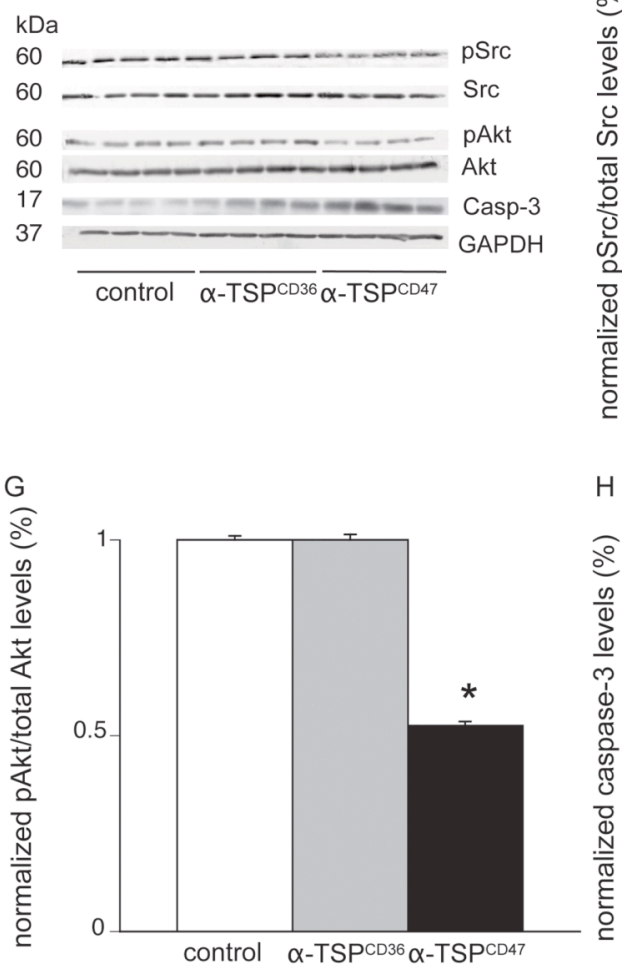
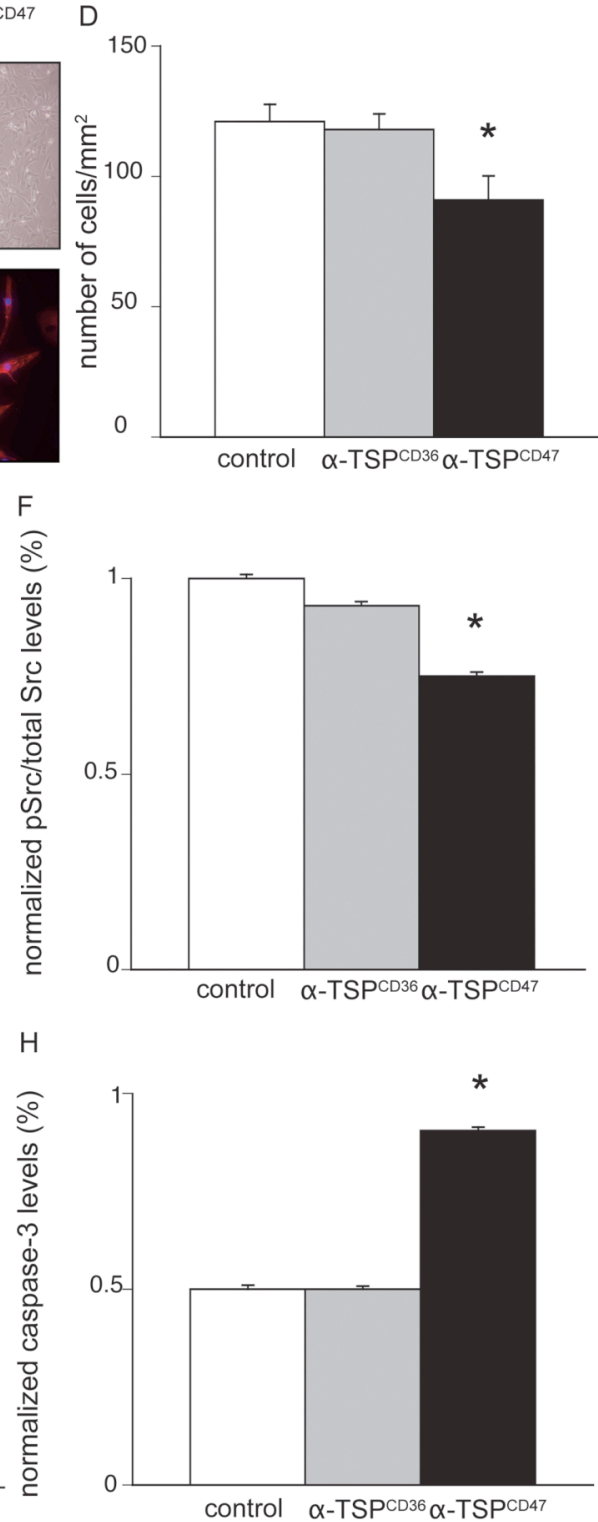

Figure 6. CD47 is involved in cardiac survival.

Cell culture of neonatal rat cardiomyocytes (NRCM) treated with a $\alpha-T_{S P}{ }^{C D 47}$ blocking antibody $(C)$ resulted in cytoskeletal impairment and a significantly decreased number of NRCM at 48 hours compared with $\alpha-\mathrm{TSP}^{\mathrm{CD} 36}$ (B) or the control group (untreated, A) $(\mathrm{E}-\mathrm{H})$ Decreased Src and Akt phosphorylation, and increased active cleaved caspase- 3 in $\alpha-$ TSP $^{\mathrm{CD} 47}$ treated NRCM. $(\mathrm{F}-\mathrm{H})(\mathrm{n}=6$ per treatment; *: $P<0.05)$. 


\section{The absence of TSP-2 affects cardiomyocyte function with aging}

To investigate the effect of the age-related cardiomyopathy on the function of surviving cardiomyocytes, active and passive forces, and $\mathrm{Ca}^{2+}$ sensitivity were determined using individual permeabilized cardiomyocytes isolated from young and older TSP-2 KO and WT left ventricles. Passive and active forces, and $\mathrm{Ca}^{2+}$ sensitivity did not differ in young TSP-2 KO compared to WT myocytes ( $\mathrm{n}=10$ cardiomyocytes out of 5 hearts per group, $P=\mathrm{NS}$ ) (Figure 7A and 7B). Forces increased with advanced age in both TSP-2 KO and WT cardiomyocytes, but active forces did not differ between TSP-2 KO and WT cardiomyocytes (Figure 7B). Passive forces were significantly higher in older TSP-2 KO compared to WT cardiomyocytes, indicating increased cardiomyocyte stiffness. Normalized force-pCa curves showed similar myofilamental $\mathrm{Ca}^{2+}$ sensitivity at young and older ages in TSP-2 WT and KO mice (data not shown).
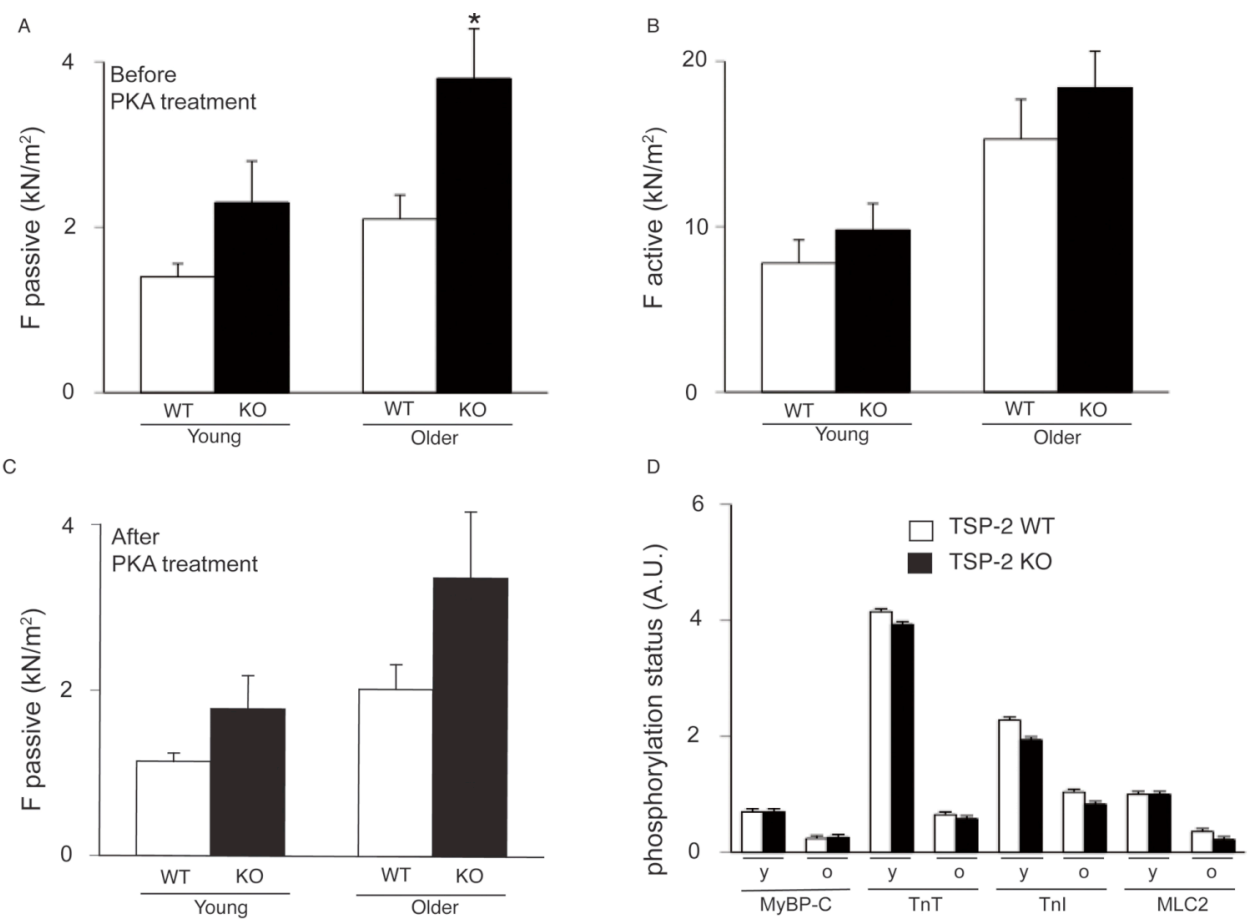

Figure 7. The absence of TSP-2 affects diastolic function of individual

isolated cardiomyocytes. Passive forces (A) are significantly increased but active (B) forces are similar in TSP-2 KO compared to WT myocytes. (C) Exogenous PKA treatment did not change the differences in passive forces. (D) Phosphorylation status of myosin-binding protein C (MyBP-C), Troponin T (TnT), Troponin I (Tnl), Myosin Light Chain-2 (MLC-2) revealed no significant differences between TSP-2 WT and KO mice at young (y) and old (o) age. ( $n=10$ cardiomyocytes per genotype per age-group; *: $P<0.05$ TSP-2 WT mice vs TSP-2 $\mathrm{KO}$ mice within the same age-group). 
Impaired diastolic function of isolated cardiomyocytes was not due to alteration in myofilament phosphorylation, since treatment with the catalytic subunit protein kinase-A (PKA) provided similar effects in TSP-2 KO and WT cardiomyocytes (Figure 7C). PKA treatment resulted in non-significant reduced passive forces in young TSP-2 KO mice (Fpassive before PKA: WT: $1,4 \pm 0.2$; KO: $2.3 \pm 0.5$ vs Fpassive after PKA WT: $1,1 \pm 0.1$; KO: 1,8 \pm 0.4 ).

Similarly, passive forces in the older mice did not significant change. Phosphorylation levels of myosin binding protein c (MyBP-C), myosin light chain 2 ( MLC2), and troponin-T and -I did not significantly differ in TSP-2 KO compared with WT hearts at both young and older ages (Figure 7D).

\section{Discussion}

With advanced medical assistance and better control of cardiovascular risk factors, the general population is getting older and many people may live to be over 90 years without experiencing cardiac dysfunction. Still, little is known concerning the physiological survival mechanisms that help to "adapt" the heart and prevent myocyte death, fibrosis and dysfunction in response to the cumulative hemodynamic stress related to aging. An understanding of these processes may lead to new therapeutic approaches that promote the longevity of the heart, even in the absence of hypertension, diabetes, smoking or coronary disease.

We provide evidence that cardiac expression of the matricellular protein TSP2 protects against aging related functional decline of the heart. Loss of TSP-2 resulted in progressive cardiomyocyte death, accompanied by inflammation and reparative scar-forming fibrosis, all together contributing to the development of progressive cardiac dilatation and dysfunction. Importantly, post-natal adeno-associated viral vector (AAV9)-mediated transfer of TSP-2 in young TSP-2 KO mice completely rescued the progressive structural and functional decline with aging.

In view of its matrix-cell regulating properties, a protective role for TSP-2 against age-related heart disease may be mediated by regulating outwardinward cell signaling and function, thereby affecting cardiac remodeling. 
First, TSP-2 seems to protect against age-related myocyte death -at least in part- by promoting the Akt-survival pathway in cardiomyocytes. ${ }^{15}$ The absence of TSP-2 in vivo or its knockdown in vitro resulted in reduced activation of Src and Akt, which are both involved in promoting myocyte survival. ${ }^{13}$ Moreover, our data indicate that the conserved C-terminal CD47binding of TSP-2 is implicated in activating the Src/Akt survival pathway in cardiomyocytes. A blocking antibody against the CD47-binding domain ( $\alpha$ $\left.\mathrm{TSP}^{\mathrm{CD} 47}\right)$, but not against the CD36-binding domain $\left(\alpha-\mathrm{TSP}^{\mathrm{CD} 36}\right)$, significantly reduced activation of Src/Akt, and increased myocyte stress and apoptosis in vitro. To exclude that other upstream regulators are responsible for activating the effector protein Akt, the interaction with Integrin Linked Kinase (ILK) was investigated in vivo. ILK functions downstream and independently of phosphatidylinositol 3-kinase (PI3K) to phosphorylate Akt. Immunoblotting for ILK together with ILK activity measurements did not show differences in KO and WT hearts. Together, our data indicate that the effect of TSP-2 on Akt phosphorylation is Src dependent. Previous reports have shown that the Aktpathway is regulated through several receptor and receptor-independent pathways (i.e. mechanical stretch) ${ }^{16,17}$. Concordantly, we can not exclude that TSP-2 might also regulate myocyte survival by influencing other survival pathways, including ERK1-2 and p38-MAPkinases ${ }^{18}$, focal adhesion kinases ${ }^{19}$ or STAT3 signalling pathways ${ }^{20}$.

A protective role for TSP-2-mediated Akt activation in physiological aging, however, fits with a crucial role for Akt1 and Akt2 in physiological growth of cardiomyocytes during exercise; Akt1 or Akt2-deficient mice are not able to develop physiological hypertrophy during exercise but develop heart failure in response to pressure overload ${ }^{13,21}$. Moreover, the implication of outsideinside signaling and more specifically Akt activation in promoting (cardio)myocyte survival has also been demonstrated for other matricellular proteins. Periostin ${ }^{22}$ and $\mathrm{CCN}-1(\mathrm{Cyr}-61)^{23}$-deficient mice have impaired myocyte survival due to reduced activation of the Akt-survival pathway.

Beside its role in outside-inside signaling, TSP-2 also regulates extracellular matrix remodeling. It forms a complex with pro-MMP-2 and TIMP-2 which is then internalized by the low density lipoprotein-related scavenger receptor, 
LRP1, and thereby down-regulates total MMP-2 activity ${ }^{24}$. MMP-2 in turn decreases total t-TG activity ${ }^{11}$ and may diminish the binding of TSP to CD47, thereby decreasing its downstream activity ${ }^{25}$. Aging in mice lacking TSP-2 results in increased MMP-2 activity, decreased tTG activity, and reduced collagen cross-linking, all contributing to increased cardiac dilatation and dysfunction ${ }^{2}$. In concordance, Agah et al. ${ }^{26}$ previously reported increased dermal TSP-2 expression together with decreased clearance of MMP-2 from the pericellular environment, as a function of age in TSP-2 WT mice.

TSP-2 was also shown to regulate angiogenesis and inflammation ${ }^{9,26,} 27$. Here, we show that myocyte death and fibrosis with progressing age were not caused by differences in vascularity. However, inflammation was increased in the absence of TSP-2 in the older but not in the younger hearts. Both progressive cardiomyocyte death and the loss of the CD47-mediated antiinflammatory effect of TSP $-2^{9}$ might have contributed to this enhanced inflammatory influx. Whether the increased inflammatory response in aged TSP-2 KO mice mainly acts to remove the necrotic cardiomyocytes or whether the increased inflammation represents a primary contributing factor that aggravates the cardiomyocyte injury, fibrosis and the age-related cardiomyopathy, remains to be resolved.

The morphological and functional features of this age-related cardiomyopathy and mortality mainly occurred in male KO mice. Several previous studies have shown that female mice display a lower mortality and less severe cardiac pathology compared with their male counterparts ${ }^{28}$. Factors, such as hormonal status, higher blood pressure and increased physical activity may predispose male $\mathrm{KO}$ mice to the severe myocardial damage, dilatation and dysfunction, and mortality compared to female mice with increasing age ${ }^{28-30}$. Intriguingly, AAV9-mediated expression of TSP-2 in 7 weeks old TSP-2 KO mice rescued this lethal phenotype, confirming that post-natal expression of TSP-2 is crucial for the normal physiological aging of the heart. These results also make it less probable that pre-natal or early, post-natal morphological changes in the heart of TSP-2 KO mice could underlie this progressive phenotype. Due to its cardiotrophic properties -AAV9-mediated gene transfer rescues a severe cardiac phenotype. AAV9-mediated gene transfer deserves 
to be further explored as a novel therapeutic tool for the clinical application of gene therapy in human cardiac diseases ${ }^{31}$.

To study whether aging of cardiomyocytes in the absence of TSP-2 may affect their function per se, isometric force measurements were performed in isolated, permeabilized cardiomyocytes. Active forces did not differ in aged TSP-2 KO compared to WT cardiomyocytes, whereas passive forces indicative of diastolic dysfunction were increased in the surviving TSP-2 KO cardiomyocytes. These alterations were independent of exogenous protein kinase-A activity, excluding myofilament phosphorylation as underlying causes for cardiac dysfunction of isolated cardiomyocytes. Together, these data indicate that the surviving individual cardiomyoyctes in the aged TSP-2 $\mathrm{KO}$ heart are characterized by increased stiffness, whereas active forces are not affected. Thus, progressive myocyte death, but not reduced contractility of individual cardiomyocytes, is responsible for the progressive cardiac dysfunction in the absence of TSP-2.

Our present study reveals a novel and pivotal role for TSP-2 in the protection against age-related cardiomyopathy. Decreased activation of the Src/Akt survival pathway in the absence of TSP-2, together with increased inflammation, MMP-2 activity and decreased collagen cross-linking, all contributed to impaired cardiomyocyte survival and increased cardiac dilatation and dysfunction with advanced age. In conclusion, TSP-2 seems to represent a novel and crucial survival mechanism that protects against senescence of the heart.

\section{Acknowledgments}

We thank Rick van Leeuwen, Wouter Verhesen, Kevin Custers and Hans Duimel for their technical support.

\section{Funding Sources}

This study was supported by a Marie Curie Exellence Progam to S.H., M.S. and Y.M.P., a research grant from the Research fund K.U. Leuven (PDMK/08/175) to D.V., Long term structural funding - Methusalem funding 
by the Flemish Government to P.C., grant of the SFB-TR 19 (Project A2) to D.W. from the Deutsche Forschungsgemeinschaft, a research grant of the Research Foundation Flanders (F.W.O.; G.0601.09 and FWO WOG) to T.V. and M.C and a research grant of the F.W.O (G.0740.09.N10) to F.V.d.W., grants to EH.S. from the Gilbertson Foundation and from the National Institute of Health (GM40711) and Ingenious Hypercare NoE from the European Union (EST 2005-020706-2), research grants from the Netherlands Heart Foundation (2007B036, 2008B011) and a VIDI grant of the NWO to S.H. Y.M.P. is an established investigator of the Netherlands heart Foundation.

\section{Conflict of interest disclosure}

None 


\section{References}

1. Susic D, Frohlich ED. The aging hypertensive heart: a brief update. Nature clinical practice. 2008; 5:104-110.

2. Spinale FG. Myocardial matrix remodeling and the matrix metalloproteinases: influence on cardiac form and function. Physiological reviews. 2007; 87:12851342.

3. Schellings MW, Pinto YM, Heymans S. Matricellular proteins in the heart: possible role during stress and remodeling. Cardiovasc Res. 2004; 64:24-31.

4. Bornstein P, Sage EH. Matricellular proteins: extracellular modulators of cell function. Curr Opin Cell Biol. 2002; 14:608-616.

5. Schroen B, Heymans S, Sharma U, Blankesteijn WM, Pokharel S, Cleutjens JP, Porter JG, Evelo CT, Duisters R, van Leeuwen RE, Janssen BJ, Debets JJ, Smits JF, Daemen MJ, Crijns HJ, Bornstein P, Pinto YM. Thrombospondin-2 is essential for myocardial matrix integrity: increased expression identifies failure-prone cardiac hypertrophy. Circ Res. 2004; 95:515-522.

6. Kyriakides TR, Leach KJ, Hoffman AS, Ratner BD, Bornstein P. Mice that lack the angiogenesis inhibitor, thrombospondin 2, mount an altered foreign body reaction characterized by increased vascularity. Proc Natl Acad Sci U S A. 1999; 96:4449-4454.

7. Monreal G, Nicholson LM, Han B, Joshi MS, Phillips AB, Wold LE, Bauer JA, Gerhardt MA. Cytoskeletal remodeling of desmin is a more accurate measure of cardiac dysfunction than fibrosis or myocyte hypertrophy. Life sciences. 2008; 83:786-794.

8. Krishnamurthy J, Torrice C, Ramsey MR, Kovalev GI, Al-Regaiey K, Su L, Sharpless NE. Ink4a/Arf expression is a biomarker of aging. J Clin Invest. 2004; 114:1299-1307.

9. Lamy L, Foussat A, Brown EJ, Bornstein P, Ticchioni M, Bernard A. Interactions between $\mathrm{CD} 47$ and thrombospondin reduce inflammation. J Immunol. 2007; 178:5930-5939.

10. Dai DF, Santana LF, Vermulst M, Tomazela DM, Emond MJ, MacCoss MJ, Gollahon K, Martin GM, Loeb LA, Ladiges WC, Rabinovitch PS. Overexpression of catalase targeted to mitochondria attenuates murine cardiac aging. Circulation. 2009; 119:2789-2797. 
11. Agah A, Kyriakides TR, Bornstein P. Proteolysis of cell-surface tissue transglutaminase by matrix metalloproteinase- 2 contributes to the adhesive defect and matrix abnormalities in thrombospondin-2-null fibroblasts and mice. Am J Pathol. 2005; 167:81-88.

12. Vanhoutte D, Schellings MW, Gotte M, Swinnen M, Herias V, Wild MK, Vestweber D, Chorianopoulos E, Cortes V, Rigotti A, Stepp MA, Van de Werf F, Carmeliet P, Pinto YM, Heymans S. Increased expression of syndecan-1 protects against cardiac dilatation and dysfunction after myocardial infarction. Circulation. 2007; 115:475-482.

13. DeBosch B, Treskov I, Lupu TS, Weinheimer C, Kovacs A, Courtois M, Muslin AJ. Akt1 is required for physiological cardiac growth. Circulation. 2006; 113:2097-2104.

14. Hannigan GE, Coles JG, Dedhar S. Integrin-linked kinase at the heart of cardiac contractility, repair, and disease. Circ Res. 2007; 100:1408-1414.

15. Calzada MJ, Annis DS, Zeng B, Marcinkiewicz C, Banas B, Lawler J, Mosher DF, Roberts DD. Identification of novel beta1 integrin binding sites in the type 1 and type 2 repeats of thrombospondin-1. J Biol Chem. 2004; 279:4173441743.

16. Manning BD, Cantley LC. AKT/PKB signaling: navigating downstream. Cell. 2007; 129:1261-1274.

17. Li M, Chiou KR, Bugayenko A, Irani K, Kass DA. Reduced wall compliance suppresses Akt-dependent apoptosis protection stimulated by pulse perfusion. Circ Res. 2005; 97:587-595.

18. Donnini S, Morbidelli L, Taraboletti G, Ziche M. ERK1-2 and p38 MAPK regulate MMP/TIMP balance and function in response to thrombospondin-1 fragments in the microvascular endothelium. Life sciences. 2004; 74:29752985.

19. Orr AW, Pallero MA, Xiong WC, Murphy-Ullrich JE. Thrombospondin induces RhoA inactivation through FAK-dependent signaling to stimulate focal adhesion disassembly. J Biol Chem. 2004; 279:48983-48992.

20. Fischer P, Hilfiker-Kleiner D. Survival pathways in hypertrophy and heart failure: the gp130-STAT axis. Basic research in cardiology. 2007; 102:393411.

21. DeBosch B, Sambandam N, Weinheimer C, Courtois M, Muslin AJ. Akt2 regulates cardiac metabolism and cardiomyocyte survival. J Biol Chem. 2006; 281:32841-32851. 
22. Kuhn B, del Monte F, Hajjar RJ, Chang YS, Lebeche D, Arab S, Keating MT. Periostin induces proliferation of differentiated cardiomyocytes and promotes cardiac repair. Nat Med. 2007; 13:962-969.

23. Yoshida Y, Togi K, Matsumae H, Nakashima Y, Kojima Y, Yamamoto H, Ono K, Nakamura T, Kita T, Tanaka M. CCN1 protects cardiac myocytes from oxidative stress via beta1 integrin-Akt pathway. Biochem Biophys Res Commun. 2007; 355:611-618.

24. Yang Z, Strickland DK, Bornstein P. Extracellular Matrix Metalloproteinase 2 Levels Are Regulated by the Low Density Lipoprotein-related Scavenger Receptor and Thrombospondin 2. J. Biol. Chem. 2001; 276:8403-8408.

25. Hayashidani $S$, Tsutsui $H$, Ikeuchi M, Shiomi T, Matsusaka H, Kubota T, Imanaka-Yoshida K, Itoh T, Takeshita A. Targeted deletion of MMP-2 attenuates early LV rupture and late remodeling after experimental myocardial infarction. Am J Physiol Heart Circ Physiol. 2003; 285:H12291235.

26. Agah A, Kyriakides TR, Letrondo N, Bjorkblom B, Bornstein P. Thrombospondin 2 levels are increased in aged mice: consequences for cutaneous wound healing and angiogenesis. Matrix Biol. 2004; 22:539-547.

27. Bornstein $\mathrm{P}$, Agah A, Kyriakides TR. The role of thrombospondins 1 and 2 in the regulation of cell-matrix interactions, collagen fibril formation, and the response to injury. The international journal of biochemistry \& cell biology. 2004; 36:1115-1125.

28. Du XJ. Gender modulates cardiac phenotype development in genetically modified mice. Cardiovasc Res. 2004; 63:510-519.

29. Schellings MW, Vanhoutte $D$, Swinnen $M$, Cleutjens JP, Debets J, van Leeuwen RE, d'Hooge J, Van de Werf F, Carmeliet P, Pinto YM, Sage EH, Heymans S. Absence of SPARC results in increased cardiac rupture and dysfunction after acute myocardial infarction. J Exp Med. 2009; 206:113-123.

30. Heymans S, Luttun A, Nuyens D, Theilmeier G, Creemers E, Moons L, Dyspersin GD, Cleutjens JP, Shipley M, Angellilo A, Levi M, Nube O, Baker A, Keshet E, Lupu F, Herbert JM, Smits JF, Shapiro SD, Baes M, Borgers M, Collen D, Daemen MJ, Carmeliet P. Inhibition of plasminogen activators or matrix metalloproteinases prevents cardiac rupture but impairs therapeutic angiogenesis and causes cardiac failure. Nat Med. Vol 5; 1999:1135-1142.

31. Daya S, Berns KI. Gene therapy using adeno-associated virus vectors. Clinical microbiology reviews. 2008; 21:583-593. 


\section{Supplemental Material and methods}

\section{Expanded methods}

\section{AAV9-TSP-2 construction and production}

AAV-CMV-GFP vectors expressed green fluorescent protein (GFP) from the human cytomegalovirus (CMV) promoter and were derived by cloning GFP into pAAV-MCS (Stratagene). AAV-CMV-TSP-2 vectors expressed TSP-2 from the CMV promoter and were derived by cloning TSP-2 into pAAV-MCS (Stratagene). Both vectors contained a b-globin intron downstream of CMV and a human growth hormone polyadenylation signal. 293 cells were cultured in Dulbecco's modified Eagle's medium (DMEM) supplemented with 2 mM Lglutamine (GIn), $100 \mathrm{IU} / \mathrm{ml}$ penicillin, $100 \mu \mathrm{g} / \mathrm{ml}$ streptomycin and 10\% heatinactivated fetal bovine serum (FBS, Invitrogen, Merelbeke, Belgium). AAV9CMV-GFP or AAV9-CMV-TSP-2 vectors were produced at high-titer by calcium phosphate transfection of 293 cells with AAV-CMV-GFP or AAVCMV-TSP-2 vector DNA, an adenoviral helper plasmid and AAV helper plasmids expressing $\mathrm{AAV} \mathrm{Rep}_{2}$ and $\mathrm{AAV} \mathrm{Cap}_{9}$ for production of AAV9 serotypes, as previously described. ${ }^{1}$ Two days post-transfection, cells were lysed by successive freeze-thaw cycles and sonication. Lysates were treated with benzonase (Merck) and deoxycholate (Sigma-Aldrich) and subsequently subjected to three successive rounds of cesium chloride density ultracentrifugation. The fractions containing the AAV particles were concentrated using an Amicon filter (Millipore) and washed with PBS $1 \mathrm{mM}$ $\mathrm{MgCl}_{2}$. Vector titer was determined in triplicate and repeated twice by quantitative PCR analysis conducted on a ABI 7700 (Applied Biosystems) using Lux primers (Invitrogen) specific for the polyadenylation signal (primer sequences: Forward: TCTATTGGGAACCAAGCTGGAGG Reverse: AGGAGGCGGAGATTGCAGTG), as described previously. The standard consisted of serially diluted AAV-CMV-GFP vector plasmids of known quantity. 


\section{Immunohistochemical and electron microscopic analysis}

After the study period, all mice were anaesthetized, and hearts were taken out and prepared for further histological and molecular analysis. Lungs, left (LV) and right ventricles (RV) were dissected, blotted dry and weighed. Immunostainings on paraffin sections were performed using antibodies against p16 (BD bioscience pharmingen, San Diego, CA), Laminin (Sigma), desmin (Abcam, Cambridge, MA), CD45 (BD Bioscience Pharmingen), active cleaved caspase-3 (Upstate Biotechnology, Euromedex, Souffelweyersheim, France), ubiquitin (Chemicon, Temecula, CA), $\alpha$-smooth muscle cell actin (Dako, Leuven, Belgium), CD31 (Dako, Leuven, Belgium) and $\varepsilon$-lysyl $\gamma$ glutaminyl cross-links (Abcam, Cambridge, MA) as previously described. ${ }^{2-4}$ For TSP-2 (BD Bioscience Pharmingen) sections were subsequently incubated with Biotin labeled secondary antibody followed by amplification with the signal amplification system steptavidin-HRP-C_fluorescein (Perkin Elmer). Nuclei were stained with DAPI (invitrogen) ${ }^{3}$. The quantity of collagen was determined as the percentage of Sirius Red staining area per total cardiac area ${ }^{2-5}$. The quality of the deposited collagen matrix was studied with Sirius Red polarization microscopy as previously described ${ }^{3,4}$.

Morphometric analysis was performed with a Leitz DMRXE microscope (Leica Imaging systems Ltd), a 3CCD color video camera (CXC-93-OP, Sony) and a Leica Qwin software system by persons unaware of the genotype.

For electron microscopic scanning, hearts were treated with $1.5 \%$ glutaraldehyde fixative buffered in $0.067 \mathrm{M}$ cacodylate at $\mathrm{pH} 7.4$. These hearts were washed in cacodylate buffer and transferred to a $1 \%$ OsO4 fixative solution buffered with phosphate-buffered saline $0.1 \mathrm{M} \mathrm{pH} 7.4$ for subsequent immersion fixation for 1 hour at $4^{\circ} \mathrm{C}$. After washing in phosphate

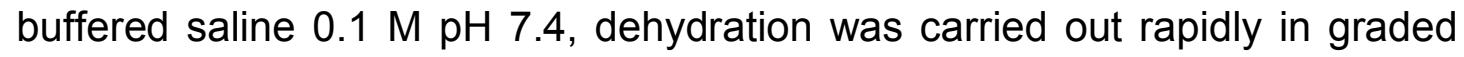
ethanol series, followed by embedding in Epon. Hearts were examined at the University of Maastricht (EM unit, Molecular Cell biology) with a Philips CM 100 electron microscope (F.E.I., Eindhoven, The Netherlands) at an accelerating voltage of $80 \mathrm{KV}$. 


\section{Zymographic MMP- and tissue transglutaminase activity with aging}

Heart tissues were homogenized and extracted, and protein concentrations were determined. MMP-2 and MMP-9 zymographic activites were determined as described ${ }^{2}$. The activity of tissue transglutaminase (tTG), a collagen crosslinking enzyme which is inactivated by MMP-2, was measured in homogenized heart tissues by incorporation of biotinylated cadaverine (BTC) into fibronectin as described ${ }^{4,6}$.

\section{RNA isolation and real time polymerase chain reaction}

RNA was extracted from cardiac tissues using an RNeasy® Fibrous Tissue Mini Kit (Qiagen $\mathrm{GmbH}$, Hilden, Germany) and was stored at $-80^{\circ} \mathrm{C}$. Transcript levels of TSP-1, TSP-2, TSP-3, TSP-4, Superoxide Dismutase-2 (SOD2), Glutathione peroxidase-1 (GPx1) and Catalase1 (CAT1) were determined with a real-time fluorescence detection method as previously described $^{7}$ (Applied Biosystems), mouse glyceraldehyde 3-phosphate dehydrogenase (GAPDH) was used as an endogenous housekeeping gene. The primers used for this study are presented in supplemental table1.

Transcript levels of TGF $\beta, \mathrm{IL}-1 \beta, \mathrm{IL}-6$ and IL-12 were determined using $\operatorname{TaqMan}^{\circledR}$ low density arrays and were performed according to the manufacturer's instructions ${ }^{8}$. Each TaqMan $^{\circledR}$ gene expression assay contains a forward and reverse primer for each of the chosen genes. 18S RNA was incorporated in our customized TaqMan Low-Density Array as internal standard.

\section{Immunoblotting}

Immunoblotting was performed on heart lysates for TSP-1 (kindly provided by Prof. Dr. M. Hoylaerts), TSP-2 (BD), TSP-3 (Santa Cruz biotechnology, Heidelberg, Germany) Integrin Linked kinase (ILK) (Cell signaling Technology Inc., Beverly, MA, USA), Src (Cell singaling), protein kinase A or Akt (Cel signaling) and their phosphorylated forms, and GAPDH (cell signaling) as 
previously described $^{3,4}$. Protein levels were expressed relative to protein levels of GAPDH.

\section{ILK activity and active TGF beta assays}

Immunoprecipitation of ILK in TSP-2 KO and WT heart homogenates together with the kinase activity assay were carried out as detailed in Weaver M. et $\mathrm{al}^{9}$. To determine active TGF- $\beta 1$ protein levels, a TGF- $\beta 1$ assay was performed according to the manufacturer's instructions (R\&D systems, Minneapolis, MN, USA). Cardiac tissue extracts were pre-adjusted to $1.0 \mathrm{mg} / \mathrm{mL}$ in protein. $^{10}$

\section{Echocardiographic measurements}

Transthoracic echocardiographic examination was performed using a $13-\mathrm{mHz}$ transducer (i13L, GE Vingmed, Horten, Norway) on a Vingmed Vivid 7 scanner (GE Vingmed,Horten, Norway) in anesthetized mice (2\% isoflurane). LV diameters at end-diastole (LVEDD) and end-systole (LVESD), septal wall thickness (SW diast), and LV posterior wall in end diastole (PW diast) were measured, and fractional shortening (FS) was calculated as described previously. ${ }^{5,11}$

\section{In vitro experimental approaches}

A rat TSP-2 (rTSP-2) short hairpin RNA (shRNA)-expressing lentiviral vector was generated by annealing complementary shTSP-2 oligonucleotides (Supplemental table 1) and ligating them into HpAl-Xhol-digested pLL3.7 puro vector DNA (modified from a donation by L. van Parijs, Massachusetts Institute of Technology, Cambridge, MA). Lentiviral production was performed as described previously, and viral supernatant was harvested after 48 hours. ${ }^{12}$ Neonatal rat ventricular cardiac myocytes (NRCMs) were isolated by enzymatic disassociation of 1- to 2-days-old neonatal rat hearts.

As neonatal hearts produce a significant amount of TSP-2 -at least- until 6 days after birth ${ }^{13}$, the use of NRCMs was suitable for our experimental setup. 
NRCMs were infected with lentivirus containing shRNA against TSP-2 or unrelated shRNA lentiviral vector (control; Sigma) and harvested after 10 days as previously described. ${ }^{12}$

Mouse monoclonal anti-TSP antibodies, Ab.3 clone C6.7 (indicated as $\alpha$ $\mathrm{TSP}^{\mathrm{CD} 47}$ ) and Ab.1 clone A4.1 (indicated as $\alpha-\mathrm{TSP}^{\mathrm{CD} 36}$ ) (Labvision Mouse, Duiven, the Netherlands), were used to block respectively the CD47 binding site ( $\mathrm{C}$ terminal domain) and the CD36 binding site respectively on TSP-1 and TSP- $2^{14}$. Cell lysates were prepared for further analysis of protein expression and transcript levels.

\section{Force measurements in single permeabilized cardiomyocytes}

Force measurements were performed in single, mechanically isolated cardiomyocytes as described previously. 15, 16 Cardiac samples were defrosted in relaxing solution (free $\mathrm{Mg} \mathrm{1,} \mathrm{KCl} \mathrm{100,} \mathrm{EGTA} \mathrm{2,} \mathrm{Mg-ATP} 4$ and imidazole $10 \mathrm{mmol} / \mathrm{L} ; \mathrm{pH}$ 7.0), mechanically disrupted and incubated for 5 minutes in relaxing solution supplemented with $0.5 \%$ Triton $\mathrm{X}-100$ to remove all membrane structures. Subsequently, cells were washed twice in relaxing solution, after which single cardiomyocytes were attached with silicone adhesive between a force transducer and a motor. Sarcomere length of isolated cardiomyocytes was adjusted to $2.2 \mu \mathrm{m}$ and myocytes were subjected to both relaxing and activating solutions. Their pCa $\left(-{ }_{10} \log \left[\mathrm{Ca}^{2+}\right]\right)$ ranged from 9.0 (relaxing) to 4.5 (maximal activation), which was used to calculate maximal calcium-activated isometric force. All force values were normalized for cardiomyocyte cross-sectional area. Exposure to a series of solutions with intermediate $\mathrm{pCa}$ yielded the baseline force-pCa relation. On transfer of the myocyte from relaxing to activating solution, isometric force started to develop. Once a steady force level was reached, the cell was shortened within $1 \mathrm{~ms}$ to $80 \%$ of its original length (slack test) to determine the baseline of the force transducer. The distance between the baseline and the steady force level is the total force (Ftotal). After $20 \mathrm{~ms}$, the cell was restretched and returned to the relaxing solution, in which a second slack test of 10 -seconds' duration was performed to determine passive $F_{\text {passive. The }}$ 
difference between Ftotal and Fpassive equalled Factive. $\mathrm{Ca}^{2+}$-sensitivity of the contractile apparatus $\left(\mathrm{pCa}_{50}\right)$ corresponded to the $\mathrm{pCa}$, at which Factive reached $50 \%$ of the value observed at maximal activation. After measurement of the baseline force-pCa relation, myocytes were incubated for 40 minutes in relaxing solution supplemented with the catalytic subunit of protein kinase A (PKA, $100 \mathrm{U} / \mathrm{mL}$; Sigma, batch-12K7495) and $6 \mathrm{mmol} / \mathrm{L}$ dithiothreitol (DTT, MP-Biochemicals).

\section{Phosphorylation status of myofilament proteins}

Myofilament protein phosphorylation was determined using Pro-Q Diamond Phosphoprotein Stain as described previously ${ }^{17}$. To preserve the endogenous phosphorylation status, frozen samples were homogenized in liquid nitrogen and re-suspended in $1 \mathrm{~mL}$ cold 10\% trichloroacetic acid solution (TCA; dissolved in acetone containing $0.1 \%(\mathrm{w} / \mathrm{v})$ DTT. TCA-treated tissue pellets were homogenized in sample buffer containing 15\% glycerol, $62.5 \mathrm{mM}$ Tris ( $\mathrm{pH} 6.8), 1 \%(\mathrm{w} / \mathrm{v})$ SDS and $2 \%(\mathrm{w} / \mathrm{v})$ DTT. Tissue samples were separated on gradient gels (Criterion tris- $\mathrm{HCl} 4-15 \%$ gel, BioRad) and proteins were stained for one hour with Pro-Q Diamond Phosphoprotein Stain. Fixation, washing and de-staining were performed according to the manufacturer's guidelines (Molecular Probes). To assess protein content subsequently gels were stained overnight with SYPRO Ruby stain (Molecular Probes). Phosphorylation status of myofilament proteins was expressed relative to protein expression of cardiac myosin-binding protein C (MyBP-C) to correct for differences in sample loading. Staining was visualized using the LAS-3000 Image Reader and signals were analyzed with AIDA.

\section{Supplemental References}

1. Vandendriessche T, Thorrez L, Acosta-Sanchez A, Petrus I, Wang L, Ma L, L DEW, Iwasaki Y, Gillijns V, Wilson JM, Collen D, Chuah MK. Efficacy and safety of adeno-associated viral vectors based on serotype 8 and 9 vs. lentiviral vectors for hemophilia B gene therapy. J Thromb Haemost. 2007; 5:16-24. 
2. Heymans S, Luttun A, Nuyens D, Theilmeier G, Creemers E, Moons L, Dyspersin GD, Cleutjens JP, Shipley M, Angellilo A, Levi M, Nube O, Baker A, Keshet E, Lupu F, Herbert JM, Smits JF, Shapiro SD, Baes M, Borgers M, Collen D, Daemen MJ, Carmeliet P. Inhibition of plasminogen activators or matrix metalloproteinases prevents cardiac rupture but impairs therapeutic angiogenesis and causes cardiac failure. Nat Med. Vol 5; 1999:1135-1142.

3. Schellings MW, Vanhoutte D, Swinnen M, Cleutjens JP, Debets J, van Leeuwen RE, d'Hooge J, Van de Werf F, Carmeliet P, Pinto YM, Sage EH, Heymans S. Absence of SPARC results in increased cardiac rupture and dysfunction after acute myocardial infarction. J Exp Med. 2009; 206:113-123.

4. Vanhoutte D, Schellings MW, Gotte M, Swinnen M, Herias V, Wild MK, Vestweber D, Chorianopoulos E, Cortes V, Rigotti A, Stepp MA, Van de Werf F, Carmeliet P, Pinto YM, Heymans S. Increased expression of syndecan-1 protects against cardiac dilatation and dysfunction after myocardial infarction. Circulation. 2007; 115:475-482.

5. Heymans S, Lupu F, Terclavers S, Vanwetswinkel B, Herbert JM, Baker A, Collen D, Carmeliet P, Moons L. Loss or Inhibition of UPA or MMP-9 Attenuates LV Remodeling and Dysfunction after Acute Pressure Overload in Mice. Am J Pathol. 2005; 166:15-25.

6. Agah A, Kyriakides TR, Bornstein P. Proteolysis of cell-surface tissue transglutaminase by matrix metalloproteinase-2 contributes to the adhesive defect and matrix abnormalities in thrombospondin-2-null fibroblasts and mice. Am J Pathol. 2005; 167:81-88.

7. Dai DF, Santana LF, Vermulst M, Tomazela DM, Emond MJ, MacCoss MJ, Gollahon K, Martin GM, Loeb LA, Ladiges WC, Rabinovitch PS.

Overexpression of catalase targeted to mitochondria attenuates murine cardiac aging. Circulation. 2009; 119:2789-2797.

8. Abruzzo LV, Lee KY, Fuller A, Silverman A, Keating MJ, Medeiros LJ, Coombes KR. Validation of oligonucleotide microarray data using microfluidic low-density arrays: a new statistical method to normalize real-time RT-PCR data. BioTechniques. 2005; 38:785-792.

9. Weaver MS, Workman G, Sage EH. The copper binding domain of SPARC mediates cell survival in vitro via interaction with integrin beta1 and activation of integrin-linked kinase. J Biol Chem. 2008; 283:22826-22837.

10. Mo W, Brecklin C, Garber SL, Song RH, Pegoraro AA, Au J, Arruda JA, Dunea G, Singh AK. Changes in collagenases and TGF-beta precede 
structural alterations in a model of chronic renal fibrosis. Kidney international. 1999; 56:145-153.

11. Schroen B, Heymans S, Sharma U, Blankesteijn WM, Pokharel S, Cleutjens JP, Porter JG, Evelo CT, Duisters R, van Leeuwen RE, Janssen BJ, Debets JJ, Smits JF, Daemen MJ, Crijns HJ, Bornstein P, Pinto YM.

Thrombospondin- 2 is essential for myocardial matrix integrity: increased expression identifies failure-prone cardiac hypertrophy. Circ Res. 2004; 95:515-522.

12. Schroen B, Leenders JJ, van Erk A, Bertrand AT, van Loon M, van Leeuwen RE, Kubben N, Duisters RF, Schellings MW, Janssen BJ, Debets JJ, Schwake M, Hoydal MA, Heymans S, Saftig P, Pinto YM. Lysosomal integral membrane protein 2 is a novel component of the cardiac intercalated disc and vital for load-induced cardiac myocyte hypertrophy. J Exp Med. 2007; 204:1227-1235.

13. Iruela-Arispe ML, Liska DJ, Sage EH, Bornstein P. Differential expression of thrombospondin 1, 2, and 3 during murine development. Dev Dyn. 1993; 197:40-56.

14. Calzada MJ, Annis DS, Zeng B, Marcinkiewicz C, Banas B, Lawler J, Mosher DF, Roberts DD. Identification of novel beta1 integrin binding sites in the type 1 and type 2 repeats of thrombospondin-1. J Biol Chem. 2004; 279:4173441743.

15. van der Velden J, Papp Z, Boontje NM, Zaremba R, de Jong JW, Janssen PM, Hasenfuss G, Stienen GJ. The effect of myosin light chain 2 dephosphorylation on $\mathrm{Ca} 2+$-sensitivity of force is enhanced in failing human hearts. Cardiovasc Res. 2003; 57:505-514.

16. van der Velden J, Papp Z, Zaremba R, Boontje NM, de Jong JW, Owen VJ, Burton PB, Goldmann P, Jaquet K, Stienen GJ. Increased Ca2+-sensitivity of the contractile apparatus in end-stage human heart failure results from altered phosphorylation of contractile proteins. Cardiovasc Res. 2003; 57:3747.

17. Zaremba R, Merkus D, Hamdani N, Lamers J, Paulus W, C. dR, Duncker D, Stienen G, van der Velden J. Quantitative analysis of myofilament protein phosphorylation in small cardiac biopsies. Proteomics Clinical Application. 2007; 1:1285-1290. 


\section{Supplemental Table 1. List of primers for Real-Time PCR and for shTSP-}

\section{2 production}

\begin{tabular}{|c|c|c|}
\hline Gene & Primer & Sequence 5'-3' \\
\hline Mouse- & $\mathrm{F}$ & 5'-ACGTGCCGCCTGGAGA-3' \\
\hline \multirow[t]{2}{*}{ GAPDH $^{a}$} & $\mathrm{R}$ & 5'-СССTCAGATGCCTGCTTCA-3' \\
\hline & Probe & 5'-CACCTTCTTGATGTCATCATACTTGGCAGG-3' \\
\hline Mouse- & $\mathrm{F}$ & 5'-CCTGGCATCGGAGCCCA-3' \\
\hline CAT1 & $\mathrm{R}$ & 5'-GTGTCCGGGTAGGCAAAAAG-3' \\
\hline - & Probe & 5'-CCCTGACAAAATGCTTCAGGGCCG-3' \\
\hline Mouse- & $\mathrm{F}$ & 5'-GACTGGTGGTGCTCGGTTTC-3' \\
\hline \multirow[t]{2}{*}{ Gxp } & $\mathrm{R}$ & 5'-CAGAATCTCTTCATTCTTGCCAT-3' \\
\hline & Probe & 5'-CGTGCAATCAGTTCGGACACCAGG-3' \\
\hline Rat- & Sense & 5'-GATATCTGCTTCTCAATTATTCAAGAGATAATTGAGAAGCAGATATCTTTTTC-3' \\
\hline shTSP-2 $2^{\mathrm{b}}$ & Antisense & 5'-TCGAGAAAAAGATATCTGCTTCTCAATTATCTCTTGAATAATTGAGAAGCAGATATC-3' \\
\hline
\end{tabular}

${ }^{\text {aH}}$ Housekeeping gene: GAPDH,glyceraldehydes3-phhosphate dehydrogenase ${ }^{b}$ rat-shTSP-2 oligonucleotides, Hairpin structure in bold.

Mouse TSP-1 ID: Mm 01335419_g1; Mouse TSP-2 ID: Mm01279241_m1;

Mouse TSP-3 ID: Mm 01212335_m1; Mouse TSP-4 ID: Mm 03003598_s1

Mouse SOD2 ID: Mm 00449726_m1 


\section{Supplemental figures}

A

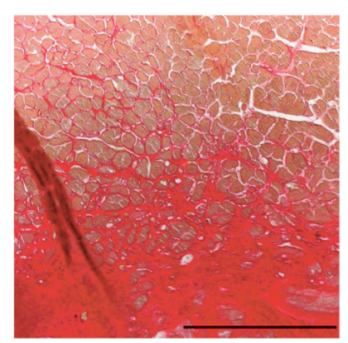

B

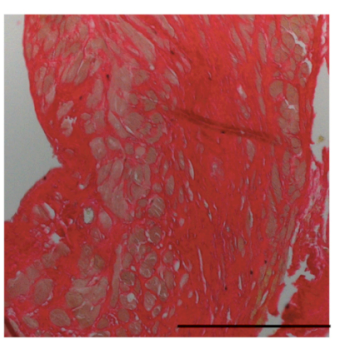

C

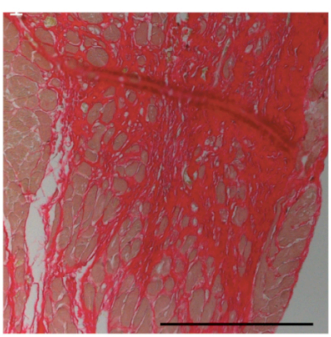

$\mathrm{D}$

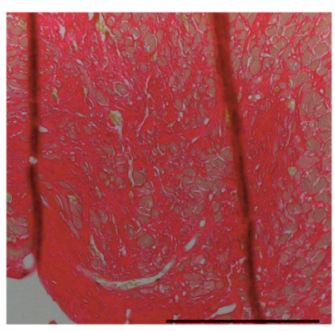

Supplemental Figure 1: The loss of TSP-2 resulted in increased cardiac fibrosis .

(A-E) Post mortem analysis of Sirius red-stained older male TSP-2 KO hearts revealing increased cardiac fibrosis and cardiomyocyte dropout. A-E represent 4 individual hearts.

Bars: (A-H) $100 \mu \mathrm{m}$

A

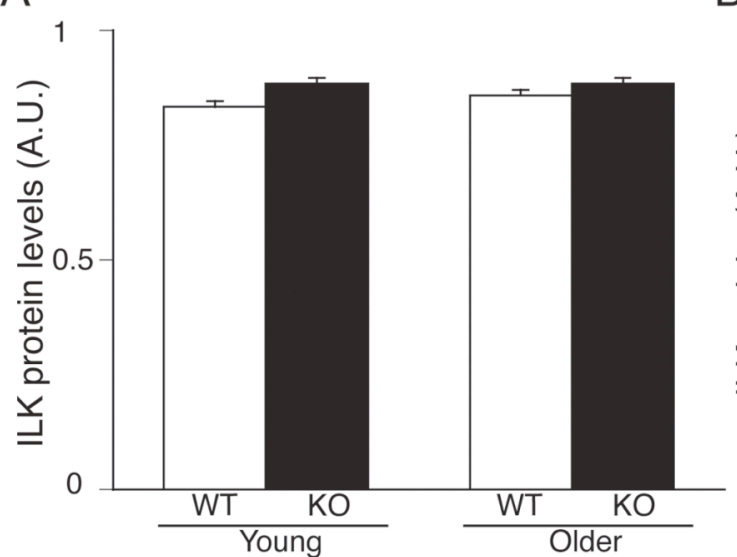

B

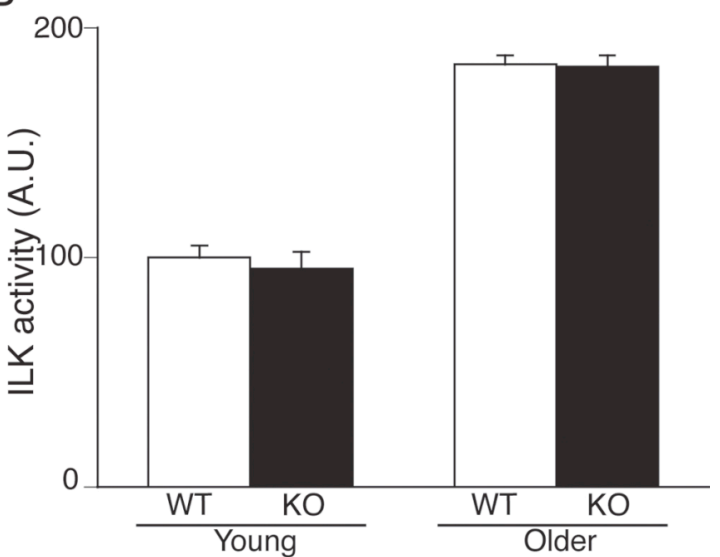

Supplemental Figure 2: The loss of TSP-2 did not resulted in differences in ILK activity levels with aging (A) Immunoblotting for ILK protein levels did not show differences in young and older TSP-2 KO hearts as compared with age-matched WT littermates $(n=5$ per genotype per age-group; $P=N S$ ). (B). ILK activity assay showed no significant differences in ILK activity levels between TSP-2 KO and WT hearts in young or older mice. 
Chapter 2 


\section{Chapter 3}

\section{Thrombospondin-2 improves cardiac function during viral- induced cardiomyopathy}

Melissa Swinnen, Davy Vanhoutte, Armando De Palma, Thierry Vandendriessche, Marinee Chuah, Johan Neyts, Paul Veulemans, Olga Lettau, W. Verhesen, Jan D'hooge, Paul Bornstein, Frans Van de Werf, Esther Lutgens, Dirk Westermann, Peter Carmeliet, Yigal M. Pinto, Stephane Heymans

Submitted 


\begin{abstract}
Background- The matricellular protein thrombospondin 2 (TSP-2), a secreted extracellular matrix (ECM) glycoprotein, plays a crucial role in controlling cellmatrix interaction in tissue repair and cancer biology. Our previous data revealed that increased TSP-2 reinforces the matrix and protects against heart failure during hypertension. The present study investigated whether TSP-2 may protects against exaggerated cardiac inflammation, injury and dysfunction during viral myocarditis.
\end{abstract}

Methods and Results- Therefore, mortality, cardiac inflammation and function were investigated in TSP-2-null (KO) and wild type (WT) mice, and after adeno-associated virus (AAV)-9 mediated TSP-2 overexpression in WT, in a mouse model of coxsackievirus B3 (CVB3)-induced myocarditis. Absence of TSP-2 resulted in an increased mortality in TSP-2-null as compared with WT mice during viral myocarditis. Ultrastructural analysis showed increased cardiac inflammation and myocyte injury in absence of TSP-2, together resulting in depressed systolic function (\% FS; $34 \pm 2.6$ in WT vs. $24 \pm 1.8$ in $\mathrm{KO}$ mice, $P<0.05)$ and increased cardiac dilatation (end-diastolic dimensions, $\mathrm{mm} ; 2.9 \pm 0.1$ in WT vs. $3.9 \pm 0.1$ in KO mice, $P<0.05)$. In concordance, AAV9gene transfer of TSP-2 resulted in reduced cardiac inflammation and injury at 14 days and improved cardiac function after 35 days as compared to control AAV9-GFP.

Conclusion- Together, these data clearly point towards a novel protective role for TSP-2 against uncontrolled inflammation, myocardial injury and dysfunction in acute viral myocarditis by regulating cardiac inflammation and function. 


\section{Introduction}

Acute viral myocarditis is a serious condition causing heart failure and sudden cardiac death in previously healthy adults. It may also result in long-term cardiac injury with the development of dilated cardiomyopathy, triggered by a chronic inflammatory process associated with viral persistence. Among the cardiotrophic viruses inducing myocarditis, enteroviruses, parvovirus B19, Epstein-Barr virus and human herpesvirus 6 are the most frequently identified etiologic agents. ${ }^{1,2}$ Especially human type $B$ coxsackieviruses (CVB) is highly prevalent, and belong to the best-studied viruses evoking myocarditis both in humans and mice. Despite intense research to unravel the mechanisms underlying severe inflammation by CVB-infection, treatment for acute myocarditis is primarily supportive, and specific therapies targeting inflammation are missing but really required.

Recent data have suggested an implication of the cardiac extracellular matrix (ECM), in particular the matrix metalloproteinase (MMP) system, in the regulation of viral infection and inflammation in the heart. Increased MMP-9 halted virus replication and prevented inflammation ${ }^{3}$, and accordingly TIMP1-blockade ameliorated CVB-induced myocarditis ${ }^{4}$. In contrast, MMP inhibition by overexpression of its physiological inhibitor TIMP-1 prevented chronic adverse remodeling and dysfunction several weeks after acute myocarditis ${ }^{5}$.

More recently, another group of ECM components, the thrombospondins (TSPs), have been implicated in cardiac disease. These are non-structural glycoproteins belonging to the family of matricellular proteins regulating cellmatrix interactions. TSPs appear to play a key-role in maintaining cardiac tissue integrity in ischemic (TSP-1) ${ }^{6}$ and hypertensive heart disease (TSP-2) 7. However, their implication in viral myocarditis remains unknown, despite evidence for their involvement in inflammatory processes outside the heart. By binding to its cell surface receptors, TSP-2 is able to regulate T-cell function and may thereby reduce inflammation in oxazolone-induced inflammation ${ }^{8}$ and in rheumatoid arthritis ${ }^{9}$. 
The aim of the present study was to investigate the specific contribution of TSP-2 to the inflammatory process and subsequent remodeling in CVB3induced myocarditis.

Here, we demonstrated that the absence of TSP-2 resulted in an exaggerated inflammatory response, cardiac necrosis and dysfunction, without affecting viral replication. TSP-2 may be a novel target for treating viral myocarditis, since overexpression of TSP-2 blunted inflammation and prevented subsequent cardiac injury and dilatation.

\section{Materials and Methods}

\section{Mouse model of viral myocardits}

All mice were maintained in an open animal facility, and experiments were performed according the guidelines for care and use of laboratory animals approved by the institution animal committee of the Leuven University.

Six to eight weeks old inbred TSP-2 knockout (KO) and wild type (WT) littermates on a 129 SvJ EMS/Ter genetic background ${ }^{10}$, and $10^{7} \mathrm{CCID50}_{\text {of }}$ CVB3 was injected intraperitoneally as previously described. ${ }^{5}$.

\section{Histological and Morphometric analysis}

Mice were sacrificed at 14 or 35 days, and hearts were taken out and prepared for further histological and molecular analysis. Lungs, left (LV) and right ventricle (RV) were dissected, blotted dry and weighted. Hearts were fixed in $1 \%$ paraformaldehyde and processed for further standard histological stainings ${ }^{5}$. Paraffin-embedded or cryo-heart sections were immunolabeled for the following proteins: CD3 (Dako; Leuven, Belgium), Mac-3 (BD Pharmingen, San José, CA, USA), CD4 (BD Pharmingen), CD8 (BD Pharmingen), TSP-2 (BD Pharmingen), CD25 (BD Pharmingen) and Foxp3 (eBioscience), and quantified per myocardial area as described previously ${ }^{11},{ }^{12}$.

Myocardial necrosis was determined by percentage of necrotic cardiomyocytes per total cardiac area. Collagen content was stained using 
Sirius red, and the amount of collagen was determined as percentage Sirius red staining area per total cardiac area ${ }^{13}$.Morphometric analysis was performed with a Leitz DMRXE microscope (Leica Imaging systems Ltd), a 3CCD color video camera (CXC-93-OP, Sony) and a Leica Qwin software system by persons unaware of the genotype.

\section{Zymographic MMP-2- activity}

Heart tissues were homogenized and protein concentrations were determined

5. Zymography of MMP-2 and MMP-9 activities in extracts of hearts on 14 and 35 days after CVB3 infection were determined as described previously. 1411

\section{RNA isolation and real time polymerase chain reaction}

RNA was extracted from heart tissues using the RNeasy ${ }^{\circledR}$ Fibrous Tissue Mini Kit (Qiagen GmbH, Hilden, Germany), whereafter, quality and concentration was determined using the Ultrosped 2100 pro UV/Visible spectrometer (Amersham Biosciences). One hundred nanogram of total RNA was reverse-transcribed into cDNA, using the Qiagen Quantitect ${ }^{\circledR}$ Reverse transcription kit (Qiagen $\mathrm{GmbH}$ ). mRNA levels of MMP-2, MMP-9, TIMP-1, TIMP-2, TIMP-3, IL-2, IL-6, IL-10, IL-10RA, IL-12, IL-13, TNF- $\alpha$, IFN- $\gamma$ and TSP-2 were determined by use of real-time fluorescence detection as previously described (Applied Biosystems, table 3). GAPDH was used as an internal loading control for semi-quantitative RT-PCR performed with the Applied Biosystems 7500 Fast Real-Time PCR stystem.

\section{Echocardiographic measurements}

The echocardiographic examination was performed by transthoracic echocardiography with a 13-Mhz transducer (i13L:KW100011, GE ultrasound; Horton Norway) on a Vingmed Vivid 7 scanner (GE ultrasound,Horton, Norway) in anesthetized mice (2\% isoflurane, ecuphar, Oostkamp, Belgium). 
LV diameters at end-diastole (LVEDD) and end-systole (LVESD), muscle thickness (SW diast), and LV posterior wall in end diastole (PW diast) were measured, and fractional shortening (FS) was calculated (table 1).

\section{Adeno Associated Viral Vector (AAV-9) gene transfer of TSP-2}

One hundred $\mu \mathrm{l}$ of $10^{9}$ viral genomic copies AAV-9 TSP-2 and the control AAV-9 green fluorescent protein (GFP) diluted in saline was injected in the tail vein, 3 days before inoculation with $10^{7}$ CCID50 of CVB3 in four-week old male $\mathrm{C} 3 \mathrm{H} / \mathrm{HeNH}$ sd mice (Harlan Laboratories, The Netherlands) weighing 15$16 \mathrm{~g}$. The design of AAV9 vectors were performed as described previously. The vector-production process involved cotransfection of human embryonic kidney cell line 293 (HEK-293).

\section{Immunoblotting}

Immunoblotting for thrombospondin-2) and control GAPDH was performed in heart lysates. Proteins were separated by SDS-PAGE and blots were incubated overnight at $4^{\circ} \mathrm{C}$ with diluted primary antibodies. Signals were visualized using Hyperfilm ECL (Amersham Biosciences, Little Chalfonts, UK) and quantified using Image $\mathrm{J}$ software. Protein levels were expressed relative to protein levels of GAPDH.

\section{Results}

TSP-2 KO mice have increased mortality and cardiac dysfunction in response to CVB3-induced myocarditis.

To investigate whether the absence of TSP-2 may affect cardiac function in CVB3-induced myocarditis, TSP-2 knockout (KO) and wild type (WT) littermates were infected with CVB3 intraperitoneally. The absence of TSP-2 resulted in an increased mortality: 6 out of 25 (38 \%) TSP-2 KO mice as compared with 0 out of 25 (0\%) WT mice died within 14 days after CVB3- 
injection (Figure 1). This increased mortality in the absence of TSP-2 appeared to be the consequence of pronounced cardiac suffering, as indicated by a significant increase in cardiac dimensions and a decrease in systolic function measured by echocardiography at 14 and 35 days (Table 1). Cardiac dimensions or function did not significantly differ between sham TSP$2 \mathrm{KO}$ and WT, or in CVB3-treated compared to sham WT mice at 14 days.

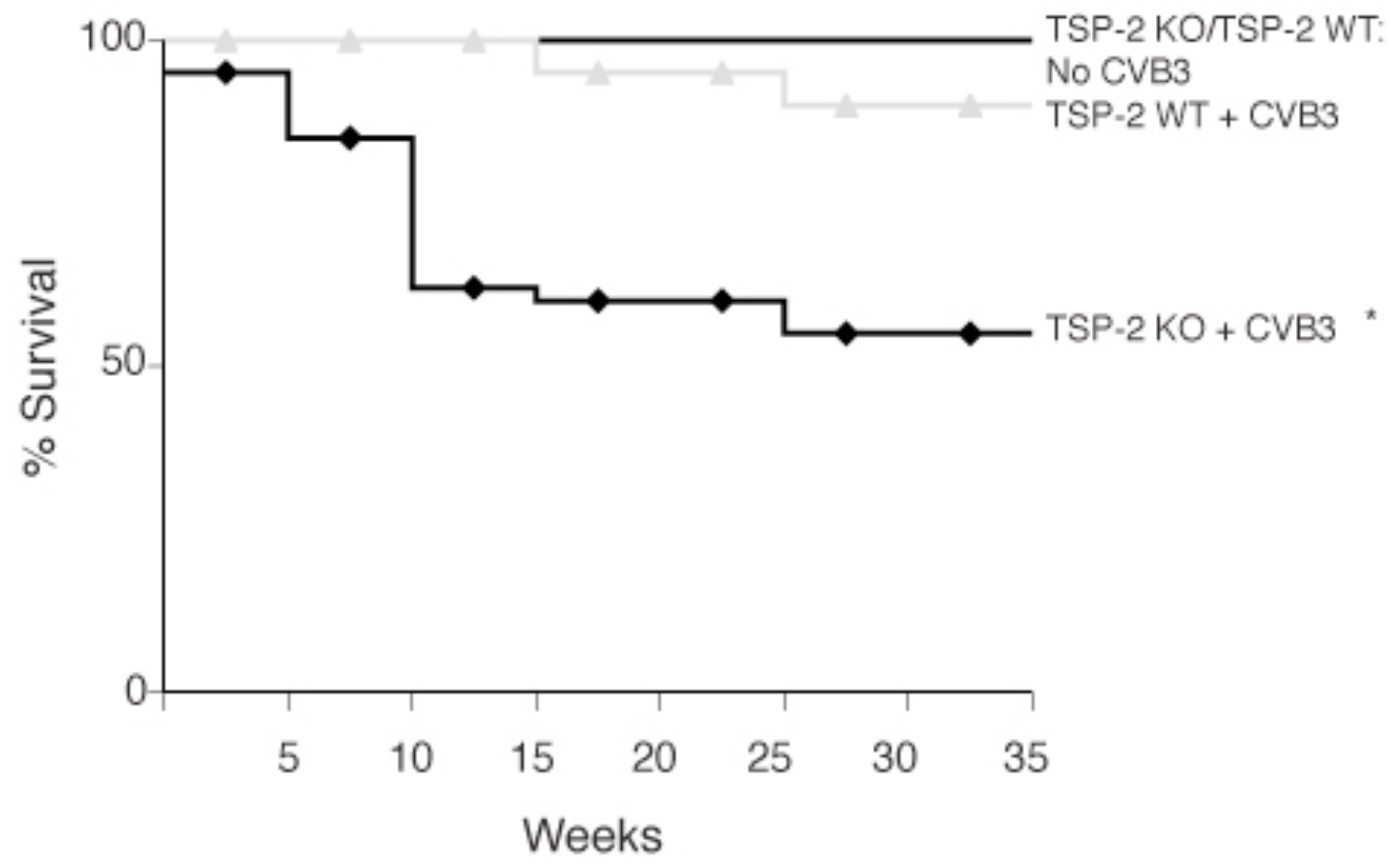

Figure 1. Increased mortalitiy during viral myocarditis in the absence of TSP-2. (A) Survival curve of TSP-2 KO and WT mice studied up to 35 days after viral infection. TSP-2 WT mice survive up to 35 weeks after viral myocarditis (95\% survival 19 out of 20 ) whereas 55 percent of the TSP-2 KO mice survive ( $55 \%$ survival 22 out of 40 ) within the same time frame. All control treated mice survived. ${ }^{*}: \mathrm{P}<0.05 \mathrm{TSP}-2 \mathrm{KO}$ mice vs. TSP-2 WT mice but with the same treatment

To study whether loss of TSP-2 might directly affect viral load and infectivity shortly after CVB3 infection, viral RNA load and infectivity were quantified in blood and infected tissues of TSP-2 KO and WT mice at 4 days after CVB3 infection. Viral load in serum or other organs did not significantly differ between TSP-2 KO and WT mice (Table 2). 


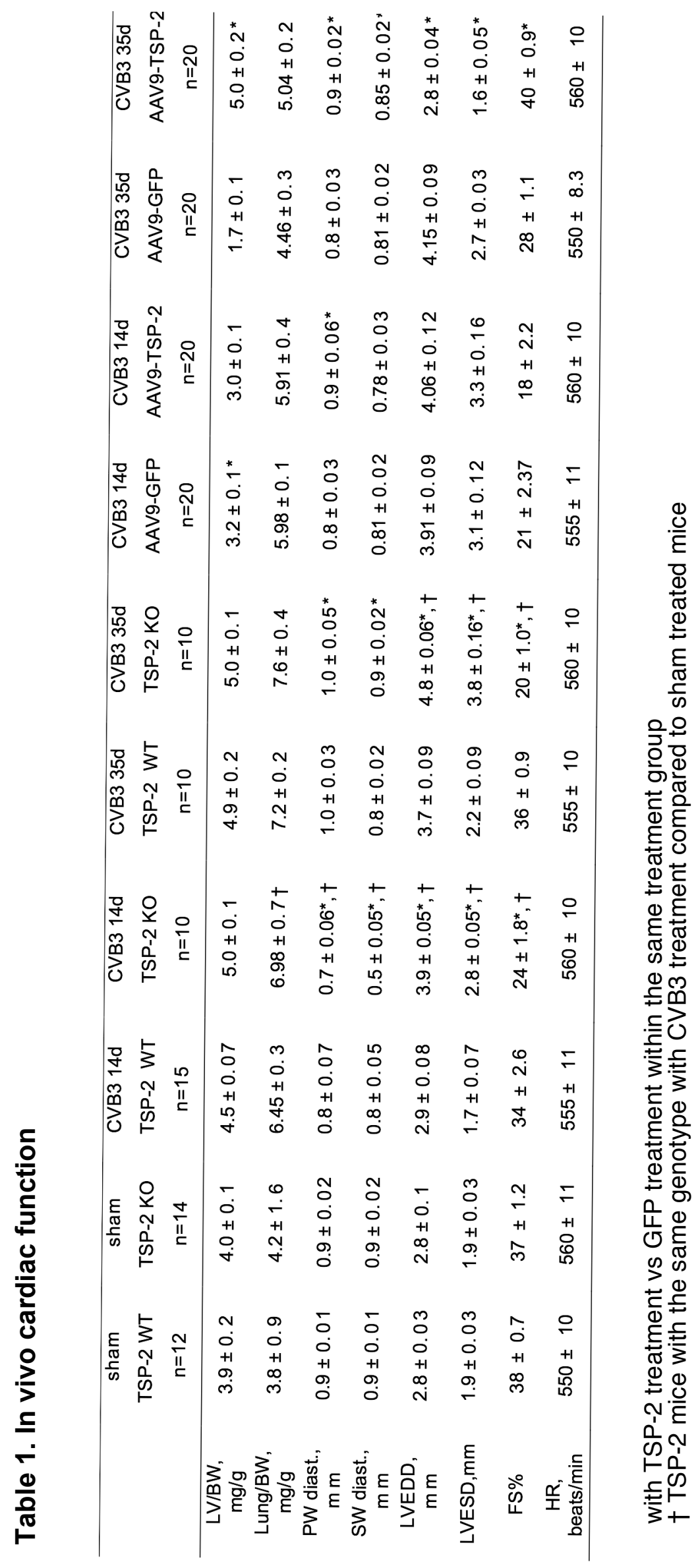


Table 2. Viral Load determination in serum and organs

\begin{tabular}{lcccccc}
\hline & $\begin{array}{c}\text { Sham } \\
\text { TSP-2 } \\
\text { WT } n=12\end{array}$ & $\begin{array}{c}\text { Sham } \\
\text { TSP-2 KO } \\
\mathrm{n}=14\end{array}$ & $\begin{array}{c}\text { CVB3 4d } \\
\text { TSP-2 WT } \\
\mathrm{n}=15\end{array}$ & $\begin{array}{c}\text { CVB3 4d } \\
\text { TSP-2 KO } \\
\mathrm{n}=10\end{array}$ & $\begin{array}{c}\text { CVB3 4d } \\
\text { AAV9-GFP } \\
\mathrm{n}=20\end{array}$ & $\begin{array}{c}\text { CVB3 4d } \\
\text { AAV9-TSP-2 } \\
\mathrm{n}=20\end{array}$ \\
\hline $\begin{array}{l}\text { Viral load } \\
\begin{array}{l}\text { Relative } \\
\text { mRNA levels }\end{array}\end{array}$ & & & & & & \\
\hline serum & $\mathrm{ND}$ & $\mathrm{ND}$ & $6.1 \pm 0.6$ & $6.0 \pm 0.3$ & $6.0 \pm 0.4$ & $6.2 \pm 0.3$ \\
heart & $\mathrm{ND}$ & $\mathrm{ND}$ & $6.2 \pm 0.2$ & $6.3 \pm 0.3$ & $6.1 \pm 0.2$ & $6.2 \pm 0.3$ \\
liver & $\mathrm{ND}$ & $\mathrm{ND}$ & $2.9 \pm 0.1$ & $2.8 \pm 0.3$ & $2.7 \pm 0.1$ & $2.8 \pm 0.1$ \\
spleen & $\mathrm{ND}$ & $\mathrm{ND}$ & $4.5 \pm 0.6$ & $4.6 \pm 0.1$ & $4.7 \pm 0.3$ & $4.7 \pm 0.2$ \\
pancreas & $\mathrm{ND}$ & $\mathrm{ND}$ & $5.6 \pm 0.1$ & $5.7 \pm 0.2$ & $5.7 \pm 0.4$ & $5.6 \pm 0.2$ \\
\hline
\end{tabular}

ND, not determined 


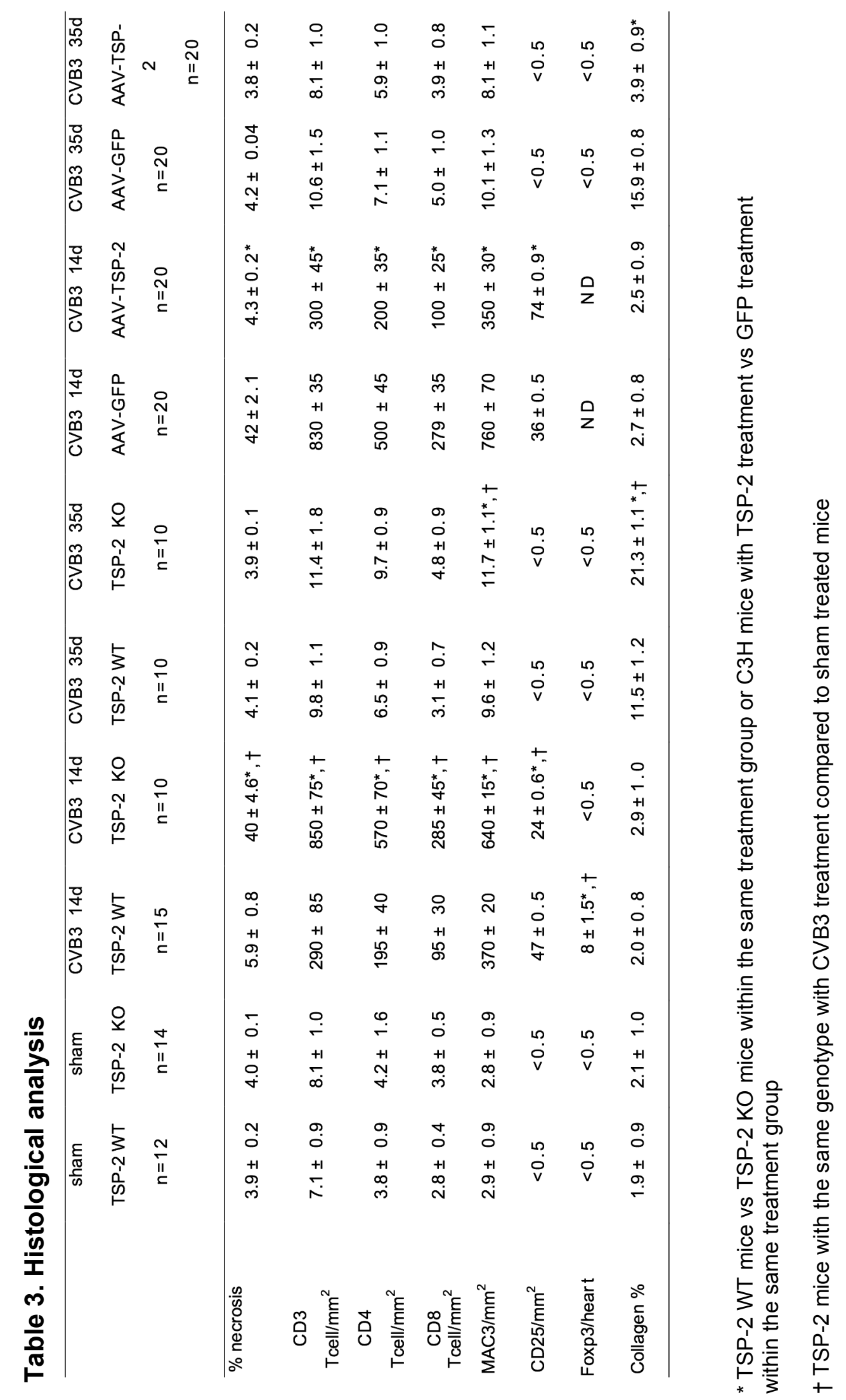




\section{Increased inflammation and fibrosis in TSP-2 KO mice}

Further histopathological analysis revealed a significant increase in inflammatory foci, resulting necrosis in TSP-2 KO compared to WT mice at 14 and increased cardiac fibrosis at 35 days of CVB3-infection.

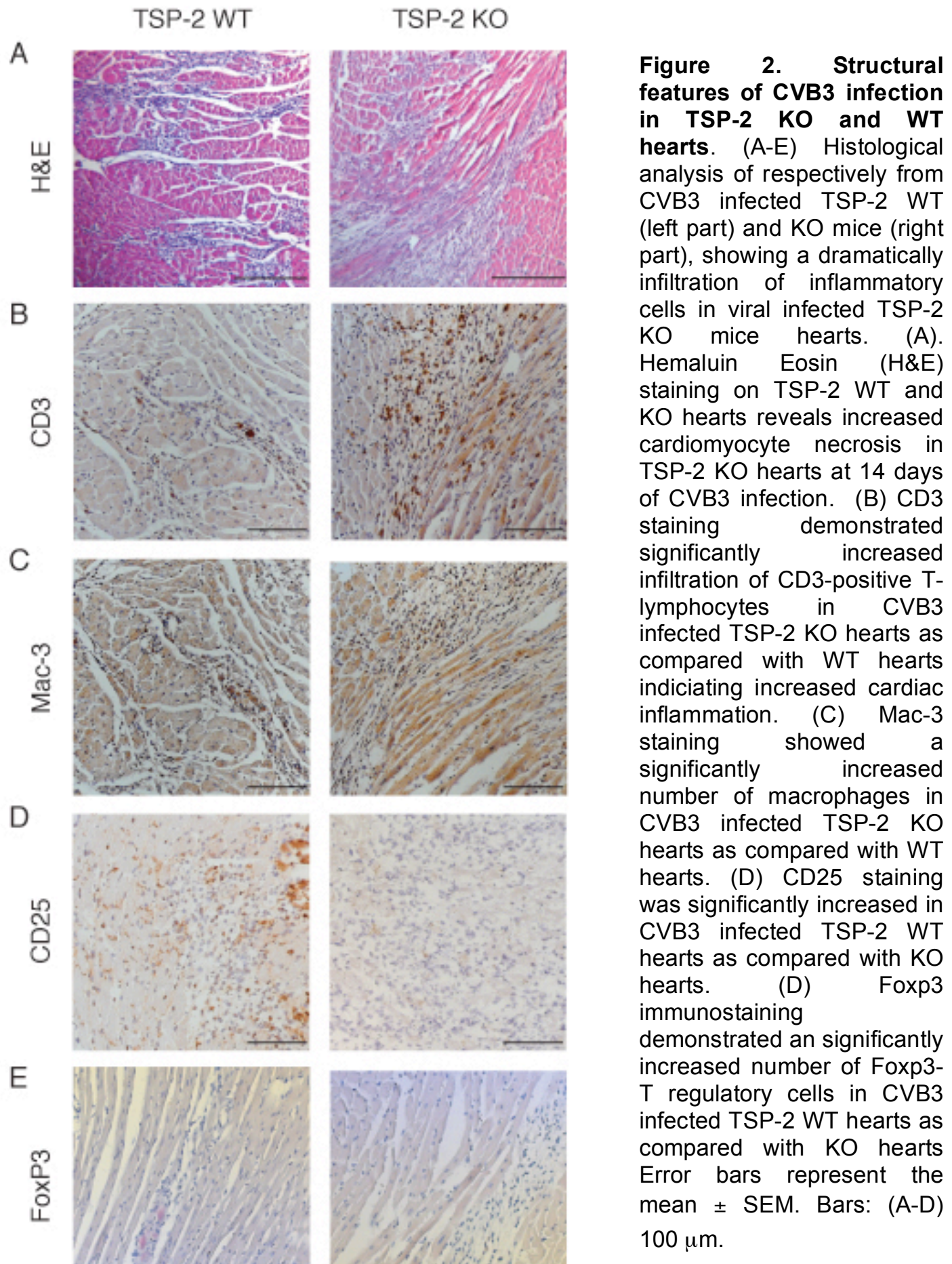


The number of CD3-positive T-lymphocytes and Mac3-positive macrophages were significantly increased in TSP-2 KO compared to WT mice (Table 3, Figure 2). Resulting fibrosis, detected by Sirius red staining, was pronounced in TSP-2 KO mice, but to a much lesser extent in WT mice both at 35 days after CVB3 infection. There was no significant difference in inflammation or the amount of collagen between the TSP-2 KO and WT control hearts.

In concordance, the number of CD4- and CD8 immunoreactive T lymphocytes was significantly increased in TSP-2 KO compared to WT hearts at 14 days wheareas no significant differences in cardiac inflammation were present at 35 days (Table 3 ).

To study the involvement of regulatory $T$ cells in the protection against viral induced cardiomyopahty, we examined the amount of CD25- and Foxp3 positive T-cells in the heart. Immunohistological analysis revealed a significantly increased influx of CD25- and Foxp3-positive T-cells in TSP-2 WT hearts as compared to TSP-2 KO hearts during viral mycoarditis (Table 3, Figure 2). No Foxp3-positive regulatory T-cells could be detected in untreated TSP-2 WT or KO hearts.

\section{Increased MMP activity in the absence TSP-2}

Since TSP-2 is able to internalize MMP-2 via binding to TIMP-2 and the low density lipoprotein receptor-related protein ${ }^{15}$, we investigated whether the marked cardiac dilatation and dysfunction in TSP-2 KO mice may be caused by increased MMP-activity. In concordance with previous findings, MMP-2 and -9 zymographic activity and transcript levels did not differ between WT and KO mice before CVB3-infection. However, the activities of both proteases were upregulated in infected animals compared with sham. MMP-2 and -9 activity levels were significantly upregulated in the hearts of CVB3-treated WT mice. (Table 4) 
Table 4. Transcript Levels of MMPs and TIMPs Relative to sham WT levels.

\begin{tabular}{|c|c|c|c|c|c|c|}
\hline & $\begin{array}{c}\text { Sham } \\
\text { TSP-2 WT } \\
n=12\end{array}$ & $\begin{array}{c}\text { Sham } \\
\text { TSP-2 KO } \\
n=14\end{array}$ & $\begin{array}{c}\text { CVB3 14d } \\
\text { TSP-2 WT } \\
n=15\end{array}$ & $\begin{array}{c}\text { CVB3 14d } \\
\text { TSP-2 KO } \\
n=10\end{array}$ & $\begin{array}{c}\text { CVB3 14d } \\
\text { AAV9-GFP } \\
n=20\end{array}$ & $\begin{array}{c}\text { CVB3 14d } \\
\text { AAV9-TSP-2 } \\
n=20\end{array}$ \\
\hline \multicolumn{7}{|l|}{$\begin{array}{l}\text { Matrix } \\
\text { Relative } \\
\text { mRNA } \\
\text { levels } \\
\end{array}$} \\
\hline MMP - 2 & $1.1 \pm 0.2$ & $4.2 \pm 0.9^{*}$ & $12.6 \pm 4.5 \dagger$ & $9.5 \pm 1.2 \dagger$ & $8.4 \pm 1.0$ & $8.5 \pm 0.9$ \\
\hline MMP - 9 & $1.0 \pm 0.1$ & $2.0 \pm 0.7^{*}$ & $7.7 \pm 2.1 \dagger$ & $5.1 \pm 1.1 \dagger$ & $6.1 \pm 0.9$ & $6.0 \pm 1.1$ \\
\hline TIMP - 1 & $1.0 \pm 0.1$ & $1.3 \pm 0.2$ & $3.5 \pm 0.7 \dagger$ & $3.8 \pm 0.7 \dagger$ & $3.5 \pm 0.7$ & $3.5 \pm 0.5$ \\
\hline TIMP - 2 & $1.0 \pm 0.1$ & $1.3 \pm 0.2$ & $7.8 \pm 1.2 \dagger$ & $8.1 \pm 0.8 †$ & $9.9 \pm 0.9$ & $10.0 \pm 1.0$ \\
\hline \multicolumn{7}{|l|}{$\begin{array}{l}\text { Acitvity } \\
\text { levels } \\
\text { (A.U.) } \\
\end{array}$} \\
\hline MMP - 2 & $8.4 \pm 0.9$ & $7.9 \pm 0.9$ & $8.6 \pm 0.8$ & $11.2 \pm 0.9^{*}, \dagger$ & $9.9 \pm 0.8$ & $8.5 \pm 0.9$ \\
\hline MMP-9 & $2.6 \pm 0.3$ & $3.5 \pm 0.3$ & $6.0 \pm 0.9 \dagger$ & $14.7 \pm 1.0^{*}, \dagger$ & $14.2 \pm 1.2$ & $5.8 \pm 1.1^{*}$ \\
\hline
\end{tabular}

* TSP-2 WT mice vs TSP-2 KO mice within the same treatment group or C3H mice with TSP-2 treatment vs GFP treatment within the same treatment group

† TSP-2 mice with the same genotype with CVB3 treatment compared to sham treated mice 
Table 5. Regulation of cytokines during viral myocarditis

\begin{tabular}{|c|c|c|c|c|c|c|}
\hline & $\begin{array}{c}\text { Sham } \\
\text { TSP-2 WT } \\
n=12\end{array}$ & $\begin{array}{c}\text { Sham } \\
\text { TSP-2 KO } \\
n=14\end{array}$ & $\begin{array}{c}\text { CVB3 14d } \\
\text { TSP-2 WT } \\
n=15\end{array}$ & $\begin{array}{c}\text { CVB3 14d } \\
\text { TSP-2 KO } \\
n=10\end{array}$ & $\begin{array}{c}\text { CVB3 14d } \\
\text { AAV9-GFP } \\
n=20\end{array}$ & $\begin{array}{c}\text { CVB3 14d } \\
\text { AAV9-TSP-2 } \\
n=20\end{array}$ \\
\hline \multicolumn{7}{|c|}{$\begin{array}{l}\text { Inflammation } \\
\text { Relative mRNA levels }\end{array}$} \\
\hline IL-1 beta & $1.0 \pm 0.5$ & $1.0 \pm 0.8$ & $3 \pm 0.9 \dagger$ & $5 \pm 0.9 *, \dagger$ & $10 \pm 1.2$ & $6 \pm 1.0^{*}$ \\
\hline IL-6 & $<0.05$ & $<0.05$ & $4 \pm 0.8 \dagger$ & $6 \pm 0.9 \dagger$ & $5 \pm 0.7$ & $4 \pm 0.8$ \\
\hline IL-10 & $<0.05$ & $<0.05$ & $152 \pm 44 \dagger$ & $36 \pm 10^{*} \dagger$ & $40 \pm 10$ & $90 \pm 20^{*}$ \\
\hline IL-10RA & $1.0 \pm 0.02$ & $1.0 \pm 0.02$ & $8.3 \pm 0.9 \dagger$ & $3.3 \pm 0.9^{*}, \dagger$ & $7.9 \pm 0.3$ & $9.1 \pm 0.8^{*}$ \\
\hline IL-12a & $1.0 \pm 0.05$ & $1.0 \pm 0.09$ & $7.8 \pm 0.9 \dagger$ & $1.8 \pm 0.5^{\star}, \dagger$ & $2.0 \pm 0.2$ & $7.9 \pm 0.4^{*}$ \\
\hline IL-13 & $1.0 \pm 0.1$ & $1.2 \pm 0.2$ & $14 \pm 1.0 \dagger$ & $4 \pm 0.5^{*}, \dagger$ & $12 \pm 0.9$ & $20 \pm 1.2^{*}$ \\
\hline $\begin{array}{l}\text { TGF- } \\
\text { beta }\end{array}$ & $1.0 \pm 0.2$ & $0.8 \pm 0.1$ & $1.3 \pm 0.5$ & $1.1 \pm 0.6$ & $1.1 \pm 0.6$ & $1.2 \pm 0.4$ \\
\hline $\begin{array}{l}\text { TNF- } \\
\text { alpha }\end{array}$ & $1.0 \pm 0.4$ & $0.69 \pm 0.1$ & $4.0 \pm 0.5$ & $3.7 \pm 0.5 \dagger$ & $3.8 \pm 0.9$ & $3.7 \pm 0.8$ \\
\hline $\begin{array}{l}\text { INF- } \\
\text { gamm a }\end{array}$ & $<0.05$ & $<0.05$ & $4.0 \pm 0.7$ & $4.9 \pm 0.9 \dagger$ & $4.5 \pm 1.0$ & $4.3 \pm 0.9$ \\
\hline $\begin{array}{l}\text { TNF-sf } \\
\text { rb }\end{array}$ & $1.0 \pm 0.04$ & $1.0 \pm 0.1$ & $5.6 \pm 0.9 \dagger$ & $2.4 \pm 0.5^{*}, \dagger$ & $3.7 \pm 0.4$ & $5.9 \pm 0.8^{*}$ \\
\hline
\end{tabular}

* TSP-2 WT mice vs TSP-2 KO mice within the same treatment group or C3H mice with TSP2 treatment vs GFP treatment within the same treatment group

† TSP-2 mice with the same genotype with CVB3 treatment compared to sham treated mice 


\section{Regulation of cytokines during CVB3 infection.}

To determine whether the decrease in inflammatory influx in TSP-2 WT hearts is related to an alteration in cytokine expression, the transcriptional regulation of cytokines was investigated (Table 5).

In the infected TSP-2 WT hearts, IL-10, IL-10RA, IL-13 and TGF sf Rb were remarkably increased compared with TSP-2 KO hearts and sham hearts.

IFN- $\gamma$ and TNF- $\alpha$ expression are increasing with CVB3 treatment. However, no differences in TNF-alpha expression could be detected between CVB3treated $\mathrm{KO}$ and WT hearts whereas IFN- $\gamma$ is significantly higher in CVB3treated TSP-2 WT hearts compared with treated KO hearts (Table 5).

\section{TSP-2 gene overexpression results in decreased cardiac inflammation and improved cardiac function during viral mycoarditis}

To provide evidence that TSP-2 may be used for therapeutic application to protect against viral myocarditis induced cardiac injury, we treated young male and female $\mathrm{C} 3 \mathrm{H}$ mice with an adeno-associated viral vector harboring mouse TSP-2 (AAV9-TSP-2) compared to a control AAV9-green fluorescent protein vector, whereafter they were injected intraperitonealy with CVB3.

At 14 days after CVB3 infection, we assessed TSP-2 protein levels in the mice hearts. Both immunoblotting and -staining revealed that AAV9-mediated transfer of TSP-2 resulted in a significant and widespread cardiac TSP-2 protein expression, whereas TSP-2-protein levels were low in the control AAV9-GFP treated mice (Figure 3A through B).

Importantly, AAV9-TSP-2 also prevented exaggerated cardiomyocyte inflammation, confirmed by reduced infiltration of CD3-, CD4- and CD8 positive $\mathrm{T}$ lymphocytes, and macrophages (Figure 3D and Table 3) Increased CD25-T lymphocytes could be detected after AAV9-medicated TSP-2 overexpression together with altered cytokine expression patterns (Table 3 and 2).

Additionally, at 35 days after CVB3 infection clearly protected against cardiac fibrosis, cardiac dilatation and dysfunction, still present in the control-treated 
mice (Figure 3C, Table 2, Table 3). Together, these data confirm that TSP-2 expression is essential to mediate cardiac inflammation and necrosis and maintain cardiac function during CVB3-induced viral myocarditis.

A
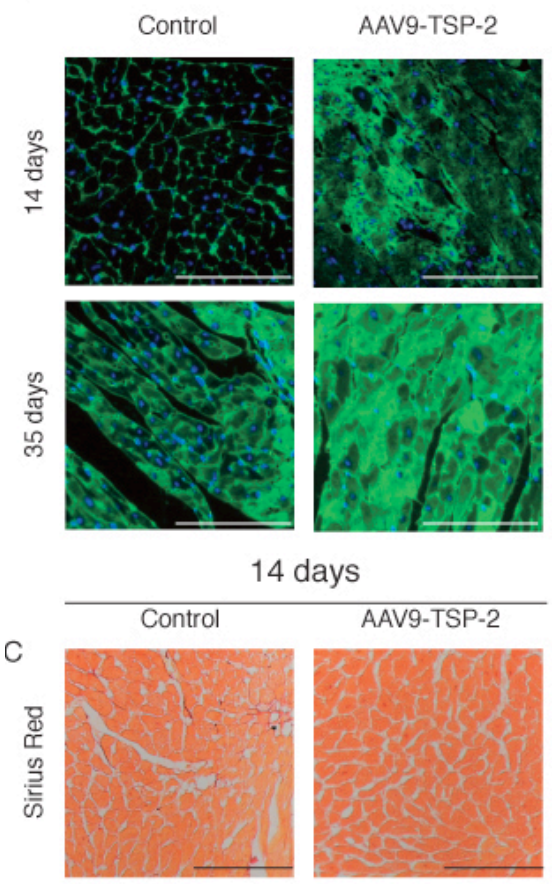

D
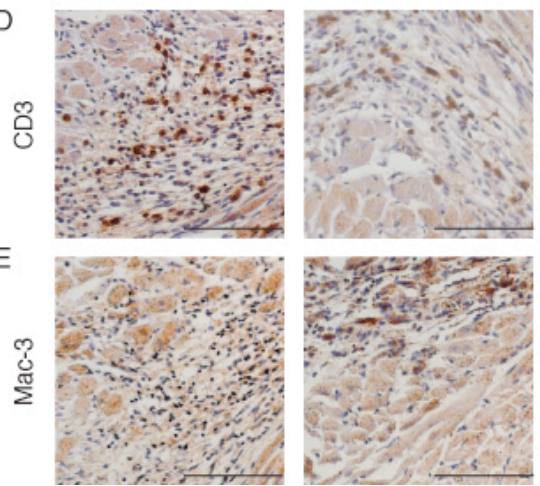

B

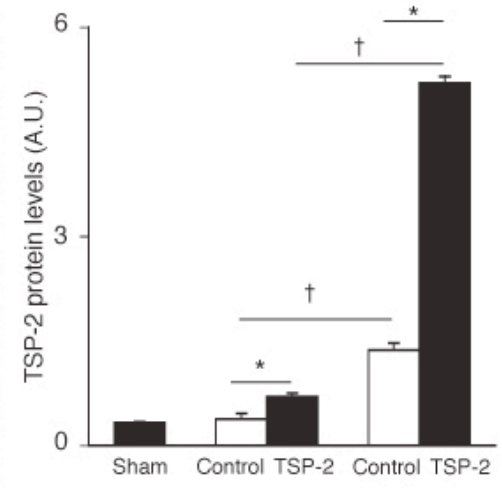

35 days

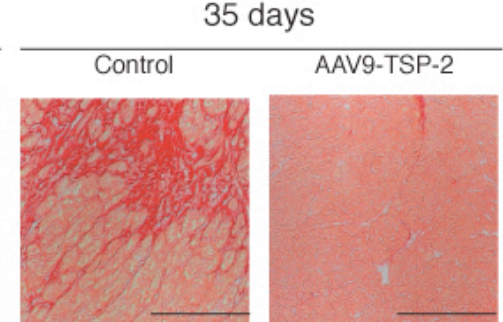

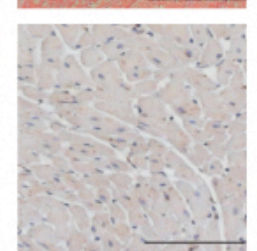
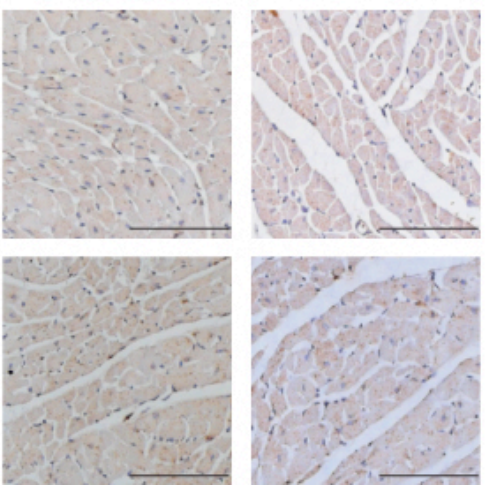

Figure 3. AAV9-mediated TSP-2 overexpression rescues mortality and exaggerated cardiac inflammation. (A) TSP-2 immunostaining confirmed the increased amount of TSP-2 present in the surrounding extracellular matrix and cardiomyocytes whereas low levels of TSP-2 could be detected in the AAV9-GFP-treated mice. (B) Immunoblotting for TSP-2 confirmed the a significant increase in TSP-2 detected in AAV9-TSP-2-treated mice 14 and 35 days after CVB3 infection( ${ }^{*} \mathrm{P}<0.05$; $\left.\dagger \mathrm{P}<0.05\right)$. ( $\left.\mathrm{C}-\mathrm{F}\right)$ Histological analysis of AAV9-GFP and AAV9-TSP-2-treated hearts were performed at 14 and 35 days after CVB3 infection. (C) Sirius Red staining on AAV9-GFP-treated and AAV9-TSP-2-treated male and female KO hearts reveals increased cardiac fibrosis in AAV9-GFP-treated hearts at 35 days after CVB3 infection whereas 14 days no differences in cardiac fibrosis could be detected between AAV9-GFP-treated and TSP-2-treated mice hearts. (D) CD3 staining revealed a significant reduction in infiltrating CD3-positive T-lymophocytes in AAV9-TSP-2-treated mice at 14 days after CVB3 infection whereas at 35 days no differences could be detected. (E) The amount of infiltrated macrophages was significantly reduced in AAV9-TSP-2 treated mice hearts at 14 days after CVB3 infection as compared with AAV9-GFP-treated hearts. After 35 days of viral infection no differences in the number of macrophages could be noticed. Error bars represent the mean \pm SEM. Bars: (C-E) $100 \mu \mathrm{m}$. 


\section{Discussion}

The present study investigated the role for TSP-2 in CVB3-induced myocarditis by combining a study comparing TSP-2 KO and WT infected mice, and AAV-9-mediated TSP-2 overexpression in WT mice. Herein, we demonstrated that the absence of TSP-2 increased inflammation, injury, dysfunction and overall mortality, whereas its overexpression in the heart was protective against viral heart disease and cardiac dysfunction.

TSP-2 KO mice showed an exaggerated influx of inflammatory cells, including CD3-positive T-lymphocytes and macrophages, compared with WT mice, resulting in increased myocyte necrosis and a progressive cardiac dilatation and systolic dysfunction. In contrast, AAV9-mediated overexpression of TSP2 significantly reduced the acute inflammatory response and prevented cardiac dysfunction and dilatation at longer term. These findings are concordant with an important role for thrombospondins in the suppression of the T-cell response in rheumatoid arthritis ${ }^{9}$, cutaneous inflammation ${ }^{8}$ and uveoretinitis $^{16}$. Binding of TSP-2 (and TSP-1) to CD47, also called the integrin-associated protein, on T-cells reduces the influx of these CD3-positive (pos.) T-cells in the skin $^{8}$, in line with our findings of decreased influx of CD3positive T-cells in the heart after AAV9-TSP-2 overexpression, in response to CVB3-infection. CD47 stimulation by TSP induces naive T-cells to become suppressive (CD25 or Foxp3 positive), which down-regulate the overall influx of T-cells and macrophages ${ }^{17}$. Binding of TSP-2 to CD47, may therefore explain why in the absence of TSP-2 the number of T-regulatory cells is strongly decreased, thereby increasing the number of T-cells and macrophages after CVB3-infection. The marked influx of T-cells and depressed number of T-regulatory cells in TSP-2 KO compared to WT hearts was further paralleled by a shift in cytokine expression. Cytokines play important roles in myocarditis and tissue remodeling because immune respones may become detrimental to myocardial function because both $\mathrm{T}$-cell and cytlone-mediated myocyte damage reduceds the number of viable cardiomyocytes and can ultmimately lead to long term remodeling. The cardiac level of the pro-inflammatory cytokines interleukin (IL)-1, IL-6 and 
TNF- $\alpha$ were higher, whereas the cytokines IL-12, IL-13 that reduce the amount of T-cells and macrophages in the inflamed region ${ }^{18}$, were decreased in mice lacking TSP-2. Furthermore, it has recently been shown that IFN- $\gamma$ protects against the development of severe myocarditis, and dilated cardiomyopathy after CVB-3 infection by reducing fibrosis, and the pro-fibrotic cytokines TGB-beta1, IL-1beta, and IL-4 in the heart. Kubota et al revealed that soluble TNF Receptor abrogates myocardial inflammation in virusinduced cardiomyopathy ${ }^{19}$. In concordance with these findings, our data indicate increased levels of IL-10, IL-10 receptor, IL-12, IL-13 and TGF beta receptor in CVB3 treated TSP-2 WT hearts compared with sham treated WT hearts or with CVB3-treated KO hearts.

A role for T-regulatory cells ( $\left.T_{\text {reg }}\right)$ was established since the absence of TSP-2 resulted in a decreased number of Foxp3 positive regulatory T-cells progressing to increased cardiac dilatation and dysfunction during viral myocarditis.

Intriguingly, AAV9-mediated expression of TSP-2 in young $\mathrm{C} 3 \mathrm{H}$ mice protected against cardiac inflammation, dilatation and dysfunction during viral myocarditis. At 14 days after CVB3 infection, the infiltrating T-lymphocytes and macrophages were dramatically decreased compared with control treated hearts. Whereas at 35 days after CVB3 infection, TSP-2 overexpression protected against cardiac necrosis, injury, dilatation and dysfunction. Due to its cardiotrophic properties -AAV9-mediated gene transfer protected a severe cardiac phenotype. Taken together these results make it more probable that TSP-2 exerts a crucial role to maintain myocardial structure and function. Cytokine levels, at 14 days after CVB3 infection, indicate increased levels of IL-10, IL10-RA, IL-12, IL-13 and TGF beta receptor in the hearts of AAV9TSP-2 treated mice compared to the control group. Therefore, AAV9mediated gene transfer deserves to be further explored as a novel therapeutic approach for the clinical application of gene therapy in human cardiac diseases. $^{20}$ 


\section{Acknowledgements}

This study was supported by a Marie Curie Exellence Progam to S.H., M.S. and Y.M.P., a research grant from the Research fund K.U. Leuven (PDMK/08/175) to D.V., Long term structural funding - Methusalem funding by the Flemish Government to P.C., grant of the SFB-TR 19 (Project A2) to D.W. from the Deutsche Forschungsgemeinschaft, a research grant of the Research Foundation Flanders (F.W.O.; G.0601.09 and FWO WOG) to T.V. and M.C and a research grant of the F.W.O (G.0740.09.N10) to F.V.d.W. and Ingenious Hypercare NoE from the European Union (EST 2005-020706-2), research grants from the Netherlands Heart Foundation (2007B036, 2008B011) and a VIDI grant of the NWO to S.H. Y.M.P. is an established investigator of the Netherlands heart Foundation. We would like to thank Abel Acosta Sanchez and Ermira Samara for producing the AAV9 constructs and Erwin Wijnands for technical support.

\section{Conflicts of Interests. None}

\section{References}

1. Kindermann I, Kindermann M, Kandolf R, Klingel K, Bultmann B, Muller T, Lindinger A, Bohm M. Predictors of outcome in patients with suspected myocarditis. Circulation. 2008; 118:639-648.

2. Dennert R, Crijns HJ, Heymans S. Acute viral myocarditis. Eur Heart J. 2008.

3. Cheung C, Marchant D, Walker EK, Luo Z, Zhang J, Yanagawa B, Rahmani M, Cox J, Overall C, Senior RM, Luo H, McManus BM. Ablation of matrix metalloproteinase-9 increases severity of viral myocarditis in mice. Circulation. 2008; 117:1574-1582.

4. Crocker SJ, Frausto RF, Whitmire JK, Benning N, Milner R, Whitton JL. Amelioration of coxsackievirus B3-mediated myocarditis by inhibition of tissue inhibitors of matrix metalloproteinase-1. Am J Pathol. 2007; 171:1762-1773.

5. Heymans S, Pauschinger M, De Palma A, Kallwellis-Opara A, Rutschow S, Swinnen M, Vanhoutte D, Gao F, Torpai R, Baker AH, Padalko E, Neyts J, Schultheiss HP, Van de Werf F, Carmeliet P, Pinto YM. Inhibition of urokinase-type plasminogen activator or matrix metalloproteinases prevents 
cardiac injury and dysfunction during viral myocarditis. Circulation. 2006; 114:565-573.

6. Frangogiannis NG, Ren $G$, Dewald $O$, Zymek $P$, Haudek $S$, Koerting A, Winkelmann K, Michael LH, Lawler J, Entman ML. Critical role of endogenous thrombospondin-1 in preventing expansion of healing myocardial infarcts. Circulation. 2005; 111:2935-2942.

7. Schroen B, Heymans S, Sharma U, Blankesteijn WM, Pokharel S, Cleutjens JPM, Porter JG, Evelo CTA, Duisters R, van Leeuwen REW, Janssen BJA, Debets JJM, Smits JFM, Daemen MJAP, Crijns HJGM, Bornstein P, Pinto YM. Thrombospondin-2 Is Essential for Myocardial Matrix Integrity: Increased Expression Identifies Failure-Prone Cardiac Hypertrophy. Circ Res. 2004; 95:515-522.

8. Lamy L, Foussat A, Brown EJ, Bornstein P, Ticchioni M, Bernard A. Interactions between $\mathrm{CD} 47$ and thrombospondin reduce inflammation. J Immunol. 2007; 178:5930-5939.

9. Park YW, Kang YM, Butterfield J, Detmar M, Goronzy JJ, Weyand CM. Thrombospondin 2 functions as an endogenous regulator of angiogenesis and inflammation in rheumatoid arthritis. Am J Pathol. 2004; 165:2087-2098.

10. Schroen B, Heymans S, Sharma U, Blankesteijn WM, Pokharel S, Cleutjens JP, Porter JG, Evelo CT, Duisters R, van Leeuwen RE, Janssen BJ, Debets JJ, Smits JF, Daemen MJ, Crijns HJ, Bornstein P, Pinto YM. Thrombospondin-2 is essential for myocardial matrix integrity: increased expression identifies failure-prone cardiac hypertrophy. Circ Res. 2004; 95:515-522.

11. Heymans S, Luttun A, Nuyens D, Theilmeier G, Creemers E, Moons L, Dyspersin GD, Cleutjens JP, Shipley M, Angellilo A, Levi M, Nube O, Baker A, Keshet E, Lupu F, Herbert JM, Smits JF, Shapiro SD, Baes M, Borgers M, Collen D, Daemen MJ, Carmeliet P. Inhibition of plasminogen activators or matrix metalloproteinases prevents cardiac rupture but impairs therapeutic angiogenesis and causes cardiac failure. Nat Med. Vol 5; 1999:1135-1142.

12. Heymans S, Lupu F, Terclavers S, Vanwetswinkel B, Herbert JM, Baker A, Collen D, Carmeliet P, Moons L. Loss or inhibition of UPA or MMP-9 attenuates LV remodeling and dysfunction after acute pressure overload in mice. Am J Pathol. 2005; 166:15-25.

13. Schellings $M W$, Vanhoutte $D$, Swinnen $M$, Cleutjens JP, Debets $J$, van Leeuwen RE, d'Hooge J, Van de Werf F, Carmeliet P, Pinto YM, Sage EH, 
Heymans S. Absence of SPARC results in increased cardiac rupture and dysfunction after acute myocardial infarction. J Exp Med. 2009; 206:113-123.

14. Vanhoutte $D$, Schellings MW, Gotte $M$, Swinnen M, Herias V, Wild MK, Vestweber D, Chorianopoulos E, Cortes V, Rigotti A, Stepp MA, Van de Werf F, Carmeliet P, Pinto YM, Heymans S. Increased expression of syndecan-1 protects against cardiac dilatation and dysfunction after myocardial infarction. Circulation. 2007; 115:475-482.

15. Yang Z, Strickland DK, Bornstein P. Extracellular Matrix Metalloproteinase 2 Levels Are Regulated by the Low Density Lipoprotein-related Scavenger Receptor and Thrombospondin 2. J. Biol. Chem. 2001; 276:8403-8408.

16. Zamiri P, Masli S, Kitaichi N, Taylor AW, Streilein JW. Thrombospondin plays a vital role in the immune privilege of the eye. Investigative ophthalmology \& visual science. 2005; 46:908-919.

17. Grimbert P, Bouguermouh S, Baba N, Nakajima T, Allakhverdi Z, Braun D, Saito H, Rubio M, Delespesse G, Sarfati M. Thrombospondin/CD47 interaction: a pathway to generate regulatory $\mathrm{T}$ cells from human $\mathrm{CD} 4+$ CD25- T cells in response to inflammation. J Immunol. 2006; 177:3534-3541.

18. Cihakova D, Barin JG, Afanasyeva $M$, Kimura $M$, Fairweather D, Berg $M$, Talor MV, Baldeviano GC, Frisancho S, Gabrielson K, Bedja D, Rose NR. Interleukin-13 protects against experimental autoimmune myocarditis by regulating macrophage differentiation. Am J Pathol. 2008; 172:1195-1208.

19. Kadokami T, McTiernan CF, Kubota T, Frye CS, Bounoutas GS, Robbins PD, Watkins SC, Feldman AM. Effects of soluble TNF receptor treatment on lipopolysaccharide-induced myocardial cytokine expression. Am J Physiol Heart Circ Physiol. 2001; 280:H2281-2291.

20. Daya S, Berns KI. Gene therapy using adeno-associated virus vectors. Clinical microbiology reviews. 2008; 21:583-593. 
Chapter 3 


\section{Chapter 4}

\section{The Absence of SPARC results}

\section{in increased cardiac rupture} and dysfunction after acute myocardial infarction

Mark W.M.Schellings*, PhD, Davy Vanhoutte*, Swinnen, Melissa, Jack P. Cleutjens, Jacques Debets, Rick E.W. van Leeuwen, Jan D'hooge, Frans Van de Werf, Peter Carmeliet, Peter, Yigal M. Pinto, E. Helene Sage, Stephane Heymans

* These authors contributed equally to this manuscript Journal of Experimental Medicine 2009 Jan 16;206(1):113-23. 


\begin{abstract}
The matricellular protein SPARC (secreted protein acidic and rich in cysteine, also known as osteonectin) mediates cell-matrix interactions during wound healing, and regulates the production and/or assembly of the extracellular matrix (ECM). This study investigated whether SPARC functions in infarct healing and ECM maturation after myocardial infarction (MI). In comparison to wild-type mice, animals with a targeted inactivation of SPARC exhibited a 4fold increase in mortality that resulted from an increased incidence of cardiac rupture and failure after MI. SPARC-null infarcts had a disorganized granulation tissue and immature collagenous ECM. In contrast, adenoviral overexpression of SPARC in wild-type mice improved the collagen maturation, and prevented cardiac dilatation and dysfunction after MI. In cardiac fibroblasts in vitro, reduction of SPARC by shRNA attenuated transforming growth factor- $\beta$-mediated increase of Smad2 phosphorylation, whereas addition of recombinant SPARC increased Smad2 phosphorylation, concordant with increased Smad2 phosphorylation in SPARC-treated mice. Importantly, infusion of transforming growth factor- $\beta$ rescued cardiac rupture in SPARC-null mice but did not significantly alter infarct healing in wild-type mice. These findings indicate that local production of SPARC is essential for maintenance of the integrity of cardiac ECM after MI. The protective effects of SPARC emphasize the potential therapeutic applications of this protein to prevent cardiac dilatation and dysfunction after MI.
\end{abstract}




\section{Introduction}

Secreted Protein, Acidic and Rich in Cysteine (SPARC, also called osteonectin and BM-40) belongs to the group of matricellular proteins, which are non-structural proteins present in the ECM. Although they do not contribute directly to tissue integrity, they are potent modulators of cellular function. SPARC is involved in tumor progression and wound healing via its regulation of cell-ECM interactions and ECM production ${ }^{1,2}$. Expression of SPARC is increased after $\mathrm{MI}$ and is spatially and temporally related to the formation of a fibrous scar ${ }^{3,4}$. Whereas previous studies indicate a role for SPARC in cutaneous wound healing ${ }^{5,6}$, evidence for a specific role for SPARC in granulation and ECM formation in an infarcted heart is lacking.

Healing after $\mathrm{MI}$ requires a tightly-regulated process of wound healing and scar formation that consists of three overlapping phases. The initial inflammatory phase, for removal of dead tissue, is followed rapidly by the formation of granulation tissue, which is rich in leukocytes, new vessels, and proliferating fibroblasts. The final, maturation phase is characterized by a regression of granulation tissue and a progressive maturation of the collagenous ECM. Alterations in this well-orchestrated response to myocardial necrosis leads to adverse infarct healing, cardiac rupture, and cardiac dysfunction ${ }^{7}$. SPARC modulates ECM turnover, in part through its effect on collagen synthesis, extracellular proteases, and growth factors ${ }^{1}$. In addition, SPARC binds to TGF- $\beta$ receptor type II in the presence of TGF- $\beta$ and thereby affects its downstream signaling in mesangial cells ${ }^{8}$.

Since SPARC is increased after MI and can affect ECM organization, we hypothesized that SPARC regulates infarct healing and ECM maturation after $\mathrm{Ml}$ and might thereby protect against cardiac rupture and dysfunction.

Our data reveal that loss of SPARC results in formation of a disorganized scar and immature collagen matrix after MI. Adverse infarct healing in SPARC-null hearts evolves into increased cardiac rupture and dysfunction, whereas adenoviral overexpression of SPARC protects against cardiac dilatation and failure after MI. SPARC is therefore a promising target to obtain proper infarct 
healing and collagen maturation, and prevents cardiac rupture, dilatation, and dysfunction after MI.

\section{Materials and Methods}

\section{Mouse model of myocardial infarction}

All described study protocols were approved by the Animal Care and Use Committee of the University of Maastricht and Leuven. Experiments were performed according to the official rules formulated in the Dutch and Belgian law on care and use of experimental animals. One-hundred-thirty ten-toeighteen week-old male and female SPARC-null mice (10x backcrossed) and WT animals on a C57B|6/J background were used in this study, and all experiments were performed using age-matched mice. Experimental MI and sham operation were performed as described ${ }^{9}$. Hearts were perfused with phosphate-buffered saline, removed, and prepared for molecular, histological, and ultrastructural analysis.

\section{Histology and Electron Microscopy}

Cardiac tissue was processed and histochemical and immunohistochemical analyses were performed as previously described ${ }^{9,10}$. To assess the quality of the newly formed collagen matrix, Sirius Red staining was performed as previously described 10, 11. All morphometric analyses were done in a standard way on two mid-saggittal sections of each heart. Morphometric analyses were performed using a Leitz DMRXE microscope (Leica Imaging Systems Ltd, Germay), and Leica Qwin morphometry software.

Ultrastructural analysis was performed as described ${ }^{12}$. All analyses were performed following standard operating procedures and confirmed by independent observers blinded to genotype or treatment group. Supplemental material and methods describes detailed histological measurements and antibodies. 


\section{Cardiac fibroblast culture and lentiviral constructs}

Cardiac fibroblasts were isolated from 2-day-old neonatal Lewis rats. Short hairpin RNA (shRNA) against SPARC was produced from small interfering RNA (siRNA, Eurogentec, Belgium), and cloned into the Xhol and Hpal sites of pLenti Lox $3.7^{13}$. Recombinant SPARC protein was produced by infection of $\mathrm{CHO}$ cells with adenovirus containing mouse SPARC. Serum-free media of these cells were collected, purified, and concentrated, as described previously 14. Supplemental material and methods describes detailed experimental methods.

\section{Western blotting}

Infarcted tissue or cell lysates were resolved by sodium dodecyl sulfate-poly acrylamide gel electrophoresis (SDS-PAGE) and were subsequently immunoblotted for the detection of phosphorylated and total Smad2 (Cell Signaling Technology), SPARC (R\&D systems) and GAPDH (RDI), as described ${ }^{15}$. GAPDH was used as a loading control.

\section{RNA isolation and expression}

RNA was isolated from infarcted and sham tissue with the RNeasy Mini Kit (Qiagen) and was stored at $-80^{\circ} \mathrm{C}$. RNA was reverse-transcribed into cDNA with the iScript ${ }^{\mathrm{TM}}$ cDNA synthesis kit (BioRad). Real-time quantitative PCR was performed with $\mathrm{iQ}^{\mathrm{TM}}$ SYBR green supermix (BioRad). Primers were designed with Primer Express Software (PE Applied Biosystems, Foster City, CA). Cyclophilin or acidic ribosomal phosphoprotein (ARBP) was used as a housekeeping gene. The primers used are shown in supplemental table 3.

\section{Echocardiography and Functional Assessments}

After sedation of mice with $2 \%$ isoflurane, standard views were obtained in 2-

$\mathrm{D}$ as well as $\mathrm{M}$-mode by transthoracic echocardiography with a $13-\mathrm{MHz}$ transducer (i13L, GE Vingmed, Horten, Norway) on a Vingmed Vivid 7 
echocardiograph (GE Vingmed,Horten, Norway). Cardiac function was assessed with increasing dosages of dobutamine in intact female SPARC-null and WT mice 14 days after surgery under urethane anesthesia $(2,5 \mathrm{~g} / \mathrm{kg} \mathrm{IP})$, as described ${ }^{15}$.

\section{Adenoviral overexpression of SPARC}

SPARC overexpression was achieved by adenoviral infection of WT mice. The design of the adenoviral vector is described by Barker et al. ${ }^{16}$ Adenovirus was produced by 293 cells, collected and purified as described ${ }^{17}$. $1 \times 10^{9}$ Adenoviral plaque-forming units were injected into the tail vein 2 days before the onset of acute $\mathrm{MI}$, to achieve high levels of SPARC at the onset of MI. One day before MI, baseline echocardiography was performed. Two weeks after $\mathrm{Ml}$, echocardiography was performed and the mice were sacrificed, after which histological and molecular analysis of infarcted hearts was performed. Overexpression of SPARC was shown by immunoblotting of the plasma of mice that had been treated with SPARC adenovirus.

\section{TGF- $\beta$ infusion in SPARC-null and WT mice}

To investigate whether exogenous administration of TGF- $\beta$ rescued increased cardiac rupture after MI, we treated SPARC-null and WT mice with TGF- $\beta$ ( $250 \mathrm{ng} /$ day) versus saline for 7 days, by the use of osmotic minipumps. Data were expressed as mean \pm SEM

\section{Statistical analysis}

No repeated measures were performed. Echocardiographic measurements and histological and molecular analysis in sham-operated and infarcted groups at 3, 7 and 14 days were performed in independent groups. Normal distribution of all continuous variables was tested according to the method of Kolmogorov and Smirnov. An unpaired t-test was used in most of the 
comparisons when groups passed the normality test. A Mann-Whitney test was used when the standard deviations of two groups significantly differed. A 2-way ANOVA was used for comparison of the dobutamine curves. Survival curves after MI were obtained by the Kaplan-Meier method, and compared by the log-rank test. A two-sided $P$ value of $<0.05$ was considered statistically significant.

\section{Online Supplemental Material}

Table S1 shows the transcript levels of ECM mRNA's in sham and infarcted WT and SPARC-null mice. Table S2 shows the transcript levels of ECM mRNA's in sham and infarcted AdR5- and AdSPARC-treated WT mice, confirming increased ECM deposition in AdSPARC-treated infarcts. Table S3 shows the primers used with real-time PCR. Supplemental materials and methods describe detailed histological measurements, antibodies, and cellculture methods.

\section{Results}

\section{SPARC expression is induced after MI.}

To assess the expression of SPARC in the cardiac healing process, we examined SPARC protein expression in myocardial tissue of WT mice after MI. Immunoblotting of SPARC in non-infarcted remote left ventricle (LV) only revealed a moderate increase of SPARC-protein expression at 3 days after MI (Figure 1A). In contrast and concordant with previous findings ${ }^{3,4}$, SPARCprotein levels were strongly increased in the infarcted LV at 7 and 14 days after MI (Figure 1A). Immunohistochemistry confirmed that SPARC was low to absent in sham-operated (figure 1B), and in non-infarcted remote LV (figure 1C), but abundantly present in the infarcted LV (figure 1D). Double immunohistochemistry revealed that SPARC mainly co-localized with $\alpha$ smooth muscle actin-positive cells (infiltrating myofibroblast, figure 1E-G), and CD45-immunoreactive leukocytes (figure 1H-J). Thus, SPARC protein 
showed a localized deposition contemporaneous with the formation of granulation tissue and progressive maturation of the infarct scar.

A
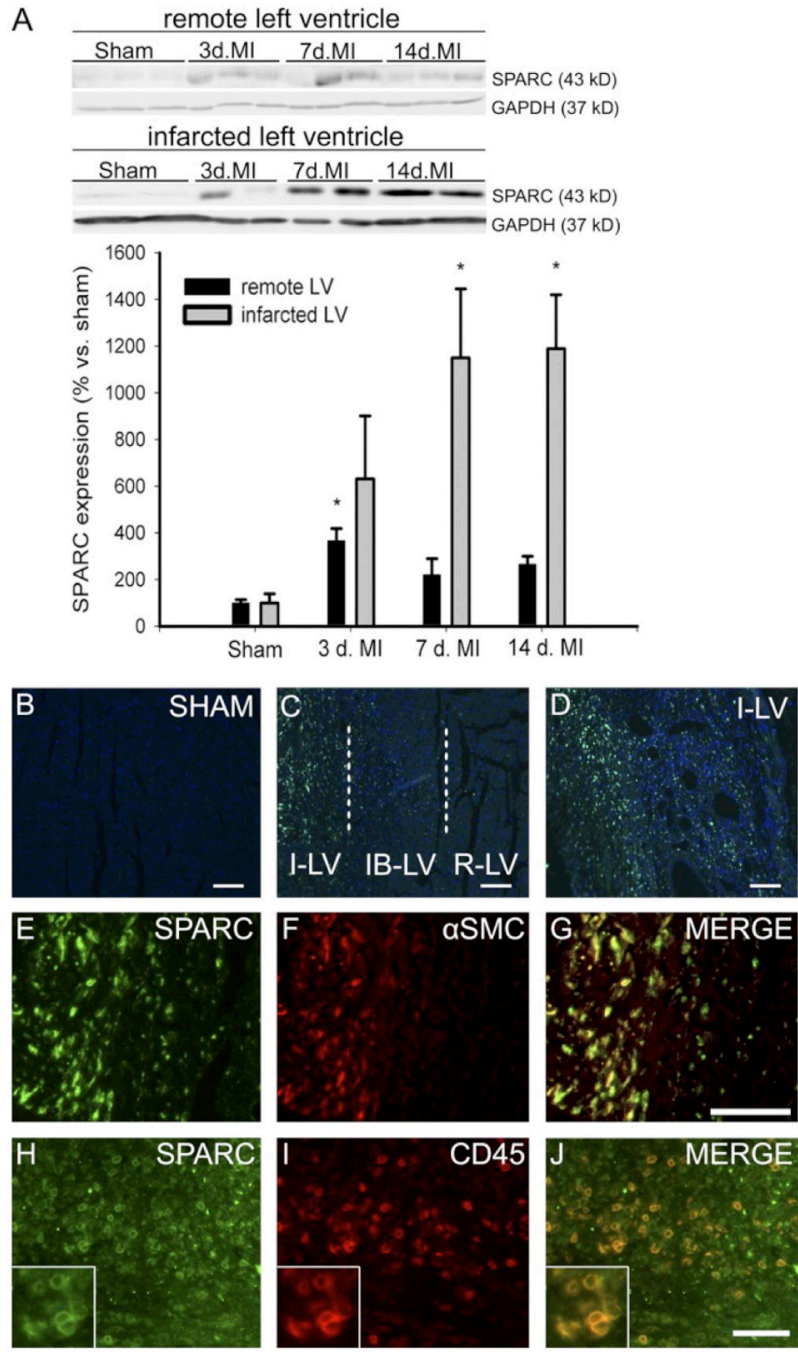

Figure $\quad 1 . \quad$ SPARC expression is induced after MI. (A) SPARC-protein is increased after $\mathrm{Ml}$ in mice. Representative Western blots of SPARC in remote and infarcted LV from WT mice at 3,7 and 14 days after $\mathrm{Ml}(\mathrm{n}=4$ per time-point, *; P<0.05). (B-D) SPARCimmunofluorescent staining (green) is absent in sham operated hearts $(B)$, remote LV (R-LV) and infarct border LV (IB-LV) (C), but strongly up-regulated in the infarcted LV (I-LV) 7 days after MI (CD). (E-J) SPARC expression $(\mathrm{E}$ and $\mathrm{H}$ ) co-localizes with $\alpha$-SMC-actin postive myofibroblasts (F-G) and CD45 immunoreactive leuckocytes (I-J) in the infarcted LV of WT infarcted hearts 7 days after MI. Error-bars represent mean \pm SEM. Scale-Bars: (C-D, H-J) $100 \mu \mathrm{m}$; (E-G) $50 \mu \mathrm{m}$.

Increased SPARC after MI protects against cardiac rupture and dysfunction.

To evaluate the function of SPARC in ECM maturation, we used a model of permanent coronary occlusion. The absence of SPARC was associated with a significantly increased incidence of cardiac rupture after MI: 41\% (13/32) of SPARC-null mice (males: $8 / 12$; females: $5 / 20$ ) compared to $9 \%(3 / 34)$ of WT mice (males: 2/14; females: 1/20) succumbed due to cardiac rupture (Figure 2 $\mathrm{A}-\mathrm{C}$ ). Increased lung weight to body weight ratios at 3 days after $\mathrm{Ml}$ in SPARC-null compared to WT mice pointed towards cardiac dysfunction in 
SPARC-null mice (Table 1). Four male SPARC-null mice that did not die from cardiac rupture displayed severe shortness of breath within 7 days. Two of them died prematurely (6 days post-MI), whereas the other two were sacrificed after echocardiography at 7 days post-MI. The fractional shortening of these two mice pointed towards severe systolic dysfunction $(7.1 \pm 3.9 \%)$, which was associated with significantly increased lung-weight-to-body-weight ratios in the 4 male SPARC-null mice surviving cardiac rupture $(14.1 \pm 0.7$ vs. $9.7 \pm 1.3$ in WT mice, $\mathrm{P}<0.05)$.
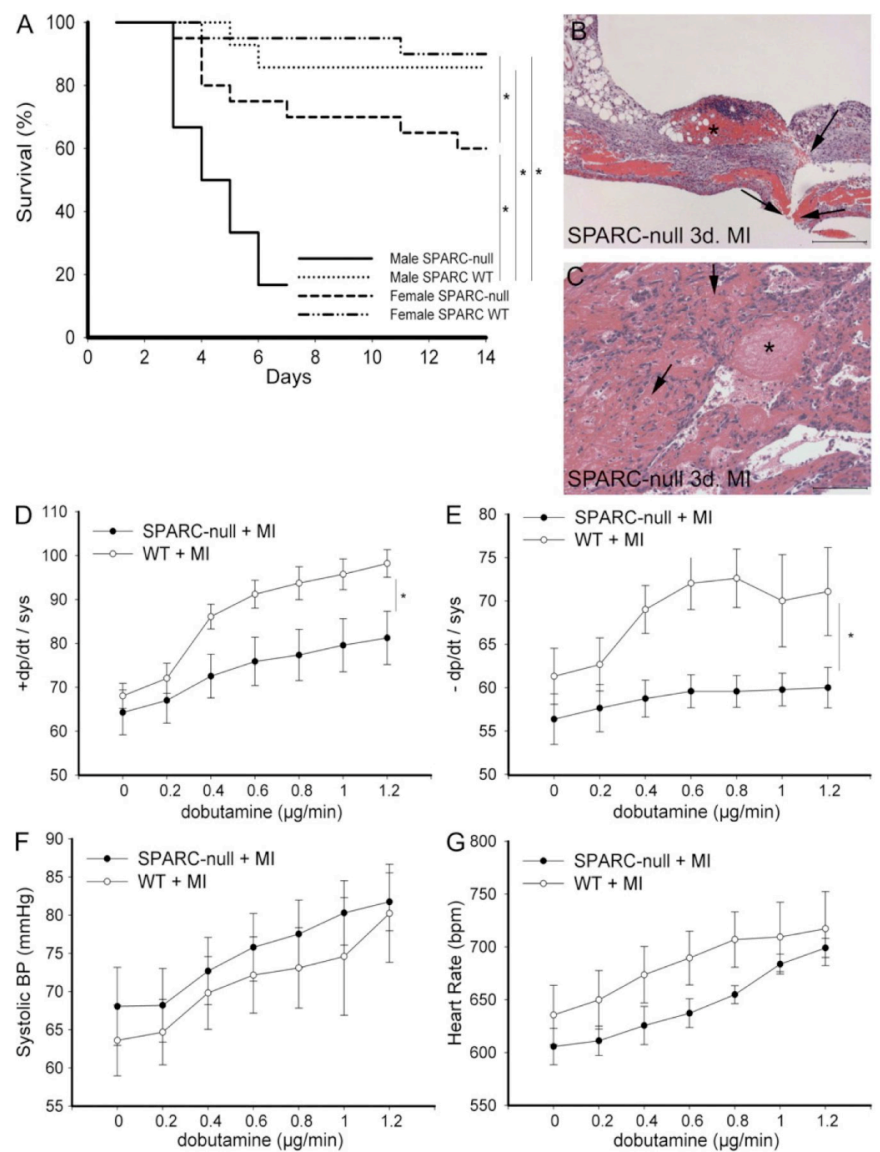

Figure 2. Absence of SPARC results in cardiac rupture and dysfunction. (A) Kaplan-Meier curve showing that targeted deletion of SPARC resulted in decreased survival of SPARC-null (mainly male) compared to WT mice after MI (*; P<0.05). Decreased survival was mainly due to cardiac rupture. Two male SPARC-null mice had to be sacrificed at 7 days after MI due to severe shortness of breath, and, therefore, were not included in the survival curve. (B-C) Histological analysis of ruptured LV of male SPARC-null infarcted hearts (H\&E), revealing rupture site (B, arrowheads), intramural hemorrhages of the infarcted ventricular wall ( $C$, arrowheads), and massive infiltration of erythrocytes, and inflammatory cells (C) and thrombi (B-C, asterisks) at 3 days after MI. (D-G) Decreased survival is associated with depressed cardiac contractility (D) and relaxation (E) during infusion of dobutamine in SPARC-null female $(n=7)$ in comparison with female WT $(n=9)$ mice, 14 days after MI, whereas systolic blood pressure $(F)$ and heart rate $(G)$ did not differ significantly $\left({ }^{*} ; P<0.05\right)$. Error-bars represent mean \pm SEM. Scale-Bars: (B) $200 \mu \mathrm{m}$; (C) $100 \mu \mathrm{m}$. 
Left ventricular pressure and heart rate were similar in sham-operated and infarcted WT and SPARC-null mice at baseline. Systolic function, as measured by echocardiography, was reduced in infarcted compared to shamoperated mice at 3,7 , and 14 days after $\mathrm{MI}$, but to a similar extent in both genotypes (table 1). Baseline $\mathrm{dP} / \mathrm{dt}_{\max }$ and $\mathrm{dP} / \mathrm{dt}_{\min }$ did not differ between infarcted female SPARC-null and WT mice at 14 days after MI (Figure 2D-E). However, hemodynamic stress induced by dobutamine increased contractility and relaxation in infarcted female WT mice, but to a lesser extent in female SPARC-null mice (Figure 2D-E). Systolic blood pressure and heart rate did not differ significantly after dobutamine infusion between infarcted female WT and SPARC-null mice (Figure 2F-G). Although SPARC deficiency does not affect cardiac structure or performance of the heart under physiological conditions, increased levels of SPARC appear to play a pivotal role in the healing process by maintenance of the structural integrity of the heart after MI. To investigate whether the absence of SPARC or gender differences resulted in compensatory changes in expression of SPARC-related factors before the onset of cardiac rupture, we determined transcript levels in male and female sham and 3-days-old infarcted hearts of SPARC-null and WT mice. SMOC1, SMOC2 and Hevin were selected since previous studies described their expression in the heart ${ }^{18-20}$, but little is known about the biological function of these proteins in the heart. Interestingly, transcript levels of SMOC2 were significantly increased in WT and SPARC-null female sham mice in comparison with male sham mice, while its expression decreased significantly after MI with no significant differences between the genders (table 2). In contrast, SMOC1 expression significantly increased 3 days after MI, but did not significantly differ between the genders or genotypes. Transcript levels of Hevin slightly decreased after MI, reaching significance in the infarcted female WT mice in comparison with the respective sham. Finally, SPARC transcript levels significantly increased at 3 days after MI in WT mice, but did not significantly differ between the genders (table 2). 
Table 1. Functional analysis of WT and SPARC-null mice after MI

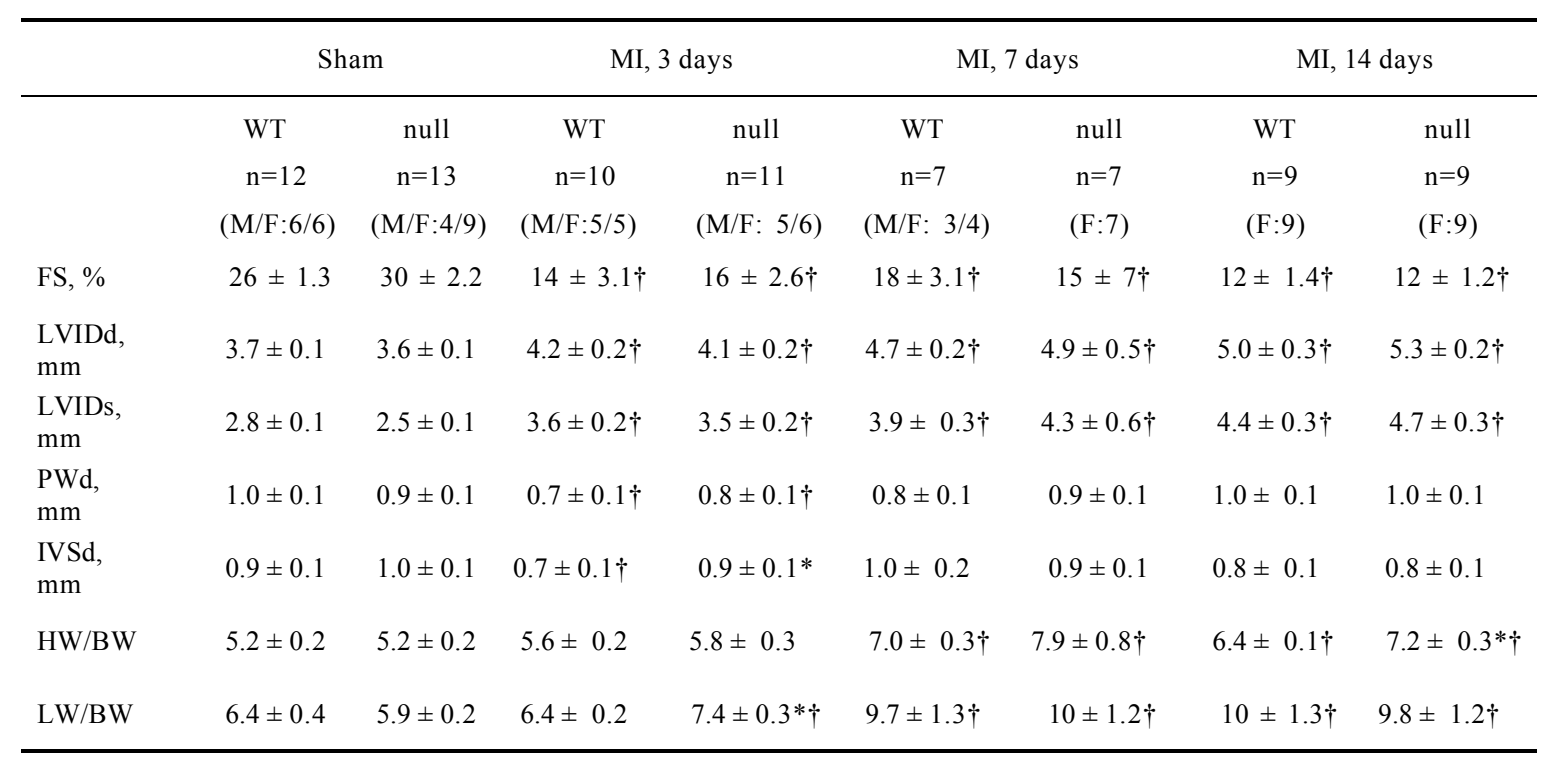

M, male; F, female; MI, myocardial infarction; FS, fractional shortening; PWd, posterior wall diastole; LVIDd, left ventricular internal diameter diastole; HW, heart weight; BW, body weight, and LW, lung weight.

${ }^{*} P<0.05$ in SPARC-null vs. WT infarcts

$\dagger P<0.05$ in infarcted vs. sham 
SPARC-null infarcts exhibit disorganized granulation tissue and deficient scar maturation

Infarct size did not significantly differ between WT and SPARC-null mice (Table 3). Histopathological analysis of infarcts revealed a disorganized scar tissue with diffuse red blood cell infiltration in SPARC-null infarcts (Figure 3AD). Adverse infarct healing in SPARC-null mice was not related to significant differences in inflammation or vascular density, except for the area of myofibroblasts, which was significantly increased in SPARC-null infarcts (Table 3).

Table 2. Transcript levels of SPARC-related factors mRNAs

\begin{tabular}{|c|c|c|c|c|c|c|c|c|}
\hline & \multicolumn{4}{|c|}{ Sham } & \multicolumn{4}{|c|}{3 days MI } \\
\hline & $\begin{array}{c}\text { WT M } \\
(\mathrm{n}=7)\end{array}$ & WT F $(n=7)$ & $\begin{array}{c}\mathrm{KO} \mathrm{M} \\
(\mathrm{n}=7)\end{array}$ & $\begin{array}{c}\mathrm{KO} \mathrm{F} \\
(\mathrm{n}=7)\end{array}$ & $\begin{array}{c}\text { WT M } \\
(\mathrm{n}=6)\end{array}$ & $\begin{array}{l}\text { WT F } \\
(n=8)\end{array}$ & $\begin{array}{c}\mathrm{KO} \mathrm{M} \\
(\mathrm{n}=5)\end{array}$ & $\mathrm{KO} \mathrm{F}(\mathrm{n}=1$ \\
\hline SMOC1 & $11 \pm 1.1$ & $12 \pm 1.5$ & $13 \pm 4.3$ & $11 \pm 1.4$ & $35 \pm 6.8^{*}$ & $34 \pm 5.3^{*}$ & $26 \pm 6.4^{*}$ & $27 \pm 5.4^{*}$ \\
\hline SMOC2 & $5.0 \pm 0.9$ & $10 \pm 0.5 \dagger$ & $7.3 \pm 0.6$ & $9.3 \pm 0.3 \dagger$ & $3.4 \pm 0.5$ & $3.0 \pm 0.5^{*}$ & $4.2 \pm 0.7^{*}$ & $4.8 \pm 0.6^{*}$ \\
\hline Hevin & $1.0 \pm 0.1$ & $1.2 \pm 0.1$ & $1.0 \pm 0.1$ & $0.8 \pm 0.1 \%$ & $0.8 \pm 0.1$ & $0.7 \pm 0.1 *$ & $0.6 \pm 0.1$ & $0.7 \pm 0.1$ \\
\hline SPARC & $3.4 \pm 1.5$ & $1.8 \pm 0.1$ & N.D. & N.D. & $14 \pm 1.6^{*}$ & $16 \pm 1.8^{*}$ & N.D. & N.D. \\
\hline
\end{tabular}

N.D.; not detectable

${ }^{*} \mathrm{P}<0.05$ in $\mathrm{Ml}$ group vs. respective sham

$\dagger P<0.05$ between males and females of the same genotype

$\ddagger P<0.05$ between WT and SPARC-null mice of the same gender

Sirius red-polarization microscopy of collagen fibers revealed a predominance of loosely-assembled (yellow-green) collagen fibers in SPARC-null infarcts at 14 days (ratio of orange-red/yellow-green birefringent collagen), in contrast to the well-aligned and thick, tightly packed (orange red) fibers in WT infarcts (Table 3, Figure $3 \mathrm{E}-\mathrm{H}$ ). Ultrastructural analysis confirmed a disorganized and immature collagen matrix in SPARC-null infarcts, as indicated by the decreased diameter of collagen fibrils, in contrast to the well-structured collagen matrix in WT infarcts (Figure $3 \mathrm{I}-\mathrm{K}$ ). Ultrastructural and histological analysis of the cardiac matrix in SPARC-null and WT sham mice did not reveal significant differences. 
The absence of SPARC did not affect collagen synthesis, as shown by the lack of significant differences in the fraction Sirius red-stained collagen (Figure 3E-G; Table 3) or transcript levels of collagen types I and III (supplementary table 1) in SPARC-null compared to WT infarcts.

Thus, increased cardiac rupture and dysfunction in SPARC-null mice are related, at least in part, to deficient maturation of the scar after MI.

Table 3. Histological analysis of the infarcted area

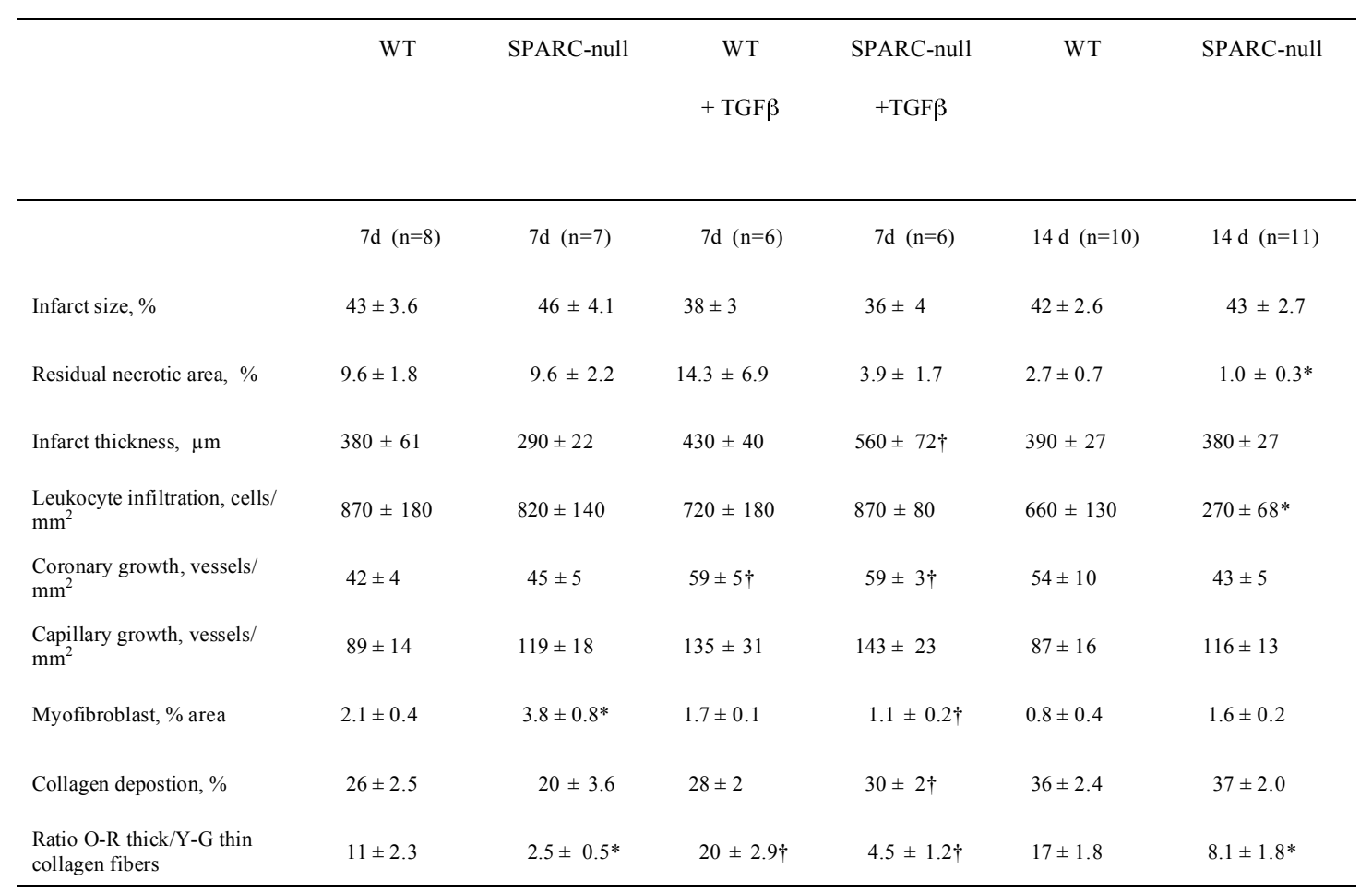

O-R indicates orange-red; $Y-G$, yellow-green.

${ }^{*} \mathrm{P}<0.05$ in SPARC-null vs. WT infarcts at corresponding time after MI

$\dagger P<0.05$ in TGF $\beta$-treated infarcts vs. untreated infarcts at corresponding time after $\mathrm{MI}$ 


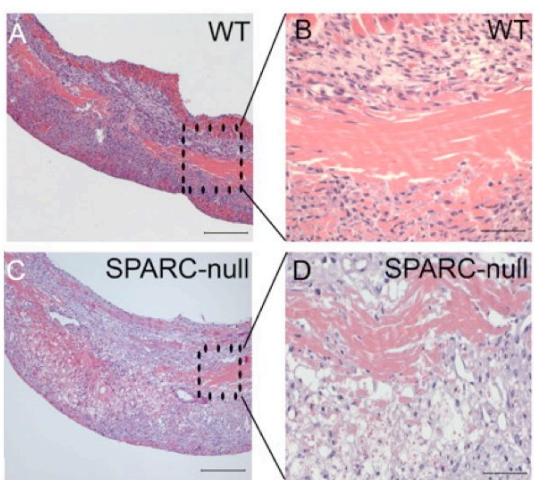

$\mathrm{E}$

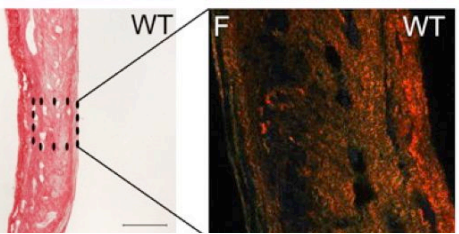

G
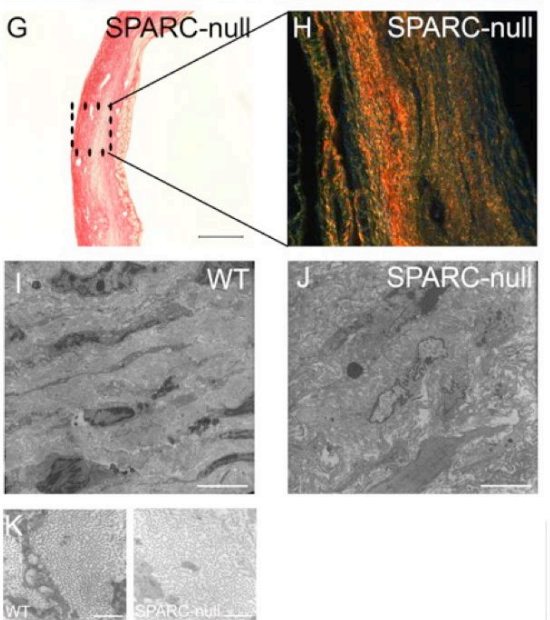

Collagen diameter Infarct zone

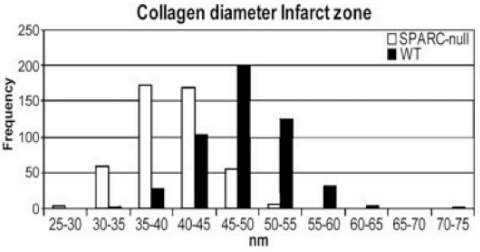

Figure 3. Adverse wound healing in SPARC-null mice. (A-D) Hematoxylin and eosin staining revealed a disorganized granulation tissue with increased red blood cell infiltration in male SPARC-null (C, D) versus WT (A, B) 7-days-old infarcts. (E-K) Abnormal collagen formation in SPARC-null infarcts. E-H; Sirius red staining did not indicate impaired collagen deposition between WT $(E, G)$ infarcts at 14 days after Ml. Sirius red polarization microscopy revealed well-aligned and tightly-packed (orange-red) collagen fibers in WT (F), but less mature fibers (yellow-green) in SPARC-null infarcts $(\mathrm{H})$. (I-K) Ultrastructural analysis confirmed a disorganized matrix in SPARCnull $(\mathrm{J})$ in comparison with WT (I) infarcts, which was associated with the deposition of smaller collagen fibrils in the infarct zone of SPARC-null mice (K, white bars: SPARC-null; black bars: WT). Scale bars: (A, C, E, G) $200 \mu \mathrm{m}$; (B, D) $50 \mu \mathrm{m}$.

\section{Adenoviral overexpression of SPARC protects against cardiac dilatation} and dysfunction after acute MI.

To investigate whether overexpression of SPARC could prevent cardiac dysfunction after MI, we enhanced SPARC expression in WT mice by injection of a replication-deficient adenovirus harboring mouse SPARC (AdSPARC) 2 days before MI. Subsequently, there was a 2.8-fold increase in expression of SPARC in plasma and a 2.6-fold increase of SPARC expression in the infarct area at 14 days after $\mathrm{MI}$, in comparison to control AdR5-injected mice (Figure 4A-B). 
Table 4 Functional analysis of WT mice treated with AdR5 or AdSPARC virus

\begin{tabular}{lcccc}
\hline & \multicolumn{2}{c}{ Sham } & \multicolumn{2}{c}{ MI, 14 days } \\
\hline & AdR5 & AdSPARC & AdR5 & AdSPARC \\
& $\mathrm{n}=4$ & $\mathrm{n}=4$ & $\mathrm{n}=9$ & $\mathrm{n}=9$ \\
& $22 \pm 2.5$ & $30 \pm 2.0 \dagger$ & $10 \pm 1.7 \dagger$ & $24 \pm 3.4^{*}$ \\
FS, \% & $3.9 \pm 0.1$ & $4.1 \pm 0.1$ & $5.8 \pm 0.2 \dagger$ & $5.0 \pm 0.2 \dagger^{*}$ \\
LVIDd, mm & $3.0 \pm 0.1$ & $2.9 \pm 0.1$ & $5.2 \pm 0.2 \dagger$ & $3.8 \pm 0.3 \dagger^{*}$ \\
LVIDs, mm & $3.0 \pm 0.1$ & $0.7 \pm 0.1$ & $0.7 \pm 0.1$ & $0.8 \pm 0.1^{*}$ \\
PWd, mm & $0.7 \pm 0.1$ & & & \\
IVSd, mm & $0.7 \pm 0.1$ & $0.7 \pm 0.1$ & $0.6 \pm 0.1$ & $0.7 \pm 0.1^{*}$ \\
HW/BW & $3.9 \pm 0.1$ & $4.3 \pm 0.2$ & $5.1 \pm 0.2 \dagger$ & $4.8 \pm 0.1 \dagger$ \\
LW/BW & $5.7 \pm 0.1$ & $5.5 \pm 0.1$ & $7.0 \pm 0.5 \dagger$ & $5.3 \pm 0.1^{*}$
\end{tabular}

MI, myocardial infarction; FS, fractional shortening; LVIDd, left ventricular internal diameter diastole; LVIDs, left ventricular internal diameter systole; PWd, posterial wall diatole IVSd, intraventricular septum diastole; HW, heart weight; BW, body weight, and LW, lung weight. $\dagger P<0.05$ in infarcted $(\mathrm{MI})$ vs. sham-operated mice or AdR5 vs. AdSPARC sham-operated mice. ${ }^{*} P<0.05$ in AdvSPARC infarcts vs. AdR5 infarcts

The increased levels of SPARC prevented cardiac dilatation and dysfunction after MI (Table 4), without alteration of infarct size (Table 5). SPARC significantly increased collagen deposition and birefringence in the infarct zone (Table 5, Figure 4C-F), but did not affect the amount of CD45-positive leukocytes, $\beta$-smooth muscle actin-positive myofibroblasts, and coronary vessels, in comparison to control AdR5-treated mice (Table 5). These findings were corroborated by the increased transcript levels of ECM proteins in the infarcts of mice treated with AdSPARC (supplementary table 2). Thus, overexpression of SPARC protects against adverse collagen remodeling, associated with reduced ventricular dilatation and failure after MI 
Table 5. Histological analysis of the infarcted area of AdR5 and AdSPARC-treated mice

\begin{tabular}{|c|c|c|}
\hline & $\begin{array}{l}\text { AdR5 MI } \\
14 d \quad(n=9)\end{array}$ & $\begin{array}{c}\text { AdSPARC MI } \\
14 d(n=9)\end{array}$ \\
\hline Infarct size, $\%$ & $35 \pm 3.9$ & $38 \pm 1.4$ \\
\hline $\begin{array}{l}\text { Residual necrotic area, } \\
\%\end{array}$ & $1.5 \pm 2.3$ & $2.1 \pm 1.5$ \\
\hline Infarct thickness, $\mu \mathrm{m}$ & $450 \pm 16$ & $520 \pm 28$ \\
\hline $\begin{array}{l}\text { Leukocyte infiltration, } \\
\text { cells } / \mathrm{mm}^{2}\end{array}$ & $570 \pm 91$ & $560 \pm 91$ \\
\hline $\begin{array}{l}\text { Coronary growth, } \\
\text { vessels/ } \mathrm{mm}^{2}\end{array}$ & $32 \pm 4$ & $35 \pm 3$ \\
\hline $\begin{array}{l}\text { Capillary growth, } \\
\text { vessels/ } \mathrm{mm}^{2}\end{array}$ & $106 \pm 11$ & $113 \pm 9$ \\
\hline Myofibroblast, $\%$ area & $1.0 \pm 0.2$ & $1.6 \pm 0.2$ \\
\hline Collagen depostion, $\%$ & $28 \pm 2.3$ & $40 \pm 2.5^{*}$ \\
\hline $\begin{array}{l}\text { Ratio O-R thick/Y-G } \\
\text { thin collagen fibers }\end{array}$ & $18 \pm 3.7$ & $60 \pm 11^{*}$ \\
\hline
\end{tabular}




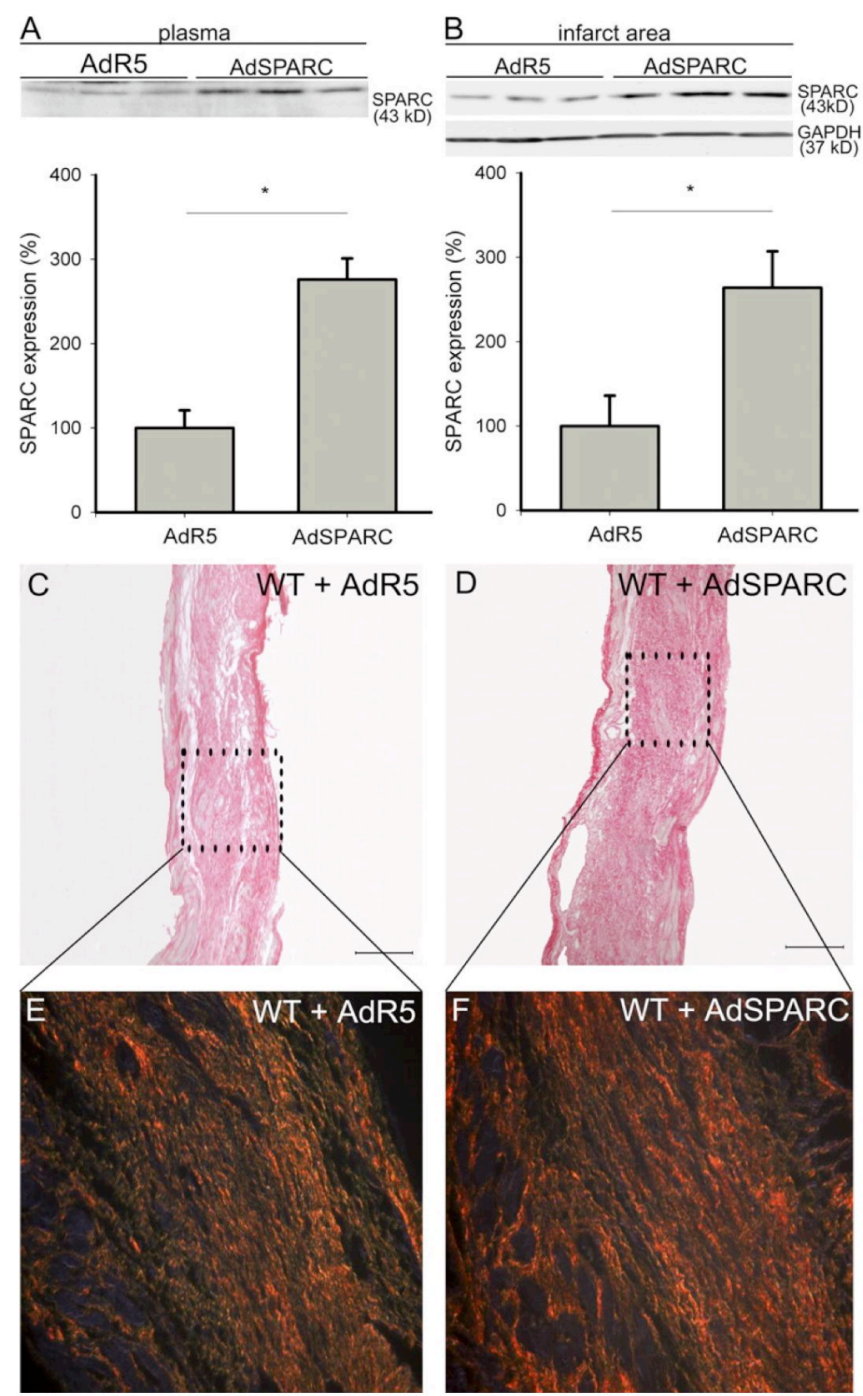

Figure 4. SPARC overexpression increases collagen deposition and quality after MI. (A, B) Representative Western blots showing a 2.8-fold increase of SPARC in plasma (A), and a 2.6-fold increase of SPARC in the infarct area (B) of AdSPARC-treated WT mice in comparison with AdR5-treated WT mice at 14 days after MI ( $n=4$, *; $P<0.05)$.( C-F) Sirius red staining and polarization microscopy revealed increased collagen deposition in AdSPARC- (D) in comparison with AdR5-treated WT infarcts (C), and more well-aligned and tightly-packed (orange-red) collagen fibers in AdSPARC- $(F)$ in comparison with AdR5-treated WT infarcts (E). Error-bars represent mean \pm SEM. Scale bars: $(C, D) 2 \mathrm{~mm}$; (E, F) $200 \mu \mathrm{m}$.

\section{SPARC modulates TGF- $\beta$ signaling}

We asked whether the increased collagen deposition found in the infarcts of SPARC-overexpressing mice was associated with altered TGF- $\beta$ signaling, a known pro-fibrotic cytokine ${ }^{21}$. The levels of phosphorylated and total Smad2 were significantly higher in the infarcts of AdSPARC-treated WT mice (Figure $5 A)$. These results were concordant with experiments in vitro, which showed 
that addition of recombinant SPARC increased Smad2 phosphorylation at baseline, as well as after stimulation with TGF- $\beta 1$ (Figure 5B).
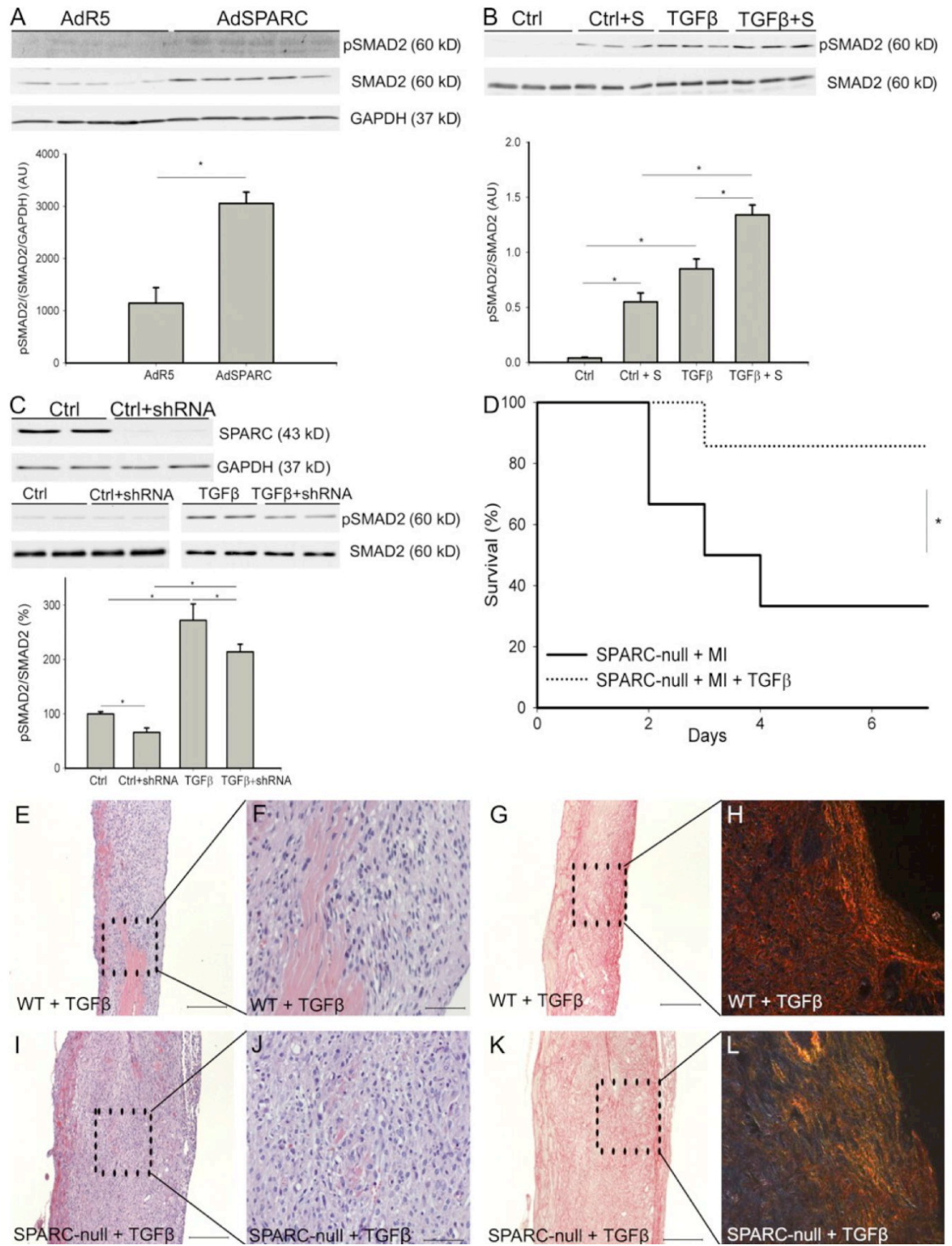

Figure 5. SPARC and TGF- $\beta$ cooperate during infarct healing. (A) Representative Western blot showing increased phosphorylated and total Smad2 levels in the infarcts of AdSPARC-treated mice $(n=9)$. (B) Representative Western blot showing that addition of recombinant mouse SPARC activated Smad2 signaling and augmented the Smad2-activating potential of TGF- $\beta(n=6)$. (C) Upper panel: representative Western blot indicating shRNA against SPARC resulted in an $80 \%$ decrease in levels of SPARC protein. Lower panel: representative Western blot showing that Smad2 phosphorylation in shRNA-treated cardiac fibroblasts was significantly decreased at baseline levels (left panel), and after 15 minutes of stimulation by TGF- $\beta$ ( $1 \mathrm{ng} / \mathrm{ml})$ (right panel)( $\mathrm{n}=5$ per group). (D) Survival curve showing that infusion of TGF- $\beta$ protected against cardiac rupture after $\mathrm{MI}$ in male SPARC-null mice, in comparison to saline-treated male SPARC-null mice. (E, F \& I, J) Hematoxylin and eosin staining revealed striking differences between TGF$\beta$-treated WT and SPARC-null mice 7 days after MI. In WT mice, infusion of TGF- $\beta$ did not significantly affect wound healing, whereas in SPARC-null animals it stimulated ECM production in the infarct zone. G, H \& K, L: Sirius Red staining and Sirius Red polarization microscopy revealed no apparent differences in collagen deposition between TGF- $\beta 1$-treated SPARC-null and WT mice, whereas the difference in wellaligned and tightly-packed (orange-red) collagen fibres in WT infarcts $(\mathrm{H})$, but less mature fibers (yellowgreen) in SPARC-null infarcts (L), was preserved. Error-bars represent mean \pm SEM. Scale bars: $(E, G, I$, K) $200 \mu \mathrm{m} ;(\mathrm{F}, \mathrm{J}) 50 \mu \mathrm{m},{ }^{*} ; \mathrm{P}<0.05$ 
Inhibition of SPARC by shRNA resulted in an $80 \%$ decrease in levels of SPARC protein (Figure $5 \mathrm{C})$. Whereas TGF- $\beta$ treatment $(1 \mathrm{ng} / \mathrm{ml})$ resulted in a significant increase in the ratio of phosphorylated Smad2 (p-Smad2) to total Smad2 protein in control fibroblasts $(100 \pm 4 \%$ in control compared to $272 \pm$ $30 \%$ in TGF- $\beta$-treated fibroblasts; $n=5, P<0.05)$, the decrease in SPARC significantly blunted the ratio of $p-S m a d 2 / S m a d 2$ at baseline $(66 \pm 8 \%, n=6$, $\mathrm{P}<0.05$ compared to WT fibroblasts), and after treatment with TGF- $\beta$ (234 \pm $14 \%, n=5, P<0.05$ compared to TGF- $\beta$-treated WT fibroblasts) (Figure $5 \mathrm{C}$ ). We did not find significant differences in Smad2 phosphorylation between WT and SPARC-null infarcts, a result that might reflect the increased presence of myofibroblasts in the SPARC-null infarcts. Together, these data confirm a role for SPARC in the regulation of TGF- $\beta$ signaling.

\section{Infusion of TGF- $\beta$ protects against cardiac rupture in SPARC-null mice}

TGF- $\beta$ is strongly implicated in infarct healing and remodeling after MI. To investigate whether aberrant TGF- $\beta$ signaling in the absence of SPARC is involved in the adverse infarct healing and increased cardiac rupture after $\mathrm{MI}$ observed in SPARC-null animals, SPARC-null and WT mice were treated with TGF- $\beta$.

Administration of TGF- $\beta$ significantly improved the survival of SPARC-null animals by its diminution of cardiac rupture ( 1 out of 7 in TGF- $\beta$-treated, compared to 8 out of 12 in saline-treated, SPARC-null mice) (Figure 5D). Histological analysis revealed increased deposition of collagen in TGF- $\beta$ treated compared to saline-treated SPARC-null hearts (Table 3, Figure 5E-L), but no significant differences in inflammation or blood vessel formation were observed (Table 3). Improved collagen maturation by infusion of TGF- $\beta$ into SPARC-null infarcted mice was demonstrated by the significantly increased numbers of thick, orange-red collagen fibers (ratio of orange-red/yellow-green 
collagen: $4.5 \pm 1.2$ in TGF- $\beta$-treated, compared to $2.2 \pm 0.4$ in saline-treated, SPARC-null infarcted mice; $\mathrm{n}=7, \quad \mathrm{P}<0.05$ ) (Table 3, Figure 5E-L). Administration of TGF- $\beta$ did not significantly affect wound healing or collagen formation in WT animals (Table 3, Figure 5E-L).

\section{Discussion}

This study indicates a crucial role for SPARC in infarct healing and collagen formation after MI. The absence of SPARC was associated with adverse healing and deficient maturation of collagen, with increased cardiac rupture and dysfunction after MI. Importantly, adenoviral-mediated overexpression of SPARC (AdSPARC) in WT mice, resulting in increased plasma and cardiac levels of SPARC, improved collagen maturation and prevented cardiac dysfunction and dilatation after Ml. Moreover, treatment with TGF- $\beta$ prevented cardiac rupture in SPARC-null infarcted mice, a result underscoring our data in vitro and in vivo showing that exogenous SPARC regulates TGF- $\beta$ signaling.

Expression of SPARC increases progressively after $\mathrm{MI}$ and is seen primarily in inflammatory cells and fibroblasts ${ }^{1,4}$, data indicating a role for SPARC during healing of the infarct scar. The increased cardiac rupture and dysfunction that we observed appeared to coincide with the disorganized and fragmented granulation tissue, as well as abnormal collagen maturation. Cardiac rupture mainly occurred in male mice; hormonal status, higher blood pressure and increased physical activity during night may predispose to the increased cardiac rupture, dysfunction and mortality in male compared to female mice after $\mathrm{MI}^{9,22-24}$. To investigate whether differences in expression of SPARC or SPARC-related factors may influence the phenotype seen after $\mathrm{MI}$, we determined transcript levels of SPARC, and the SPARC-related factors SMOC1, SMOC2, and Hevin in males and females of both genotypes. Since these SPARC-related factors are expressed in the heart ${ }^{18-20}$, and Hevin is involved in collagen assembly ${ }^{25}$, these proteins may be implicated in infarct remodeling. Lack of SPARC did not result in compensatory changes of 
SPARC-related factors. However, sham WT and SPARC-null female mice displayed increased transcript levels of SMOC2 in comparison with male sham mice. In contrast, SMOC2 transcript levels did not differ significantly between the genders at 3 days after MI, indicating that SMOC2 may not protect female mice after MI. SMOC1 transcript levels were strongly increased at 3 days after $\mathrm{MI}$, suggesting that SMOC1 may be involved in regulation of the inflammatory response. Lack of clear differences in the expression pattern of Hevin at 3 days after MI precludes a significant role for this protein in cardiac rupture or early wound healing after MI. However, further investigation to delineate the specific roles of SPARC-related proteins in the pathogenesis of $\mathrm{Ml}$ is mandatory.

We found that the total amount of collagen did not differ between SPARC-null and WT infarcts, but Sirius red polarization and electron microscopy revealed a disorganized and immature collagen matrix in the absence of SPARC. Importantly, infarcts from AdSPARC-treated WT mice displayed increased collagen deposition and improved maturation, in comparison with infarcts of mice treated with control virus, data clearly emphasizing the importance of SPARC for appropriate infarct healing.

SPARC likely regulates infarct healing and collagen maturation by several different mechanisms. First, SPARC directly interacts with collagen type I fibers ${ }^{26},{ }^{27}$ and thereby affects their assembly. Variations in the structure of SPARC alter its affinity for collagen type I, and the absence of SPARC results in the formation of immature collagen fibers during wound healing in the skin ${ }^{6}$ and in response to a foreign body ${ }^{12}$. Moreover, SPARC-null fibroblasts lack the capacity to create a mature collagen matrix, due to defects in procollagen processing ${ }^{27}$. A second mechanism by which SPARC can regulate collagen matrix maturation is the capacity of SPARC to regulate fibronectin matrix assembly ${ }^{16}$. In vitro, collagen fibril formation is dependent on the assembly of fibronectin into fibrils ${ }^{28}$. Previous studies revealed that lack of SPARC results in impaired fibronectin unfolding, regulated via $\alpha_{5} \beta_{1}$ integrin and integrinlinked kinase, which could lead to the defective collagen maturation.

Here, we provide data that SPARC-mediated TGF- $\beta 1$-signaling is important in regulating infarct healing in the heart. TGF- $\beta 1$ is a cytokine involved in wound 
healing and collagen production, that produces multiple, and often opposing, cellular responses throughout the different phases of post-MI wound healing ${ }^{21}$. Two independent studies demonstrated that early inhibition of TGF- $\beta$ signaling increased mortality and exacerbated LV dilatation and contractile dysfunction after MI, whereas blocking TGF- $\beta$-signaling during a later phase prevented adverse LV remodeling ${ }^{29,30}$. We have now shown that SPARC regulates TGF- $\beta$ signaling in cardiac fibroblasts, and demonstrate that the increased TGF- $\beta$ signaling in the infarct is beneficial for strengthening of the infarct scar. These findings are concordant with previous observations of SPARC-mediated TGF- $\beta$ signaling in epithelial ${ }^{31}$ and mesangial ${ }^{8}$ cells. Our finding that treatment with TGF- $\beta$ prevented infarct rupture and rescued collagen maturation in SPARC-null mice, but did not significantly affect infarct healing in WT animals, provides strong evidence in vivo for an important role for SPARC-mediated TGF- $\beta$ signaling in infarct healing and collagen maturation after MI.

The importance of matricellular proteins and proteoglycans in cardiac wound healing and remodeling has previously been noted ${ }^{32}$. These macromolecules, which are minimally expressed in the normal, uninjured heart, are highly upregulated in the injured heart. Recent publications have described roles for thrombospondin-1 ${ }^{33}$, osteopontin ${ }^{34}$, tenascin- $C^{35}$, and syndecan- $1^{10}$ in wound healing of the infarcted heart. Thrombospondin-1 and syndecan-1, expressed early after MI, serve as a "barrier" limiting the influx of inflammatory cells, and thereby regulate proper infarct healing and prevent infarct expansion and cardiac dilatation. In contrast, osteopontin 3, 34, tenascin-C ${ }^{35}$, and SPARC ${ }^{3,4}$ are expressed principally during the formation of granulation tissue and fibrous scar, and are implicated in the assembly and maturation of collagen fibers.

In conclusion, this is the first study to reveal that expression of SPARC after $\mathrm{MI}$ is essential for proper infarct healing and function after MI. SPARC should be considered as a novel therapeutic agent to improve cardiac remodeling and function after MI. 


\section{Funding Sources}

This study was supported by a research grant of the Netherlands Heart Foundation (NHS, 2005B082 and 2007B036) to S.H., an Ingenious Hypercare NoE EU grant to S.H., a Research grant of the Research fund K.U. Leuven (PDMK/08/175) to D.V., and National Institutes of Health grant GM-40711 to E.H.S. Y.M.P. is an established investigator of the Netherlands Heart Foundation.

\section{Conflicts of interest disclosure.None}

\section{References}

1. Framson PE, Sage EH. SPARC and tumor growth: where the seed meets the soil? J Cell Biochem. 2004; 92:679-690.

2. Bradshaw $A D$, Sage $E H$. SPARC, a matricellular protein that functions in cellular differentiation and tissue response to injury. J Clin Invest. 2001; 107:1049-1054.

3. Dobaczewski M, Bujak M, Zymek P, Ren G, Entman ML, Frangogiannis NG. Extracellular matrix remodeling in canine and mouse myocardial infarcts. Cell Tissue Res. 2006; 324:475-488.

4. Komatsubara I, Murakami T, Kusachi S, Nakamura K, Hirohata S, Hayashi J, Takemoto S, Suezawa C, Ninomiya Y, Shiratori Y. Spatially and temporally different expression of osteonectin and osteopontin in the infarct zone of experimentally induced myocardial infarction in rats. Cardiovasc Pathol. 2003; 12:186-194.

5. Basu A, Kligman LH, Samulewicz SJ, Howe CC. Impaired wound healing in mice deficient in a matricellular protein SPARC (osteonectin, BM-40). BMC Cell Biol. 2001; 2:15.

6. Bradshaw AD, Reed MJ, Sage EH. SPARC-null mice exhibit accelerated cutaneous wound closure. J Histochem Cytochem. 2002; 50:1-10.

7. Lindsey ML, Mann DL, Entman ML, Spinale FG. Extracellular matrix remodeling following myocardial injury. Ann Med. 2003; 35:316-326. 
8. Francki A, McClure TD, Brekken RA, Motamed K, Murri C, Wang T, Sage EH. SPARC regulates TGF-beta1-dependent signaling in primary glomerular mesangial cells. Journal of cellular biochemistry. 2004; 91:915-925.

9. Heymans S, Luttun A, Nuyens D, Theilmeier G, Creemers E, Moons L, Dyspersin GD, Cleutjens JP, Shipley M, Angellilo A, Levi M, Nube O, Baker A, Keshet E, Lupu F, Herbert JM, Smits JF, Shapiro SD, Baes M, Borgers M, Collen D, Daemen MJ, Carmeliet P. Inhibition of plasminogen activators or matrix metalloproteinases prevents cardiac rupture but impairs therapeutic angiogenesis and causes cardiac failure. Nat Med. 1999; 5:1135-1142.

10. Vanhoutte D, Schellings MW, Gotte M, Swinnen M, Herias V, Wild MK, Vestweber D, Chorianopoulos E, Cortes V, Rigotti A, Stepp MA, Van de Werf F, Carmeliet P, Pinto YM, Heymans S. Increased expression of syndecan-1 protects against cardiac dilatation and dysfunction after myocardial infarction. Circulation. 2007; 115:475-482.

11. Junqueira LC, Bignolas G, Brentani RR. Picrosirius staining plus polarization microscopy, a specific method for collagen detection in tissue sections. The Histochemical journal. 1979; 11:447-455.

12. Puolakkainen $P$, Bradshaw $A D$, Kyriakides $T R$, Reed $M$, Brekken $R$, Wight $T$, Bornstein P, Ratner B, Sage EH. Compromised production of extracellular matrix in mice lacking secreted protein, acidic and rich in cysteine (SPARC) leads to a reduced foreign body reaction to implanted biomaterials. Am J Pathol. 2003; 162:627-635.

13. Rubinson DA, Dillon CP, Kwiatkowski AV, Sievers C, Yang L, Kopinja J, Rooney DL, Ihrig MM, McManus MT, Gertler FB, Scott ML, Van Parijs L. A lentivirus-based system to functionally silence genes in primary mammalian cells, stem cells and transgenic mice by RNA interference. Nat Genet. 2003; 33:401-406.

14. Sage EH. Purification of SPARC/osteonectin. Current protocols in cell biology / editorial board, Juan S. Bonifacino ... [et al. 2003; Chapter 10:Unit 1011.

15. Schellings MW, Baumann M, van Leeuwen RE, Duisters RF, Janssen SH, Schroen B, Peutz-Kootstra CJ, Heymans S, Pinto YM. Imatinib attenuates end-organ damage in hypertensive homozygous TGR(mRen2)27 rats. Hypertension. 2006; 47:467-474.

16. Barker TH, Baneyx G, Cardo-Vila M, Workman GA, Weaver M, Menon PM, Dedhar S, Rempel SA, Arap W, Pasqualini R, Vogel V, Sage EH. SPARC regulates extracellular matrix organization through its modulation of integrin- 
linked kinase activity. The Journal of biological chemistry. 2005; 280:3648336493.

17. Allaire E, Hasenstab D, Kenagy RD, Starcher B, Clowes MM, Clowes AW. Prevention of aneurysm development and rupture by local overexpression of plasminogen activator inhibitor-1 [see comments]. Circulation. 1998; 98:249255.

18. Soderling JA, Reed MJ, Corsa A, Sage EH. Cloning and expression of murine SC1, a gene product homologous to SPARC. J Histochem Cytochem. 1997; 45:823-835.

19. Vannahme $C$, Gosling $S$, Paulsson M, Maurer $P$, Hartmann U. Characterization of SMOC-2, a modular extracellular calcium-binding protein. The Biochemical journal. 2003; 373:805-814.

20. Vannahme C, Smyth N, Miosge N, Gosling S, Frie C, Paulsson M, Maurer P, Hartmann U. Characterization of SMOC-1, a novel modular calcium-binding protein in basement membranes. The Journal of biological chemistry. 2002; 277:37977-37986.

21. Bujak M, Frangogiannis NG. The role of TGF-beta signaling in myocardial infarction and cardiac remodeling. Cardiovasc Res. 2006.

22. Cavasin MA, Sankey SS, Yu AL, Menon S, Yang XP. Estrogen and testosterone have opposing effects on chronic cardiac remodeling and function in mice with myocardial infarction. Am J Physiol Heart Circ Physiol. 2003; 284:H1560-1569.

23. Cavasin MA, Tao ZY, Yu AL, Yang XP. Testosterone enhances early cardiac remodeling after myocardial infarction, causing rupture and degrading cardiac function. Am J Physiol Heart Circ Physiol. 2006; 290:H2043-2050.

24. Gao $X M, X u Q$, Kiriazis $H$, Dart $A M$, Du XJ. Mouse model of post-infarct ventricular rupture: time course, strain- and gender-dependency, tensile strength, and histopathology. Cardiovasc Res. 2005; 65:469-477.

25. Sullivan MM, Barker TH, Funk SE, Karchin A, Seo NS, Hook M, Sanders J, Starcher B, Wight TN, Puolakkainen P, Sage EH. Matricellular hevin regulates decorin production and collagen assembly. The Journal of biological chemistry. 2006; 281:27621-27632.

26. Kaufmann B, Muller S, Hanisch FG, Hartmann U, Paulsson M, Maurer P, Zaucke F. Structural variability of BM-40/SPARC/osteonectin glycosylation: implications for collagen affinity. Glycobiology. 2004; 14:609-619. 
27. Rentz TJ, Poobalarahi $F$, Bornstein $P$, Sage $E H$, Bradshaw AD. SPARC regulates processing of procollagen I and collagen fibrillogenesis in dermal fibroblasts. The Journal of biological chemistry. 2007; 282:22062-22071.

28. Velling T, Risteli J, Wennerberg K, Mosher DF, Johansson S. Polymerization of type I and III collagens is dependent on fibronectin and enhanced by integrins alpha 11beta 1 and alpha 2beta 1. The Journal of biological chemistry. 2002; 277:37377-37381.

29. Ikeuchi M, Tsutsui $\mathrm{H}$, Shiomi T, Matsusaka $\mathrm{H}$, Matsushima S, Wen J, Kubota T, Takeshita A. Inhibition of TGF-beta signaling exacerbates early cardiac dysfunction but prevents late remodeling after infarction. Cardiovasc Res. 2004; 64:526-535.

30. Okada H, Takemura G, Kosai K, Li Y, Takahashi T, Esaki M, Yuge K, Miyata S, Maruyama R, Mikami A, Minatoguchi S, Fujiwara T, Fujiwara $H$. Postinfarction gene therapy against transforming growth factor-beta signal modulates infarct tissue dynamics and attenuates left ventricular remodeling and heart failure. Circulation. 2005; 111:2430-2437.

31. Schiemann BJ, Neil JR, Schiemann WP. SPARC inhibits epithelial cell proliferation in part through stimulation of the transforming growth factor-betasignaling system. Molecular biology of the cell. 2003; 14:3977-3988.

32. Schellings MW, Pinto YM, Heymans S. Matricellular proteins in the heart: possible role during stress and remodeling. Cardiovasc Res. 2004; 64:24-31.

33. Frangogiannis NG, Ren G, Dewald O, Zymek P, Haudek S, Koerting A, Winkelmann K, Michael LH, Lawler J, Entman ML. Critical role of endogenous thrombospondin-1 in preventing expansion of healing myocardial infarcts. Circulation. 2005; 111:2935-2942.

34. Trueblood NA, Xie Z, Communal C, Sam F, Ngoy S, Liaw L, Jenkins AW, Wang J, Sawyer DB, Bing OH, Apstein CS, Colucci WS, Singh K. Exaggerated left ventricular dilation and reduced collagen deposition after myocardial infarction in mice lacking osteopontin. Circ Res. 2001; 88:10801087.

35. Tamaoki M, Imanaka-Yoshida K, Yokoyama K, Nishioka T, Inada H, Hiroe M, Sakakura T, Yoshida T. Tenascin-C regulates recruitment of myofibroblasts during tissue repair after myocardial injury. Am J Pathol. 2005; 167:71-80. 


\section{Supplemental Methods}

Supplementary Table 1. Transcript levels of ECM mRNAs after MI (arbitrary

\begin{tabular}{lcc}
\hline & WT & SPARC-null \\
& $\mathrm{n}=6$ & $\mathrm{n}=6$ \\
\hline Sham & & \\
Collagen I & $0.12 \pm 0.01$ & $0.10 \pm 0.01$ \\
Collagen III & $0.05 \pm 0.01$ & $0.07 \pm 0.01$ \\
Fibronectin & $0.05 \pm 0.01$ & $0.08 \pm 0.01$
\end{tabular}

MI, 7 days

Collagen I

$1.18 \pm 0.23 \dagger \quad 1.14 \pm 0.08 \dagger$

Collagen III

$0.91 \pm 0.16 \dagger \quad 0.97 \pm 0.08 \dagger$

Fibronectin

$0.81 \pm 0.14 \dagger \quad 0.87 \pm 0.13 \dagger$

MI, 14 days

$\begin{array}{lll}\text { Collagen I } & 2.03 \pm 0.36 \dagger & 1.79 \pm 0.23 \dagger \\ \text { Collagen III } & 1.50 \pm 0.26 \dagger & 1.49 \pm 0.14 \dagger \\ \text { Fibronectin } & 1.58 \pm 0.32 \dagger & 1.81 \pm 0.32 \dagger\end{array}$

$\dagger P<0.05$ in infarcted (MI) vs. sham-operated mice 
Supplementary Table 2. Transcript levels of ECM mRNAs after MI in AdR5 and AdSPARC-treated mice (arbitrary units).

\begin{tabular}{lcc}
\hline & $\begin{array}{c}\text { AdvR5 } \\
\mathrm{n}=6\end{array}$ & $\begin{array}{c}\text { AdvSPARC } \\
\mathrm{n}=6\end{array}$ \\
\hline Sham & & \\
Collagen I & $0.10 \pm 0.02$ & $0.09 \pm 0.03$ \\
Collagen III & $0.04 \pm 0.01$ & $0.05 \pm 0.02$ \\
Fibronectin & $0.05 \pm 0.02$ & $0.06 \pm 0.01$ \\
& & \\
MI, 14 days & & \\
Collagen I & $1.72 \pm 0.32 \dagger$ & $2.3 \pm 0.25 \dagger$ \\
Collagen III & $0.67 \pm 0.11 \dagger$ & $1.02 \pm 0.09 \dagger^{*}$ \\
Fibronectin & $0.59 \pm 0.10 \dagger$ & $1.13 \pm 0.17 \dagger^{*}$ \\
\hline
\end{tabular}

$\dagger P<0.05$ in infarcted $(\mathrm{MI})$ vs. sham-operated mice

${ }^{*} \mathrm{P}<0.05$ in AdvSPARC infarcts vs. AdR5 infarcts

\section{Supplementary table 3.}

\begin{tabular}{|c|c|c|}
\hline Gene & Fw primer $5^{\prime}-3^{\prime}$ & Rev primer 5' - 3' \\
\hline Collagen I & CTTCACCTACAGCACCCTTGTG & CTTGGTGGTTTTGTATTCGATGAC \\
\hline Collagen III & TCGGAACTGCAGAGACCTAAA & CCCCAGTTTCCATGTTACAGA \\
\hline Fibronectin & ATGTGGACCCCTCCTGATAGT & GCCCAGTGATTTCAGCAAAGG \\
\hline Cyclophilin & CAAATGCTGGACCAAACACAA & GCCATCCAGCCATTCAGTCT \\
\hline ARBP & GGACCCGAGAAGACCTCCTT & GCACATCACTCAGAATTTCAATGG \\
\hline SMOC1 & AAAACGAGCAGGCACAAACC & GCCTTTTGCTTTTTCCACTCTTTAG \\
\hline SMOC2 & CACTGCTGTGGCCCACAA & GCGGCACCTTTTCATTTATTG \\
\hline Hevin & CACAAGGGAAACCTCACTGTGTT & AAGCCTGATCTAGGATTTTTGCA \\
\hline SPARC & GAGGAGGTGGTGGCTGACAA & СACCTTGCCATGTTTGCAAT \\
\hline $\begin{array}{l}\text { ShRNA } \\
\text { SPARC }\end{array}$ & \multicolumn{2}{|c|}{ sequence } \\
\hline $\begin{array}{c}\text { Sense 5'- } \\
\text { Antisense } \\
3^{\prime}\end{array}$ & \multicolumn{2}{|c|}{$\begin{array}{c}\text { ggtggaaatgggagagtttttcaagagaaaactctcccatttccaccttttc } \\
\text { tcgagaaaaaggtggaaatgggagagttttctcttgaaaaactctcccatttccacc }\end{array}$} \\
\hline
\end{tabular}




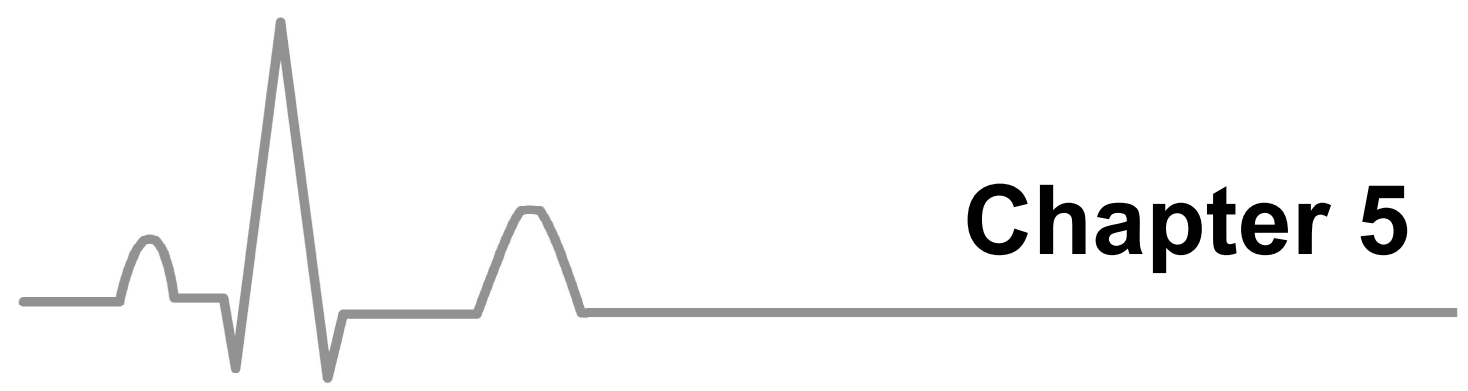

General Discussion 
Heart failure is an increasing health problem with increasing incidence and prevalence, leading to frequent admission to hospital and long-term drug costs. Despite many years of intense research, our understanding of the development of cardiovascular diseases and the progression to heart failure is still inadequate and insufficient. Therefore, the elucidation of the molecular factors involved in the development of cardiovascular diseases is of remarkable significance to recognize novel targets for therapeutic implications in heart failure.

This thesis focuses on the implication of matricellular proteins in different cardiovascular diseases as age-related cardiomyopathy, viral-induced cardiomyopathy and ischemic heart disease and their implications in therapeutic strategies.

\section{Trombospondin-2, a guardian against age-related and virus- associated dilated cardiomyopathy.}

\section{Thrombospondin-2 attenuates the progression to heart failure during cardiac aging by reducing cardiac injury and promoting cardiomyocyte survival}

Aging has become a major health issue and socio-economic burden worldwide. The aging population is increasing, and with it, the morbidity and mortality that are largely caused by cardiovascular defects. The primary function of the heart, to generate the force that pumps blood, depends upon the harmonized contraction of cardiac myocytes. Approximately five billion myocytes are contained within a normal human Left Ventricle (LV), although this cell population is depleted with age by both extrinsic and intrinsic factors ${ }^{1}$. The most trivial, though by no means least important, mechanism by which aging can alter and decline cardiac function is by simply allowing time for accumulated damage and pathology to occur. Known risk factors for heart disease carry a strong interaction with age, including diet, smoking and family history, although in each case behavioral modification, is acknowledged to be affective at any each ${ }^{2}$. A life span of cardiomyopathic insults combined with cellular senescence leaves the aged myocardium with lower hemodynamic 
performance and a diminished contractile reserve. Often, this impaired function leads to a structural remodeling downward spiral ending in heart failure. The aged myocardium is also more susceptible to damage following pathological insults. Deterioration of cardiac function is also often an indirect result of vascular abnormalities, such as hypertension and atherosclerosis, which themselves occur more often and with greater severity in the elderly ${ }^{3}$. Additionally to simply standing as a indication for time, aging also caries a horde of physiological changes to cardiac tissue that occur even in the perceptible absence of any abnormal diseased state ${ }^{4}$.

Cross-sectional studies of subjects without hypertension or clinically apparent cardiovascular disease indicate that LV wall thickness, measured via echocardiography, increases progressively with age. In older hospitalized patients without apparent cardiovascular disease, in wham overall LV mass was not increased, cardiac myocyte enlargement was observed at autopsy, along with a decrease in the estimated cardiomyocyte number. An increase in the amount and a change in the physical properties of collagen, also occur within the myocardium with aging. The cardiac myocyte-to-collagen ratio in the older heart either remains constant or increases, however, because of an increase in myocyte size $e^{3,5}$.

Alterations in mitochondrial function are of significant importance accounting for some of the most critical age-related changes that cardiomyocytes endure. Mitochondria in aged cardiomoycytes have a tendency to become larger and swollen in appearance and to display lower amounts of crista. As a result, ATP production per cell is also reduced with age. Additionally, swollen mitochondria produce higher rates of reactive oxygen species, therefore leading to more mitochondrial damage and so on in a vicious cycle. This may be expected to occur in an accelerated fashion in a cell with high-level ATP usage, such as a cardiomycoyte, and is expected to cause considerable damage in an organ where cells are generally post-mitotic. Damaged mitochondria, as well as damaged proteins and other macromolecules, are removed by the process of autophagy, in which cellular components are digested in lysosomes in order to protect cellular integrity ${ }^{4}$. Unfortunately, lysosomes themselves do not escape the negative effects of age. Over time, lysosomes gradually accumulate a strongly pigmented, granular substance 
called lipofuscin, composed of undegradable lipid and protein residues. Once too much lipofuscin becomes loaded into a lysomome, it ceases to function effectively. Thus, the gradual reduction of autophagic processes may enhance the accumulation of damaged mitochondria and thus add to the damaging cylce ${ }^{5}$.

As described in chapter 2, the matricellular protein TSP-2 protects against aging-related functional decline of the heart. Loss of TSP-2 resulted in progressive cardiomoycte death, accompanied by inflammation and reparative scar-forming fibrosis, all contributing to the development of progressive cardiac dilatation and dysfunction with progressing age. Histological and ultrastructural analysis at older age demonstrated increased cardiomyocyte injury in absence of TSP-2 together with mitochondrial swelling, myocytolysis and matrix disruption. TSP-2 gene deficiency also resulted in increased MMP-2 activity, decreased collagen crosslinking by tissue transglutaminase activity and impaired collagen quality, indicating the involvement of TSP-2 in matrix remodeling.

On the other hand, TSP-2 is also implicated in activating the Src/Akt survival pathway in cardiomyocytes by its conserved C-terminal CD47-binding resulting in decreased myocyte -stress and enhanced cardiomyocyte survival. AAV9-mediated TSP-2 gene transfer in young TSP-2 KO mice rescued the lethal phenotype, confirming that postnatal expression of TSP-2 is crucial for the normal physiological aging of the heart.

\section{Thrombospondin-2 improves cardiac function and alleviates cardiac injury Coxsackievirus B3-induced viral myocarditis}

Myocardial inflammation appears to play a central role in the pathogenesis of viral myocardatis and dilated cardiomyopathy, whereas direct infection of cardiomyocytes by the virus seems less critical in regard to cardiomyocyte damage. The switch in the delicate balance between defensive and harmful effect on immune response may determine the disease progression and may be the decisive factor in the development of dilated cardiomyopathy since chronic inflammation is observed in the myocardium of patients with dilated cardiomyopathy and also in mouse models of chronic viral mycoarditis. Due 
to the intricacy of the disease pathogenesis, the switch in the immune response may be multifactorial involving an array of interactions between the resident myocardial cells and invading inflammatory cell types that alter myocardial cellular and extracellular metabolism and function. The cumulative effect may eventually lead to impairment of cardiac function and long-term remodeling progressing to the dilated cardiomyopathic phase of the disease.

Clinically, patients with acute viral myocarditis will spontaneously recover in about three-fourth of cases, whereas the remaining one-fourth will develop progessive heart failure. Cardiac biopsies and autoimmune serology are therefore essential in the diagnostic process of myocarditis evolving to idiopathic dilated cardiomyopathy (ICM). Recent biopsy series in patients with ICM have revealed that long-term persistence of cardiotrophic viruses triggers heart failure at long term: more then $70 \%$ of patients with ICM carry a cardiotrophic virus in the heart. Elimination of the virus after acute myocarditis, either spontaneously or after treatment, results in improvement of cardiac function, supporting a causal role of viral infection in ICM. The many facets of immune responses during myocarditis are reflected in the heterogeneous nature of the disease in humans making the decision about diagnosis and treatment uncertain. A better understanding of the pathogenesis of virus-induced heart disease is essential to develop improved diagnostic and therapeutic tools.

In several studies in humans, corticosteroids or cyclosporine were used to reduce cardiac inflammation during viral myocarditis. However, these did not distinguish between acute fulminant or chronic autoimmune viral mycoarditis. Furthermore, the treatment strategies may enhance the viral titer during the early phase of viral infection and may even result in increased mortality and cardiac insufficiency ${ }^{6-8}$. Cytokine therapy may be either protective or deleterious, depending on the cellular and molecular states of the inflammatory phase ${ }^{8}$. Therefore, a detailed characterization of viral presence, inflammation and immune status in myocarditis is needed to study a disease that affects people of all ages in a dramatic way.

Recent findings highlight the importance of TSP-2 in cardiac function. Thrombospondin-2 is a potent anti-inflammatory molecule, which is transiently 
released at high concentrations after pathological conditions as in injured and damaged tissues. TSP-2 is composed of several structural domains that specifically interact with a range of cellular receptors differentially expressed by a variety of cells, which could explain its broad variety of biological activities.

Lymphocyte programmed cell death plays a crucial role in controlling immune responses, notably in terminating peripheral $\mathrm{T}$ cell responses and achieving a return to homeostasis. Failure to eliminate inflammatory $T$ cells results in harmful reactions, leading to tissue injury and disease. An important mechanism to inactivate or kill activated $T$ cells was reported by Lamy et al ${ }^{9}$. The interactions between CD47 and TSP reduce inflammation. CD47 is one of the equivocal initiators of lymphocyte death in T cells. Additionally, CD47 has shown to trigger a wide variety of cellular functions in T cells, including activation, proliferation, arrest and spreading on an inflamed vascular endothelium. Under certain conditions it can also induce anergy of generate regulatory $T$ cells. CD47 null mice display a crucial role for CD47 in limiting the course of an inflammatory immune response by eliminating activating lymphocytes in an in vivo model of T cell-determined skin inflammation; TSP1 and TSP-2 null mice display a similar deficient phenotype to that displayed by CD47 null mice in controlling cutaneous inflammation, implying a role for these two ligands of CD47 in T cell clearance ${ }^{9}$.

In addition, CD47 ligation induces naïve $T$ cell anergy. The interaction between CD47 on activated CD4+CD25- $T$ cells promoted the generation CD4+ Foxp3+ regulatory T-cells that suppressed the proliferation and cytokine production of Th1 and Th2 cells via a contact dependent mechanism. The induction of extra-thymic regulatory $\mathrm{T}$ cells in response to TSP-2 represents a mechanism whereby TSP-2 may interfere with the inflammatory process, thus identifying the interaction between CD47 and TSP-2 as potential targets for therapeutic implications. It is striking that the selective expression of the Foxp3 gene in naturally occurring regulatory $T$ cells during thymic development is not sufficient to protect otherwise Foxp3-null mice from developing disease $\mathrm{e}^{10,11}$.This suggests that continued peripheral expression of Foxp3 is required to control disease. TGF-beta participates to the maintenance of peripheral Foxp3 expression suggesting that intact TSP-2 
may indirectly contribute to this process in vivo. Foxp3 expression is definitely required to confer suppressive activity in murine regulatory T cells. TSP-2 may convert naïve CD4+CD25- T-cells into regulatory $T$ cells that negatively control the inflammatory process either in lymphoid organs and/or in sites of inflammation. Increased recruitment of naturally occurring regulatory $\mathrm{T}$ cells combined with peripheral conversion of naive $\mathrm{T}$ cells appear to occur in situ when exacerbated inflammation takes place, for instance in joint of rheumatoid arthritis patients ${ }^{12}$.

The most interesting part of the study was the observation that myocarditis could be overcome by AAV9-mediated TSP-2 gene transfer. Diminished cardiac inflammation together with reduced cardiac injury and cardiomyocyte loss could be detected after AAV9 mediated TSP-2 gene transfer. The most striking observation is the improved cardiac function after AAV9-mediated TSP-2 gene transfer indicating its clinical relevance.
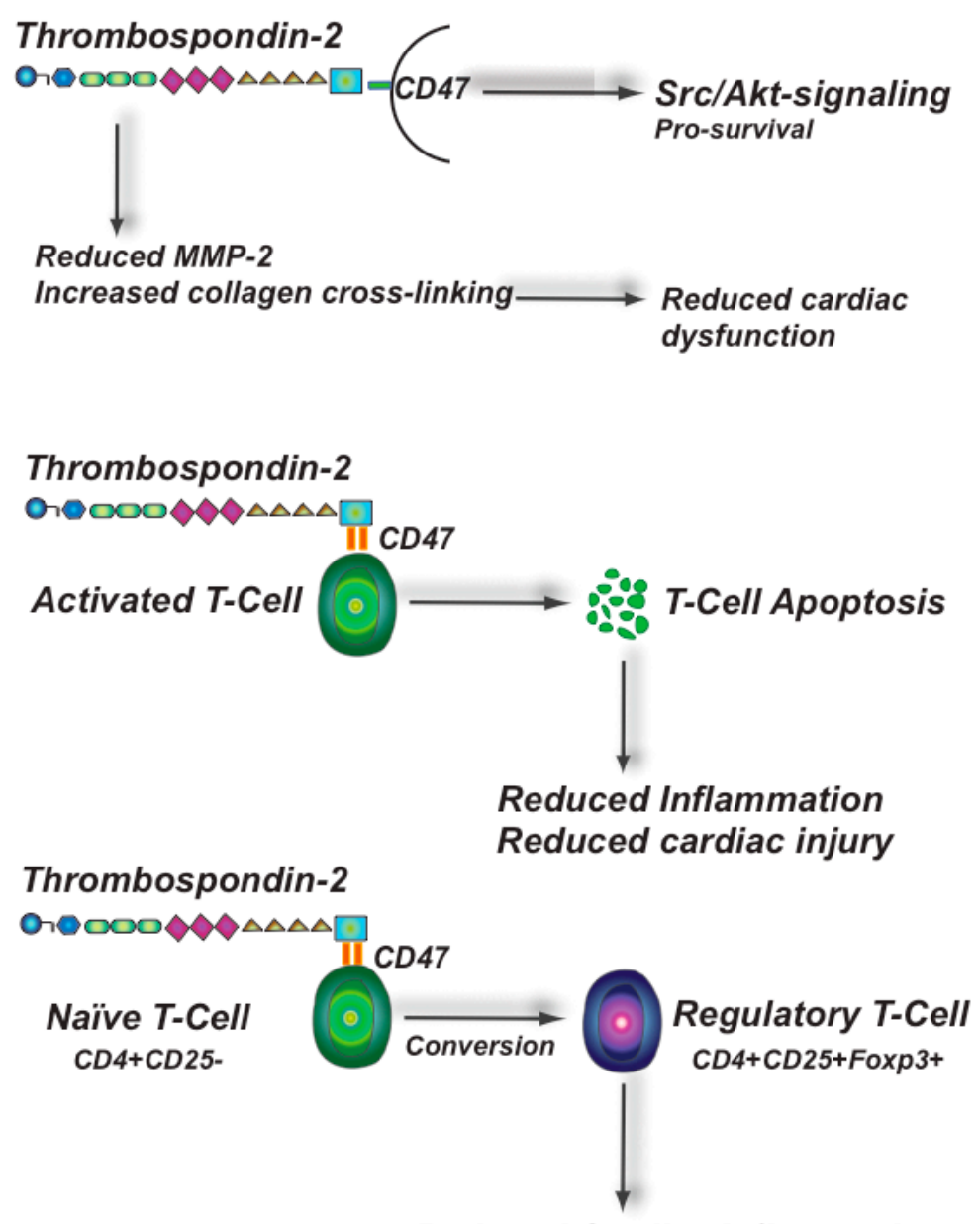

Reduced Cardiac Inflammation

Figure 1. Thrombospondin-2 guards against heart failure: overview 
The studies described in chapter 2 and 3 clearly demonstrated the important role for TSP-2 in clinical and therapeutic implications. Figure 1 shows an overview on the underlying mechanisms how TSP-2 protects against heart failure. Based on our results, showing decreased cardiac injury and fibrosis accompanied with improved cardiac function after AAV9-mediated TSP-2 gene transfer, raised the importance of TSP-2 as clinically relevant approach to attenuate cardiac aging and to prevent the detrimental consequences of sustained cardiac inflammation during viral myocarditis.

\section{SPARC, a crucial modulator of cardiac remodeling during ischemic heart disease}

Myocardial infarction (MI) is a frequent cardiovascular event in the Western society. Due to improved clinical management, acute mortality after MI has been reduced. In chapter 4 of this thesis, we investigated the implication of the matricellular protein, SPARC, in the cardiac wound healing process.

Following MI, cardiac structural remodeling is associated with an inflammatory reaction, followed by scar formation at the site of infarction as well as changes in the non-infarcted myocyardium, including interstitial fibrosis and vascular remodeling. Fibrous tissue that forms at the site of cardiomyoycte loss preserves structural integrity and is essential to the heart's recovery, whereas structural remodeling of viable myocardium impairs tissue behavior. Substances involved in cardiac remodeling are of considerable interest and an important clinical issue, given that the repairing response can be subjected to therapeutic intervention.

Matricellular proteins may act as critical modulators of cell-matrix interactions in healing infarcts. In addition to structural matrix proteins such as collagen and fibronectin, matricellular proteins are transiently induced in healing infarcts and may function as modulators of cell-matrix interactions. Matricellular proteins represent an important component of the extracellular matrix network of the infarct. They are markedly but transiently induced and do not serve a structural role but modulate cell behavior by activating 
intracellular signaling pathways through binding of specific cell-surface receptors.

A highly regulated process of cardiac repair/remodeling follows the necrotic loss of cardiomyoyctes post-MI. It starts with the activation of latent MMPs, which degrade the existing extracellular matrix and coronary vasculature. The proteolytic activity declines at 7 days post-MI and is coincident with the increased expression of MMP inhibitors, tissue inhibitors of MMPs or TIMPs. Circulating inflammatory cells that include neutrophils, monocytes and macrophages arrive at the infarct site soon after MI. They respectively contribute to the proteolytic digestion and phagocytosis of the infarcted tissue. SPARC-gene deficiency resulted in disorganized and fragmented granulation tissue and altered collagen scar formation and maturation in the infracted myocardium that manifested with regular cardiac rupture after MI. SPARC protein expression was significantly increased in the infracted LV at 7 and 14 days post-MI. Although SPARC deficiency does not affect cardiac structure or performance of the heart under physiological conditions, increased levels of SPARC appear to play an essential role in the healing process by maintenance of the structural integrity of the heart after MI.

Treatment with TGF-beta protected fatal cardiac rupture in SPARD KO mice, suggesting the involvement of SPARC in TGF- $\beta$ signaling after MI. In addition, adenoviral-mediated SPARC gene transfer advanced collagen maturation and protected against fatal cardiac dysfunction and rupture after MI. These results indicate an important clinical implication for SPARC in ischemic heart disease.

Despite recent declines in the incidence of myocardial infarction and recent advances in cardiovascular therapeutics and the development of novel strategies that recover myocardium and improve early mortality in patients with myocardial infarction, approaches directly targeting the healing process are lacking. Neurohumoral pharmacologic interventions, such as the administration of angiotensin-converting enzyme (ACE) inhibitors, betablockers and aldosterone antagonist, are the only established therapeutic modalities that reduce adverse remodeling in patients with myocardial infarction. Understanding of the specific events involved in infarct healing is 
crucial to design novel therapeutic strategies aiming at optimizing cardiac repair and attenuating post-infarction remodeling. Chapter 4 of this thesis examines the role of SPARC involved in infarct healing and how they could serve as novel curative tools to protect ventricular remodeling and dilatation post-MI.

\section{Concluding remarks}

Taken together, the work presented in this thesis implies the role and clinical implication of two matricellular proteins, TSP-2 and SPARC, in cardiovascular disease. We validated that the presence of TSP-2 protects against cardiac aging and exaggerated inflammatory responses during viral-induced cardiomyopathy. Furthermore, AAV9-mediated TSP-2 gene transfer improved cardiac function and reduced cardiac injury in favor of cardiomyoycte survival implying an important clinical application in cardiovascular disease. Additionally, we demonstrated a protective role for SPARC during ischemic heart disease. However, despite the promising results established in our studies, further research is necessary to provide better diagnostic and therapeutic tools in our struggle against heart failure. 


\section{References}

1. Burgess ML, McCrea JC, Hedrick HL. Age-associated changes in cardiac matrix and integrins. Mechanisms of ageing and development. 2001; 122:1739-1756.

2. Lakatta EG, Sollott SJ, Pepe S. The old heart: operating on the edge. Novartis Foundation symposium. 2001; 235:172-196; discussion 196-201, 217-120.

3. Patel MB, Sonnenblick EH. Age Associated Alterations in Structure and Function of the Cardiovascular System. The American journal of geriatric cardiology. 1998; 7:15-22.

4. Sussman MA, Anversa P. Myocardial aging and senescence: where have the stem cells gone? Annual review of physiology. 2004; 66:29-48.

5. Wessells RJ, Bodmer R. Cardiac aging. Seminars in cell \& developmental biology. 2007; 18:111-116.

6. Mason JW. Myocarditis and dilated cardiomyopathy: an inflammatory link. Cardiovasc Res. 2003; 60:5-10.

7. Monrad ES, Matsumori A, Murphy JC, Fox JG, Crumpacker CS, Abelmann $\mathrm{WH}$. Therapy with cyclosporine in experimental murine myocarditis with encephalomyocarditis virus. Circulation. 1986; 73:1058-1064.

8. Tomioka N, Kishimoto C, Matsumori A, Kawai C. Effects of prednisolone on acute viral myocarditis in mice. J Am Coll Cardiol. 1986; 7:868-872.

9. Lamy L, Foussat A, Brown EJ, Bornstein P, Ticchioni M, Bernard A. Interactions between CD47 and thrombospondin reduce inflammation. J Immunol. 2007; 178:5930-5939.

10. Ramsdell F, Ziegler SF. Transcription factors in autoimmunity. Current opinion in immunology. 2003; 15:718-724.

11. Khattri R, Cox T, Yasayko SA, Ramsdell F. An essential role for Scurfin in CD4+CD25+ T regulatory cells. Nature immunology. 2003; 4:337-342.

12. De Kleer IM, Brinkman DM, Ferster A, Abinun $M$, Quartier $P$, Van Der Net $J$, Ten Cate R, Wedderburn LR, Horneff G, Oppermann J, Zintl F, Foster HE, Prieur AM, Fasth A, Van Rossum MA, Kuis W, Wulffraat NM. Autologous stem cell transplantation for refractory juvenile idiopathic arthritis: analysis of clinical effects, mortality, and transplant related morbidity. Annals of the rheumatic diseases. 2004; 63:1318-1326. 
Chapter 5 

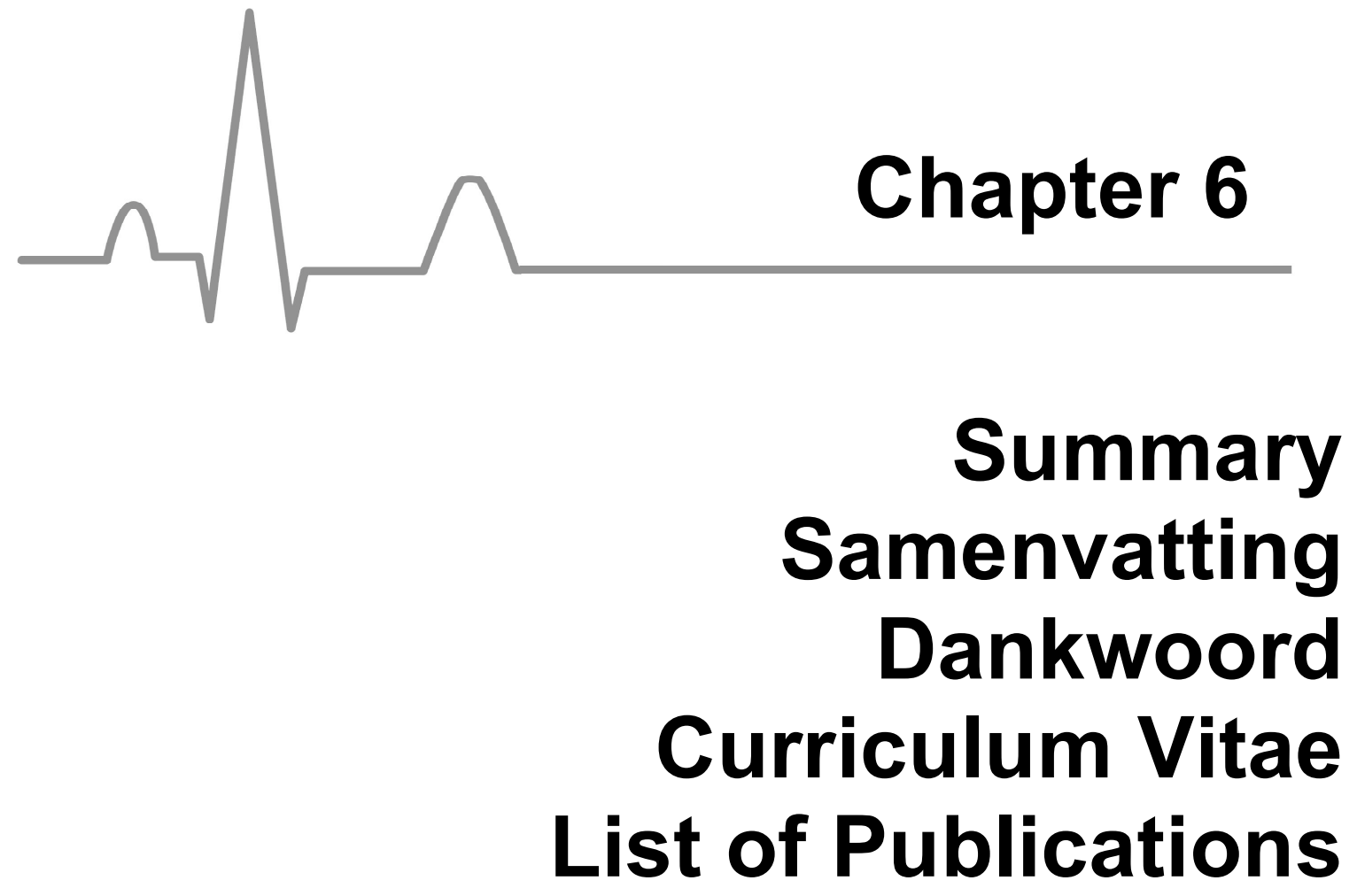
Summary 
Heart Failure (HF) afflicts over 15 million Europeans and results in increased hospitalization and mortality. The major causes of heart failure are ischemic heart disease, hypertension and viral infection of the heart.

With the increasing mean age of the global population, the incidence of HF is increasing and the number of patients at risk of developing this condition is expected to grow. Despite clinical standards, improved medical technologies, better understanding of the pathogenesis of heart failure is essential to improve diagnosis and treatment strategies. The research conducted in this thesis describes the role of a subset of matricellular proteins (MCPs) and their clinical implications in heart disease. Generally, this thesis adds new insights regarding cardiac remodeling during physiological aging, viral myocarditis or after myocardial infarction directing to improved treatment of heart disease.

Chapter 2 describes the protective character of Thrombospondin-2 (TSP-2), a matricellular protein, in cardiac aging. TSP-2 guards against cardiac injury, cardiomyocyte suffering and impaired cardiac function as seen in aged TSP-2 deficient mice. TSP-2 can influence the cardiac matrix by decreasing matrix metalloproteinase-2 (MMP-2) and increasing tissue transglutaminase (tTG) activity levels both protecting extracellular matrix degradation, cardiac dilatation and dysfunction. Furthermore, TSP-2 can influence cardiomyocyte survival by inducing Src/Akt signaling via CD47-mediated activation both in vivo and in vitro. Additionally, gene transfer of TSP-2 in TSP-2 deficient mice, completely blunted cardiac aging compared with control treated mice resulting in reduced cardiac injury, fibrosis and improved cardiac function.

In chapter 3, we described the implication of TSP-2 during Coxsackievirus B3 (CVB3)-induced viral myocarditis. Myocardial inflammation appears to play a central role in the pathogenesis of viral moycarditis and the progression to dilated cardiomyopathy. TSP-2 is able to avert the detrimental consequences of viral myocarditis. This was due to decreased cardiac inflammatory responses and decreased MMP-2 and MMP-9 activities. TSP-2 preserves its protective role by eliminating inflammatory T-cells reducing tissue injury and disease. Furthermore, TSP-2 is involved in the extra-thymic generation of regulatory T-cells via its interaction with CD47 on activated $\mathrm{CD}^{+}{ }^{+} \mathrm{T}$-cells. 
Regulatory T-cells will protect against exaggerated inflammatory responses and cardiomyocyte death during viral myocarditis. TSP-2-overexpression diminished cardiac inflammation an improved cardiac function during viral myocarditis.

In chapter 4 , the function of the matricellular protein SPARC after MI is described. SPARC-gene deficiency resulted in disorganized and fragmented granulation tissue and altered collagen scar formation and maturation in the infracted myocardium that manifested with regular cardiac rupture after MI. SPARC protein expression was significantly increased in the infracted left ventricle at 7 and 14 days after MI. SPARC appears to play an essential role in the healing process by maintenance of the structural integrity of the heart after MI. Treatment with TGF-beta rescued the fatal cardiac rupture in SPARC KO mice, suggesting the involvement of SPARC in TGF-beta singaling after $\mathrm{Ml}$. Both in vivo and in vitro experiments showed an important role for SPARC in TGF-beta signaling. Additionally, adenoviral-mediated SPARC gene transfer advanced collagen maturation and protected against fatal cardiac dysfunction and rupture after MI. Together these results indicate an important clinical implication of SPARC in ischemic heart disease.

In conclusion, this thesis explains the importance of matricellular proteins during cardiac remodeling during cardiac aging, viral myocarditis and ischemic heart disease. This research emphasizes the potential of matricellular proteins to influence intracellular signaling cascades and provides novel insights to develop diagnostic tools for clinical implications in cardiovascular disease. 
Hartfalen treft meer dan 15 miljoen Europeanen en resulteert in een toegenomen hospitalisatie en mortalitieit. De voornaamste oorzaken van hartfalen zijn ischemisch hartlijden, hypertensie en virale infectie van het hart. Met de toegenomen gemiddelde leeftijd van de globale bevolking stijgt uiteraard ook de incidentie van hartfalen en het aantal risico-patiënten dat hartfalen zal ontwikkelen, dreigt nog toe te nemen. Ondanks de huidige klinische normen, blijft het beter begrijpen van de pathogenese van hartfalen essentieel voor de vooruitgang van diagnostische en therapeutische strategieën. De resultaten die geleid hebben tot dit proefschrift, beschrijven de rol van een aantal matricellulaire eiwitten en hun klinische toepasbaarheid bij hartlijden. In het algemeen verbreedt dit proefschrift de kennis over cardiale remodelering bij het ouder worden van het hart, virale myocarditis of na het doormaken van een hartinfarct waardoor verbeterde behandeling van deze hartaandoeningen mogelijk wordt.

Hoofdstuk 2 omschrijft het beschermende karakter van thrombospondine-2 (TSP-2), een matricellulair eiwit, tijdens het ouder worden van het hart. TSP2 beschermt tegen hartschade en een gestoorde hartfunctie zoals gediagnosticeerd kan worden bij oude TSP-2 deficiente muizen. TSP-2 oefent ook een invloed uit op de matrix van het hart door een reductie te induceren in matrix metalloproteinase(MMP)-2 niveau's en weefsel transglutmainase niveau's te doen toenemen en zo bescherming te bieden tegen extracellularie matrix afbraak, cardiale dilatatie en disfunctie van het hart. Anderzijds kan TSP-2 ook een rol spelen bij het overleven van hartspiercellen door Src/Akt signalering te indcueren via CD47-gemedieerde activatie zowel in vivo als in vitro. Additioneel, voorkwam TSP-2 gen-transfer veroudering van het hart in TSP-2 deficiënte muizen wat eveneens resulteerde in verminderde hartschade, fibrose en een verbeterde hartfunctie in vergelijking met de controle behandeling.

Hoofdstuk 3 beschrijft de implicatie van TSP-2 bij Coxsackievirus-B3 (CVB3)geïnduceerde virale myocarditis. De ontstekingsreactie in het hart blijkt een voorname rol te spelen bij de pathogenese van virale myocarditis en de progressie tot gedilateerde cardiomyopathie. TSP-2 kan de schadelijke 
gevolgen van virale myocarditis voorkomen via afgenomen ontstekingsreacties en lagere MMP-2 en MMP-9 activiteiten. TSP-2 vervult een beschermende rol via het elimineren van inflammatoire T-cellen om zo weefselschade en ziektes te verminderen. Verder is TSP-2 eveneens betrokken bij de aanmaak van regulatoire T-cellen buiten de thymus via de interactie met CD47, aanwezig op geactiveerde CD4-positieve T-cellen. Regulatoire T-cellen beschermen tegen extreme onstekingsreacties die de sterfte van hartspiercellen bevorderen tijden virale myocarditis. Overexpressie van TSP-2 vermindert de onsteking van het hart en verbetert eveneens de hartfunctie tijdens virale myocarditis.

In hoofdstuk 4 wordt de functie van het matricellulaire eiwit SPARC na een hartinfarct beschreven. Deficiëntie van het SPARC-gen resulteert in gedesorganiseerd en gefragmenteeerd granulatie weefsel, gewijzigde collagen littekenvorming en -maturatie in het geïnfarctiseerde hartweefsel dat zich manifesteert in cardiale ruptuur na een hartinfarct. Eiwitexpressie van SPARC nam sterk to in het geïnfarctiseerde linker ventrikel tussen 7 en 14 dagen na het doormaken van een hartinfarct. SPARC blijkt een voorname rol te spelen in het helingsproces na een hartinfarct door het behoud van de structurele integriteit van het hart. Behandeling met TGF-beta beschermt de SPARC-deficiënte muizen tegen cardiale ruptuur, dat de betrokkenheid van SPARC bij TGF-beta signalering na een hartinfarct doet vermoeden. Additioneel verbeterde SPARC gen transfer de maturatie van collagen en bood tevens bescherming tegen hartdisfunctie en ruptuur na een hartinfarct. Deze resultaten tonen de belangrijke klinische toepasbaarheid van SPARC aan bij ischemisch hartlijden.

Concluderend beschrijft dit proefschrift het belang van matricellulaire eiwtiten bij cardiale remodelering tijdens het ouder worden van het hart, virale myocarditis en ischemisch hartlijden. Dit onderzoek benadrukt het potentieel van matricellulaire eiwitten om intracellulaire signalerings-cascades te beïnvloeden en levert tevens nieuwe inzichten om betere diagnostische hulpmiddelen te ontwikkelen voor klinische toepassingen bij harfalen. 


\section{Dankwoord}

Vol enthousiasme startte ik met m'n doctoraatsonderzoek en zonder het goed en wel te beseffen is het dan zover, het einde komt in zicht. Het was een boeiende reis boordevol nieuwe ervaringen en uitdagingen waardoor een nieuwe wereld voor me is opengegaan. Ik besef natuurlijk dat dit niet mogelijk was zonder de hulp van vele mensen. Daarom wil ik dan ook mijn dank en waardering uiten aan alle mensen die elk op een eigen manier hun steentje bijgedragen hebben tot dit proefschrift.

Allereerst wil ik mijn grote dank betuigen aan Dr. Stephane Heymans, beste Stephane, als kapitein van het schip wist je me altijd in de goede richting te sturen zelfs op de meest 'woelige' zeëen. Mijn waardering voor je is enorm groot. Veel succes met the Heart Failure Research Center.

Prof. dr. Yigal Pinto, beste Yigal, hartelijk dank dat ik deel kon uitmaken van het toenmalige lab "Experimentele en Moleculaire Cardiologie". Je koos een ander pad door Maastricht in te ruilen voor Amsterdam en ik wens je daar dan ook alle succes.

Prof. dr. Peter Carmeliet, beste Peter, mijn oprechte dank opdat ik m'n onderzoek grotendeels kon uitvoeren in zulke uitzonderlijke wetenschappelijke omgeving waar experimenteel niets onmogelijk lijkt.

De beoordelingscommissie, bestaande uit Prof. dr. Harry Crijns, Prof. $d r$. Frans Van de Werf, Prof. dr. Marc Hoylaerts, Dr. Esther Lutgens en Dr. Marc van Bilsen, wil ik graag bedanken voor het kritisch evalueren van mijn thesis.

Graag zou ik eveneens mijn dank willen betuigen aan Prof. dr. em. Desiré Collen, voormalig hoofd van "Center for Molecular and Vascular Biology", het was een eer om aan uw departement te werken.

I would like to thank all co-authors of the manuscripts for their contributions. 
Dr. Davy Vanhoutte, mon cher collègue, samen hebben we heel wat watertjes doorzwommen. Ondanks het feit dat onze dag/nacht-ritmes niet gelijk lopen, waren we toch het ideale team, zo perfect op elkaar afgestemd. Jouw motivatie en enthousiasme werkten zeer aanstekelijk en al snel evalueerde je van collega tot echte vriend. Nooit zal ik onze avonturen vergeten gaande van de hoteldeur en de nachtelijke blueberry pancakes in New Orleans, de zakdoek in München tot sleeën in les diablerets. Helaas moeten onze wegen nu scheiden. Ik wens je ontzettend veel succes in Cincinetti maar ben ervan overtuigd dat je het daar zal maken (en hoop stiekem ook dat binnen enkele jaren we elkanders pad terug zullen kruisen). Je zit voor altijd in mijn hart. Ik ga je missen.

Graag wil ik verder de Maastrichtse garde bedanken: Rick, Wouter, Gonda, Rudy, Viola en Sylvia, bedankt voor jullie expertise en raad. Joost, bedankt voor de vele gezellige praatjes en veel succes in Amsterdam. Geert, de grapjas en geestigste onder ons, de laatste tijd werken we intensiever samen en jij wist het altijd gezellig te maken. En je moet nu toch toegeven dat blaren en pleisters plakken een band schept ;-) Maarten, hou je enthousiasme en werklust vast, dan komt het allemaal goed. Mark, jij bent ondertussen al uitgevlogen, veel succes in je verdere carrière en bedankt voor alle leuke gesprekken, goede raad en samenwerkingen (mss kan je deze zomer eens overvliegen om extreem italiaanse schoenen op de kop te tikken). Blanche, bedankt voor je luisterend oor en alle raad en steun gedurende de jaren. Veel succes met je baby, ik ben ervan overtuigd dat je een schitterende mama zal zijn. Anna jouw werklust, het nodige kritisisme en vrolijkheid betekenen een enorme verrijking voor ons labo. Je probeert altijd te helpen waar je kan en dat siert je enorm. Robbert, bedankt voor de leuke gesprekken en je interesse in mijn onderzoek. Barbara, bedankt om de administratieve kantjes te organiseren.

Ook m'n Leuvense collega's verdienen hier een plekje. Paolo, thank you for your help, the interesting talks and your italian translations. Enjoy your stay in Belgium. Lucas, bedankt voor de samenwerking en veel success met je doctoraat. Alle mensen van het animal lab: Marijke, Tom, Annemie, Hanne 
en in het bijzonder Anneke, bedankt voor alle hulp en het luisterend oor op de werkvloer. Ge zijt een toffe (ondanks wat 'ze' zeggen ;-)) De genotypering: Peggy, Brecht, Martine, Hélène, Annemarie en Ester, bedankt voor de goede zorgen om de muizenkolonies. Arnold, jij kon altijd m'n praktische problemen oplossen (hoe krijg ik nu die lamp in die heating cage???), bedankt hiervoor. Histologie team: Ann-An-Bjorn en Naima, bedankt voor alle hulp. De moleculaire experts: Sabine, Maria, Sandra, Kevin, Kathleen, Wendy, Els en An, bedankt voor alle goede raad. Halimah, bedankt voor alle toffe gesprekken in de koffie-kamer en voor de liters lekkere koffie. Evelien, Erwin, Leen, Agnes, Christel en Katie, bedankt voor jullie hulp. Jan, mercikes voor het oplossen van alle computer-problemen. Gilles, als jij er niet was geweest dan hadden we pas miserie gekend, bedankt om alles altijd in orde te brengen. De Lijnen-clan: Leentje, Valerie en I/se, jullie maakten het aangenaam... op maar ook buiten de werkvloer. Wat hebben we uit onze kookavonden geleerd: hou Leentje zover mogelijk weg van de Pili Pili!!! Petra, Marleen, Tom, Kristien bedankt, want de sociale kant is ook belangrijk!

Office-collegues: Frederik, Emmanuel, Liesbeth, Lore, Ilse Geudens, Christophe, Karen, Laura, Matthias and other PhD- en postdoc-collegues, thank you very much for the friendship and the pleasant environment. Karlien, Joke, Glenn, Frank, Vanessa, Bianca, Peter, Maria, Ian, Aernout, Koen.

Frank, dank je wel om altijd met een lach op het gezicht te helpen daar waar je kon. Ook Bart Jonckx, mercikes voor het gezelschap tijdens de vakanties en voor alle hulp.

Mijn paranimfen Nard en Ester. Nard, we kennen elkaar reeds van tijdens onze studies en hebben elkaar nooit uit het oog verloren. Je hebt me altijd gesteund als ik het moeilijk had en ben dan ook enorm blij dat je hier naast me wil staan. Je 'trans-atlantisch avontuur' heeft je duidelijk deugd gedaan en hoop dan ook dat jouw promotie snel nadert. Verder heb ik dankzij jou nader kennis gemaakt met de nederlandse uitdrukkingen: persoonlijk vond ik de bokkenpruik de beste (in mijn fantasie dan toch). Bedankt voor je vriendschap door de jaren heen. 
Ester, carpool-buddy, zumba-maatje, mascotte bij m'n sollicitaties (om mijne froefroe krulvrij te krijgen en nog zoveel meer) en bijna echte limburgse, uren hebben we ondertussen al gebabbeld in de auto over koetjes en kalfjes maar ook over serieuze 'zaken'. Ik moet toegeven dat jouw gezelschap de filles veel aangenamer maakte. Bedankt voor alles en ik ga je missen meid.

Ik wil nog de mensen bedanken die me erg nauw aan het hart liggen. Glenda, bedankt voor alle steun en hulp. Meter zijn van Emily is een prachtig cadeau. Bomma en bompa, bedankt voor jullie interesse en de lekkere taarten (ik hoop dat bompa trots op me is daarboven).

Oma en Opa, vol interesse hebben jullie altijd geluisterd als ik enthousiast begon te vertellen over de lopende experimenten. Oma, bedankt voor het lekkere eten dat altijd klaarstond als ik thuiskwam en de overheerlijke soep (de pompoensoep blijft mijn favoriet). Ik weet dat het altijd met veel liefde klaargemaakt werd. Opa, alles kon ik je vragen en niets was ooit te veel, toen wij les hadden in Maastricht reed jij speciaal elke maandag naar de universiteit van Diepenbeek om er mijn taak en die van m'n klasgenoten in het postvakje van de professor statistiek te leggen. Bedankt voor jullie steun en door de jaren heen en alles wat jullie al voor me gedaan hebben.

Mama en papa, woorden schieten te kort, zonder jullie was dit zeker nooit gelukt. Jullie onvoorwaardelijke steun is altijd ontzettend belangrijk voor me geweest. Bedankt dat ik kon opgroeien in een warm gezin, vol liefde en genegenheid. Jullie gaven me alle kansen en bleven steeds in me geloven. Op jullie kon ik altijd rekenen: waar ik nu sta, heb ik aan jullie te danken. Ik hou van jullie.

Gert, lk kan me inbeelden dat het niet altijd eenvoudig is om samen te leven met een doctoraatsstudent. Geboeid luisterde je naar m'n presenaties en probeerde je toch te snappen waar het om draait. Je relativerende woorden hebben me moed gegeven om door te zetten en mijn grenzen steeds weer te verleggen. Je brengt rust in mijn leven en tegelijkertijd geef je me toch de nodige ruimte om mijn ding te doen. Bedankt voor je liefde, steun, begrip en vertrouwen. Samen kunnen we alles aan.

$$
\text { Melissa }
$$




\section{Curriculum Vitae}

Melissa Swinnen was born September $11^{\text {th }}$ in Heusden-Zolder, Belgium. She attended the Humaniora Kindsheid Jesu in Hasselt where she graduated in 2000. From 2000 till 2004 she studied 'Biomedical Sciences' at the Limburg University Centre (currently Hasselt University) in Diepenbeek. After her first two years, she continued her study at the transnational University Limburg (tUL) and obtained her Msc degree in 2004 ('Licentiate in Biomedical Sciences/Master in Health Sciences'). In 2005 she started a predoctoral trainingship at the laboratory of Prof. D. Collen and P. Carmeliet at the University of Leuven under supervision of Dr. Stephane Heymans. She studied the role of Matricellular proteins and Matrix Metalloproteinases in cardiac inflammation during viral myocarditis and cardiac rejection after heart transplantation. In 2006 she started as a PhD student at the department of Cardiology at Maastricht University and the Vesalius Research Center at Leuven University under agreement for a joint research doctoral thesis. She studied the role of matricellular proteins in heart failure under supervision of Dr. Stephane Heymans, Prof. Y. Pinto and Prof. P. Carmeliet funded by a Marie Curie fellowship. She also participated several international conferences, where she had the opportunity to present her research both orally and by poster presentations. After obtaining her $\mathrm{PhD}$ title, Melissa will continue here battle against heart failure in Milan, by conducting postdoctoral Research at the Institute for Biomedical Technologies of the National Research Council. 


\section{List of Publications}

\section{Published Papers}

Heymans S, Pauschinger M, De Palma A; Kallwellis-Opara 1, Rutschow S, Swinnen M, Vanhoutte D, Gao F, Torpai R, Baker AH, Padalko E, Neyts J, Schultheiss HP, Van de Werf F, Carmeliet P, Pinto YM. Inhibition of urokinase-type plasminogen activator or matrix metalloproteinases prevents cardiac injury and dysfunction during viral myocarditis.Circulation. 2006 Aug 8;114(6):565-73

Vanhoutte $D^{*}$, Schellings $M^{*}$, Götte $M$, Swinnen $\mathbf{M}$, Herias $V$,Wild $M$, Vestweber P, Chorianopoulos E, Rigotti A, Cortes V, Stepp MA, Van de Werf F, Carmeliet P, Pinto Y, Heymans S. Increased expression of Syndecan1 protects against cardiac dilatation and dysfunction after myocardial infarction. Circulation 2007 Jan:115(4):475-82

Schellings $\mathrm{MW}^{*}$, Vanhoutte $\mathrm{D}^{*}$, Swinnen M, Cleutjens JP, Debets J, van Leeuwen RE, D'hooge J, Van de Werf F, Carmeliet P, Pinto YM, Sage EH, Heymans S. Absence of SPARC results in increased cardiac rupture and dysfunction after acute myocardial infarction. J Exp Med. 2009 Jan $16 ; 206(1): 113-23$

Swinnen M., Vanhoutte D., van Almen GC., Hamdani N., Schellings MW., D'hooge J., Van der Velden J., Weaver MS., Sage EH., Bornstein P., Verheyen FK., VandenDreissche T., Chuah MK., Westermann D., Paulus WJ., Van de Werf F., Schroen B., Carmeliet P., Pinto YM., Heymans S. The absence of Thrombospondin-2 results in aging related cardiomypopathy. Circulation.2009 Oct 20: 120(16): 1585-1597

De Palma AM., Thibaut HJ., Li S, Van Aelst I, Dillen C, Swinnen M, Verbeken E, Neyts J, Opdenakker G. Inflammatory rather than infectious insults play a 
role in exocrine tissue damage in a mouse model for coxsackievirus B4induced pancreatitis. Journal of Pathology. 2009 Apr: 217(5): 633-41.

Schellings MW., Vanhoutte D., van Almen GC., Swinnen M., Leenders JJ., Kubben N., van Leeuwen REW., Hostra L., Heymans S., Pinto YM. Syndecan-1 amplifies angiotensin II-induced cardiac fibrosis.Hypertension. 2010 Feb: 55(2): 249-56

\section{Submitted Papers}

Swinnen M.*, van Almen GC*., Vanhoutte D., Verhesen, W., Vanleeuwen REW., Cleutjens JP., D'hooge J., Verheyen FK., Carmeliet P., Pinto YM., Schroen B., Heymans S. The absence of Thrombospondon-2 increases cardiomyocyte damage, matrix disruption and systolic dysfunction in doxorubicin-induced cardiomyopathy. Circulation Research: in submission.

Swinnen M., Vanhoutte D., De Palma AM, Westermann D., Vandendriessche T., Chuah M., Lutgens E., Van de Werf F., Pinto YM., Carmeliet P., Heymans S. Thrombospondin 2 improved cardiac function during viral myocarditis: Journal of Experimental Medicine: in submission

Leenders JJ.*, Creemers EE. *, Swinnen M., Hoydal M., Poharel S., Lentink V., van Leeuwen REW., Herias V., de Windt LJ., ten Dijke P., Heymans S., Chuah MK., Mokentin JD., Pinto YM. P38 MAP-Kinase mediated loss of KLF15 causes pathological cardiac hypertrophy.Circulation. in submission.

\section{Congress participation}

Heymans S., Swinnen M., Gao F., Carmeliet P., Pinto Y., Pauschinger M. Inhibition of proteinases prevents cardiac injury during viral myocarditis.. Circulation 114 (6): 565-573.European Society of Cardiology. Annual meeting, 2005. Abstract of Oral presentation. 
Swinnen M., Vanhoutte D., Schellings M., Vandenbergh A., Herijgers P., Pinto Y., Heymans S. Thrombospondin-2 acts as a soldier against age-related cardiomyopathy. European Heart Journal. 27:149-149 World Congress of Cardiology, Annual meeting, 2006. Abstract of Oral presentator in Young Investigator Award session

Swinnen M., Vanhoutte D., Pinto Y., Heymans S. Thrombospondin-2 protects against uncontrolled cardiac inflammation and injury during viral and doxorubicin-induced myocarditis. European Heart Journal. 27:961-961World Congress of Cardiology, Annual meeting, 2006. Abstract of Poster presentator

Swinnen M., Vanhoutte D., Schellings M., Vandenbergh A., Vandermieren G., Herijgers P., Carmeliet P., Pinto Y., Heymans S. Thrombospondin-2 acts as a soldier against age-related cardiomyopathy. Hypertension 48(4):761761.European Council for Cardiovascular Research, Annual meeting, 2006. Abstract of Oral presentator.

Swinnen M., Vanhoutte D., denAdel B., Carmeliet P., Pinto Y., Heymans S. Thrombospondin 2 acts as a guardian against uncontrolled cardiac inflammation and oxidative stress during doxorubicin-induced myocarditis. Hypertension 48(4):763-763 European Council for Cardiovascular Research, Annual meeting, 2006. Abstract of Poster presentation

Swinnen M., Vanhoutte D, denAdel B., Carmeliet P, Pinto Y, Heymans S. Thrombospondin-2 acts as a guarian against uncontrolled cardiac inflammation and oxidative stress during doxorubicin-induced myocarditis. Circulation 114 (18): 11-11 American Heart Association, Annual meeting, 2006. Abstract of Poster presentation

Swinnen M., Vanhoutte D., Hamdani N., Vanderbergh A., Herijgers P., Paulus W., Carmeliet P, Pinto YM., Heymans S. Thrombospondin-2 protects against aging-related cardiomyopathy by increasing beta-integrin-mediated signaling. Heart Failure Winter Research Meeting, Annual meeting, 2008. Abstract of Poster presentator 
Swinnen M., Vanhoutte D., Hamdani N., Vanderbergh A., Herijgers P., Carmeliet P., Paulus W., Pinto Y.M, Heymans S. Thrombospondin-2 guards against aging-related cardiomyopathy by increasing beta-integrin-mediated signaling. Heart Failure Association Meeting. Annual meeting, 2008. Abstract of Poster presentation

Swinnen M., Vanhoutte D., De Palma A., Pinto Y.M., Carmeliet P., Heymans S. Thrombospondin 2 protects against uncontrolled cardiac inflammation and injury during viral myocarditis. European Society of Cardiology, Annual meeting, 2008. Abstract of Oral presentation

Swinnen M., Vanhoutte D, De Palma A, Pinto Y.M., Carmeliet P, Heymans S. Thrombospondin 2 protects against uncontrolled cardiac inflammation and injury during viral myocarditis. Circulation:118(18)S282-S282 American Heart Association, Annual meeting, 2008. Abstract of Poster presentation

Swinnen M., Vanhoutte D, De Palma A, Lutgens E, Westermann D, Vandendriessche T, Chuah M, Van de Werf F, Pinto Y.M., Carmeliet P, Heymans S. Thrombospondin 2 protects against uncontrolled cardiac inflammation and injury during viral myocarditis. European Society of Cardiology, Annual meeting, 2008. Abstract of Poster presentation

Swinnen M., Vanhoutte D, De Palma A, Lutgens E, Westermann D, Vandendriessche T, Chuah M, Van de Werf F, Pinto Y.M., Carmeliet P, Heymans S. Thrombospondin 2 protects against uncontrolled cardiac inflammation and injury during viral myocarditis. Heart Failure Association Research Wintermeeting, Annual meeting, 2009. Abstract of Poster presentation 